\title{
Digital Library Services: Perceptions and Expectations of User Communities and \\ Librarians in a New Zealand Academic Library
}

By

Wei Xia

A thesis submitted to the Victoria University of Wellington in fulfillment of the requirements for the degree of Master of Arts in Library and Information Studies

Victoria University of Wellington September 2002 


\begin{abstract}
Digital services provided on demand by academic libraries offer simple and fast access to collections and services tailored to users' information needs from anywhere in the world through computer networks in an online environment. This case study was conducted at the Victoria University of Wellington Library. It has investigated the extent of and reasons for different perceptions and expectations relating to digital services between different user communities, and between users and librarians. The research, which sheds light on the users' satisfaction of the digital services, follows Taylor's (1986) user-centered and value-added theories, and Parasuraman's (1988) Gap Model. In addition, some evaluation indicators used in this research were also extracted and revised from some previous evaluation models (e.g., SERQUAL).
\end{abstract}

Both qualitative and quantitative research methods were used in this research. Questionnaire surveys collected data on the perceptions and expectations of the digital services from the perspectives of undergraduates, postgraduates, academic staff and librarians individually. The comparative results from the survey data identified variations of perceptions and expectations between users communities, and between users and librarians. Issues raised in the questionnaires were explored in more depth through follow-up interviews with librarians. The research concluded with a range of recommendations for ways to improve the digital services offered by the VUW Library with a view to helping the Library meet the information needs of its user communities. 


\section{Acknowledgements}

In acknowledgement of the various contributions made to this research, I would like to express my gratitude to those who made the realization of this thesis possible:

Dr. Dan Dorner, who not only supervised this research but encouraged, guided, supported and when required motivated me toward its realization. Undoubtedly, without his guidance, I would never have reached my goals. Alastair Smith gave me much help at the stage of designing the methodology and the survey questionnaires for this research. He also gave his insight and understanding without reservation. Professor Gary Gorman also gave me lots of help at the beginning of my master degree program. Other administration officers in the School of Information Management also provided help by providing a collection point for the completed questionnaires that were submitted by many of the project's participants.

I also wish to acknowledge my appreciation of the scholarship funding provided to me by the Trustees of the National Library of New Zealand, and the research funding allocated to me by the School of Information Management, Victoria University of Wellington. These sources of funding assisted my in covering the costs of this research project.

Finally, I wish to thank my parents for their continuous encouragement and concern from China. 


\section{Table of Contents}

ABSTRACT ..................................................................................................... II

ACKNOWLEDGEMENTS ..................................................................II

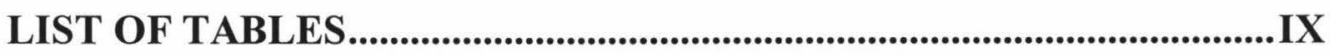

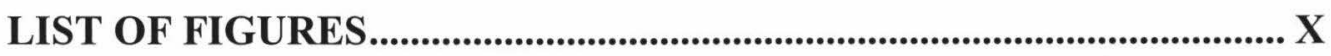

CHAPTER 1. INTRODUCTION.......................................................... 1

1.1The Importance of this Study ............................................................. 2

1.2 The Statement of the Problem ............................................................. 4

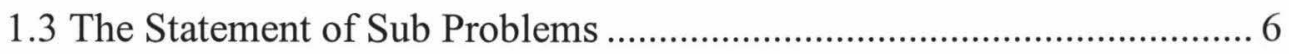

1.4 The Research Questions and Hypotheses ............................................... 7

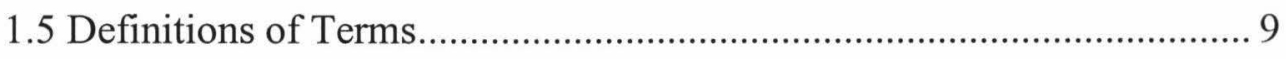

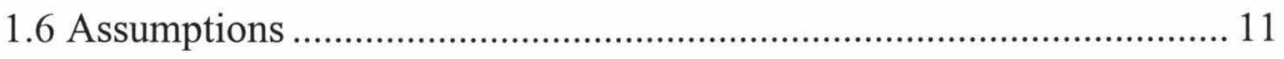

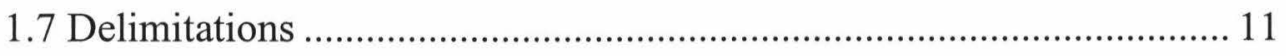

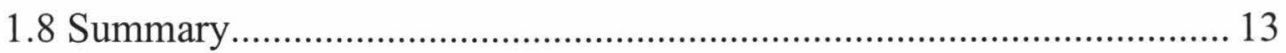

CHAPTER 2. LITERATURE REVIEW: A STUDY OF THE DELIVERY OF SPECIFIC DIGITAL SERVICES IN ACADEMIC

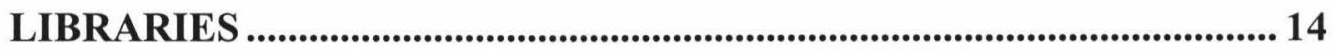

2.1 Overview of the Development of Digital Services............................... 14

2.1.1 Development of Digital Services .............................................. 14

2.1.2 Specific Digital Services .................................................... 16

2.2 Theoretical Framework ......................................................................... 20

2.2.1 The Development of Theories before the Mid-1980s ................. 20

2.2.2 Taylor's User-Centered and Value-Added Theory ..................... 20

2.2.3 Parasuraman's Gap Model .................................................. 21

2.2.4 Service Quality Model and User Satisfaction Model .................. 22

2.2.5 The Preliminary Integrated Theory Model Supporting This

Research 24

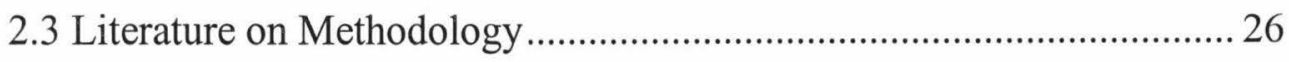

2.4 The Evaluation of the Literature........................................................... 29 


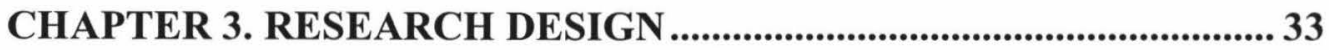

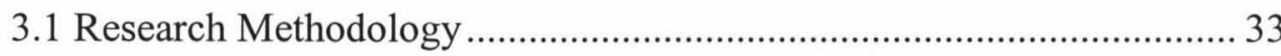

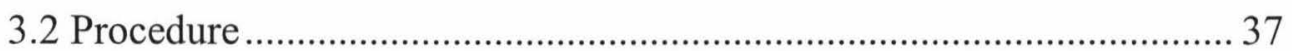

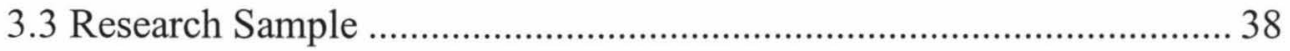

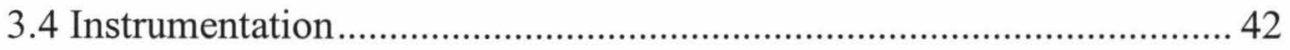

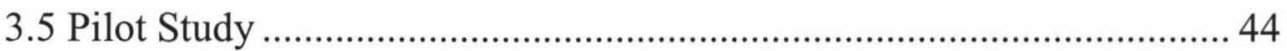

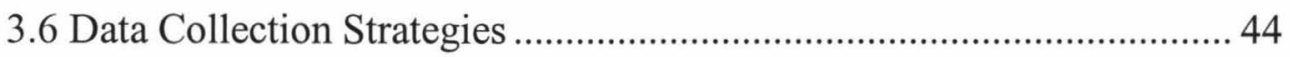

3.7 Treatment of the Data ....................................................................... 46

3.7.1 Treatment of the Data for the Preliminary Problem ................... 46

3.7.2 Treatment of the Data for Sub Problem One ............................... 46

3.7.3 Treatment of Data of Sub Problem Two...................................... 48

3.7.4 Treatment of the Data for Sub Problem Three ........................... 48

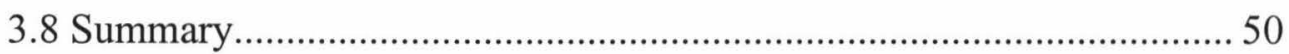

CHAPTER 4. INVESTIGATION OF DIGITAL SERVICES PROVIDED BY THE VICTORIA UNIVERSITY OF WELLINGTON LIBRARY ... 51

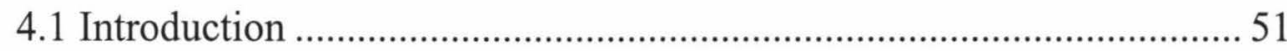

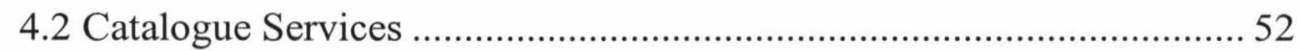

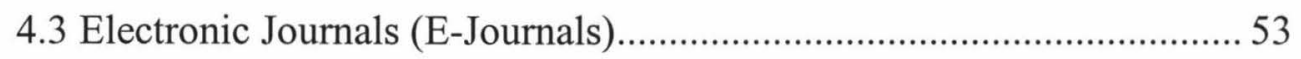

4.4 Electronic Databases ........................................................................... 54

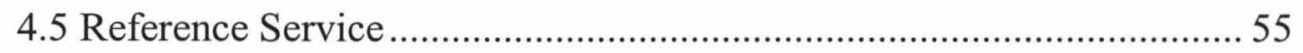

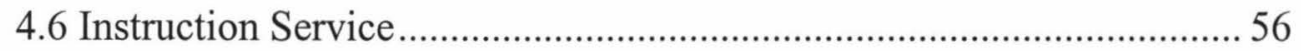

4.7 Distance Learning Service .................................................................. 57

4.8 Other Selected Internet Resources....................................................... 57

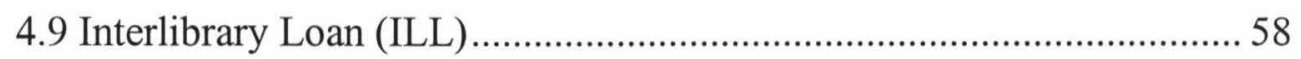

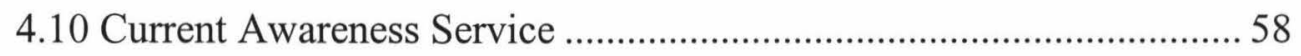

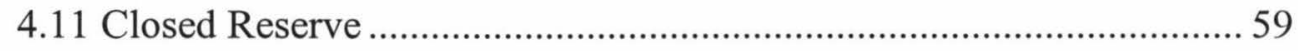

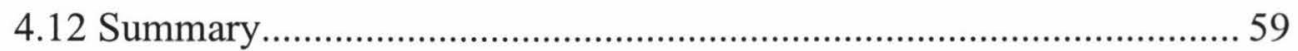

CHAPTER 5. DATA INTERPRETATION AND ANALYSIS ................ 61

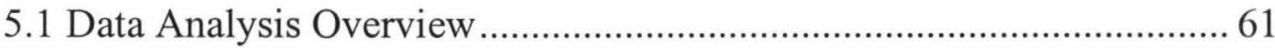

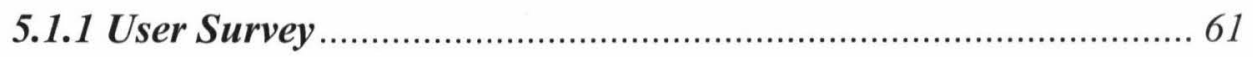

5.1.2 Librarian Survey ........................................................................ 73 
5.2 Comparative Results

5.2.1 Comparisons of Different User Communities

5.2.2 Comparison between Users and Librarians 94

5.3 Summary.

CHAPTER 6. DISCUSSION OF THE FINDINGS AND TESTING OF THE HYPOTHESES.

6.1 Different User Communities Have Different Opinions on Digital

Services

6.1.1 Different user communities have different information needs.. 105

6.1.2 Different user communities have different perceptions on the current digital services.

6.1.3 Different user communities are not satisfied with the digital services to the same extent.

6.1.4 Different user communities have different expectations for future digital services.

6.2 There Are Relationships between Future Use of a Service and Users'

Satisfaction with the Service, and Between Future Use of a Service and the

Rating of Importance of This Service

6.2.1 The more important the service is, the more likely it is that users will use this service in the future.

6.2.2 The more satisfied with the services the users are, the more likely they will use the service in the future.

6.3 There Are Different Perceptions and Expectations Regarding Some

Specific Digital Services between the Users and the Librarians

6.3.1 The level of users' awareness of some specific digital services will be lower than librarians thought.

6.3.2 Users have different perceptions from those of librarians on the current delivery of the digital services.....

6.3.3 The percentage of users who are satisfied with the performance of the digital services is different from that of librarians.

6.3.4 Users' expectations on the importance and usefulness of future digital services differ from the expectations of librarians. 
6.4 Some Other Findings.

6.5 Summary

CHAPTER 7. CONCLUSIONS AND RECOMMENDATIONS 122

7.1 Summary of Key Findings. 122

7.2 Issues and Recommendations. 124

7.2.1 Awareness of the Services 124

7.2.2 Access 126

7.2.3 Currency of Information 127

7.2.4 OPAC 128

7.2.5 Issues with Databases. 129

7.2.6 Issues of E-journals. 131

7.2.7 Future Services. 133

7.2.8 General Issues Related to Digital Services 135

7.2.9 Summary. 138

7.3 Assessing the Relevant Theories in Relation to Comparing Perceptions and Expectations of Digital Library Services from Different Communities

7.4 Limitations of the Study 140

7.5 Recommendations for Future Research and Final Conclusion 142

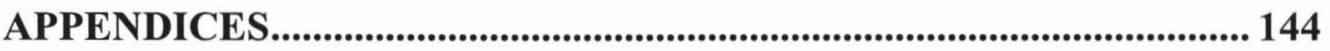

Appendix A: Flow Chart of the Research Method .................................... 145

Appendix B: Questionnaire Samples and Interview Checklist ................ 146

Questionnaire for undergraduates, postgraduates and academic staff 146

Questionnaire for librarians. 155

Interview Checklist 160

Appendix C: Information Sheets 162

Letter to the undergraduates in the research sample (going along with the questionnaire) 
Letter to the postgraduates in the research sample (going along with the questionnaire).

Letter to the academic staff in the research sample (going along with the questionnaire).

Letter to librarians in the research sample (going along with the questionnaire to the librarian)

Letter to librarians in the research sample whom I am going to interview (going along with the interview)

VICTORIA UNIVERSITY OF WELLINGTON CONSENT TO

PARTICIPATE IN RESEARCH. 167

REFERENCES 168 


\section{List of Tables}

Table 1. Reason for using the library website and information services (general users).

Table 2. Frequency of use of current services (general users) ..................... 63

Table 3. Assessment of current digital services (general users) ................... 65

Table 4. The importance of the features of the digital services (general users)

Table 5. Spearman Correlation Test results across different services (general users) 72

Table 6. Assessment of current digital services (librarians) 74

Table 7. Purposes for using the library website and information services.... 78

Table 8. Frequency of use of current services 80

Table 9. The percent of the preferences of delivery format of results from databases/E-journals

Table 10. The five choices for improvements ............................................... 90

Table 11. Spearman Correlation Test results across different services. 92

Table 12. The preference of delivery format of the results from databases/Ejournals. 101

Table 13. The selection of five choices for improvements. 103 


\section{List of Figures}

Figure 1. Generic Model of information and library services (from Brophy, 2000)

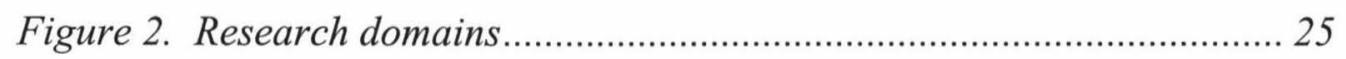

Figure 3. The Structure of Evaluation Measures .......................................... 26

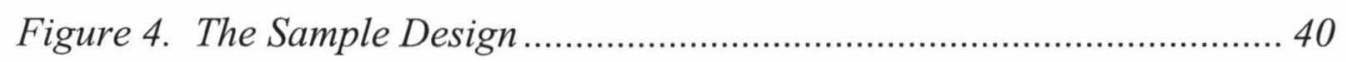

Figure 5. Assessment of current services based on the mean ratings (general

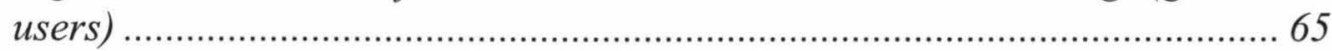

Figure 6. Preferences of delivery format of results from databases/E-journals

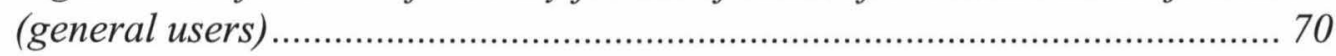

Figure 7. Assessment of three future services (general users) ....................... 71

Figure 8. Assessment of three future services (librarians)............................ 75

Figure 9. Importance of the current services (academic staff VS. postgraduates VS. undergraduates)

Figure 10. Satisfaction with current services (undergraduates VS. postgraduates VS. academic staff)

Figure 11. Future use of current services (undergraduates VS. postgraduates VS. academic staff)

Figure 12. Assessment of "availability of information about this service" (three user communities)

Figure 13. Assessment of "convenient and easy access" (three user communities). 84

Figure 14. Assessment of "easy to use" (three user communities). 85

Figure 15. Assessment of "useful information provided by this service" (three user communities).

Figure 16. Location when using databases (undergraduates VS. postgraduates VS. academic staff) 86

Figure 17. Importance of three future services (three user communities) ...... 88

Figure 18 Usefulness of three future services (three user communities) ........88 
Figure 19. Future use of three future services (three user communities) ....... 89

Figure 20. Importance of the services (librarians VS. general users) .......... 94

Figure 21. Satisfaction with the services (librarians VS. general users)....... 95

Figure 22. Future use of the services (librarians VS. general users) ............ 95

Figure 23. Assessment of E-journals (librarians VS. academic staff VS. postgraduates VS. undergraduates)

Figure 24. Assessment of online request forms (librarians VS. academic staff

VS. postgraduates VS. undergraduates)

Figure25. Importance of "convenient and easy access" (librarians VS general users) 98

Figure 26. Importance of "easy to us" (librarians VS general users) 98

Figure 27. Importance of "useful information provided by this service" (librarians VS general users).....

Figure 28. Importance of "availability of information about this service" (librarians VS general users) 99

Figure 29. The importance of features of databases (general users VS. librarians) 100

Figure 30. Importance of three future services (general users VS. librarians)

Figure 31. Usefulness of three future services (general users VS. librarians)

Figure 32. Future use of three future services (general users VS. librarians) 


\section{Chapter 1. Introduction}

In the past, academic libraries have had several complementary functions, such as providing an information source, researching and learning support, reference services, etc. (Sloan, 1998). Now the information landscape is changing rapidly. Information resources are shifting from traditional static tangible formats to more dynamic digital ones. The digital academic library can provide information services based on networked technologies to users at any time and place.

The digital academic library plays a role in providing scholarly resources and services that are closely connected to institutional goals. The main function of academic libraries addressed in this research is to support research and learning. As more and more information sources become available online, many libraries are introducing digital services. The aim of these services is to broaden the range of information resources available and to add value to their content by making them accessible through telecommunication networks so that users can access them anytime and anywhere.

This research identifies differences in the preferences of users and library staff regarding digital services provided by an academic library, and determines the reasons for those differences. It examines the performance of digital services from the users' point of view. This research is based on user satisfaction and preference evaluation. It follows the user-centered and value-added theory developed by Taylor (1986). The Gap Model (Parasuraman et al. 1988) is also a key supporting theory for this research. In addition, some indicators of SERVQUAL are used in the evaluation of service quality. This research focuses primarily on users' opinions of the digital services and identifies any differences of opinion among users and the library staff. The user community is divided into undergraduates, postgraduates and academic staff. Questionnaire surveys and interviews were the two main approaches of this research. Questionnaire surveys were given to both users and librarians. The library manager and some of the librarians involved in providing digital 
services were interviewed. Accordingly, both qualitative and quantitative methods are used to analyze the data. More attention was paid to users' needs than has been the case in most previous research. Recommendations to improve digital services based on the findings are discussed, in terms of accessibility and the flexibility to meet various needs and encourage more users.

\subsection{The Importance of this Study}

Ferguson and Bunga $(1997,253)$ pointed out that when librarians provide digital services, the implications extend beyond the limits of our imagination:

"This does not speak to just access to information provided by the library or support for use of the network from locations inside the library but, rather, to the full range of services and support to an extent and of a nature heretofore barely imagined deliverable outside the confines of the library itself."

The information landscape is changing from a more familiar static mode to a less tangible, more elusive and more dynamic one. Modern technologies have obvious impacts on various library activities, especially library services to users. The digital or hybrid ${ }^{1}$ academic library not only provides a rich information environment for users but also seamless access to various forms of information. The major goal of a university library is to facilitate the use of information and materials that support the institutions' researching and teaching programs. Digital services can support the realization of this goal.

This study employs the following general model for information services put forward by Brophy (2000).

\footnotetext{
${ }^{1}$ The term 'hybrid library' was introduced by Brophy (1998) and has been coined in recent times to describe the way in which the libraries of the future will function. The hybrid library is the form of digital library currently in practice since all physical materials and services cannot yet be excluded from libraries. In this sense, when the term digital library is used here, it means hybrid library.
} 
Using this model as a foundation, this research helps bridge the gap between users and information sources by investigating different viewpoints in relation to digital services. In Brophy's opinion, libraries are a necessary intermediary to deliver information services and provide access to information.

Figure 1. Generic Model of information and library services (from Brophy, 2000)

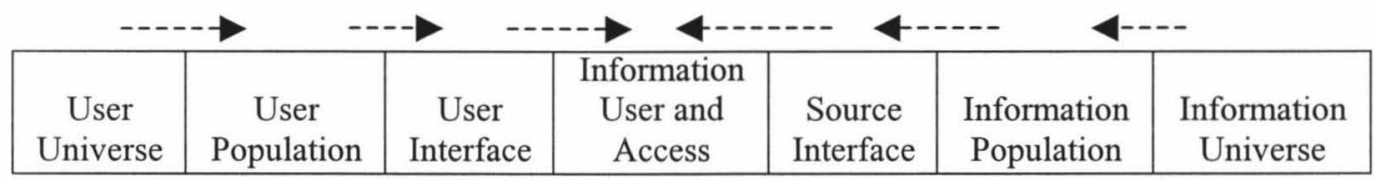

Digital services have already been the subject of research. However, there are a number of weaknesses in the earlier research with regard to academic libraries. Most studies are confined to the introduction of one or two services and give few useful assessments and recommendations. For example, Lindauer (1998) and Jones (1998) only addressed distance learning resources and searching services in their research. The variety of theories and models used in pervious work needs to be integrated into a unified measurement framework. Without a clear theoretical framework and appropriate methodology, researchers cannot make sound recommendations that library managers can use to improve their services.

A key objective of digital services is to provide information to the right users at the right time. According to the Gap Model (Parasuraman et al. 1988) and disconfirmation theory, different opinions from various parties are found by user satisfaction evaluation. This research follows the user-driven and valueadded theory suggested by Taylor (1986) to find the extent of the differences of perceptions and expectations relating to digital services and the reasons for them. Users' information needs and their level of satisfaction with digital services are critical factors for the improvement of services. It is important, therefore, to determine if users, library managers and librarians have different perspectives related to the performance of digital information services. This research advances understanding of the existing performance and potential of some digital services in order to encourage more users to take advantage of these information services. 
The primary purpose of this research is to analyze the problems of digital services in academic libraries, and put forward recommendations for better ways to deliver them in order to increase use. Unlike previous research, this study provides a balanced perspective by investigating users, library managers and librarians.

The results of this research will be useful to university students, academic staff and university librarians. This research will provide librarians with a better understanding of the kinds of digital services that need to be delivered to users. This study aims to improve the accessibility and flexibility of existing services and thus increase the use of those services that have not been widely used. The results of this study can also help academic librarians when developing plans to adopt and implement digital services, and maximize the use of information.

\subsection{The Statement of the Problem}

The introduction of modern information technology has forced libraries to make changes to the way that they provide services. Academic libraries have changed dramatically over the past decade with the aim of improving performance in their specialized functions and roles. With the aid of modern digital technology, university students and staff can access their libraries' collections remotely and conveniently to get the information they require for their work. The main function of university libraries is to support teaching, learning, and researching. Getting the right information to the right users at the right time is becoming the basis for determining the effectiveness of university libraries.

The evaluation of the application and performance of digital services differs between library users and librarians. When designing and delivering digital services, librarians are likely more concerned about factors such as the library's technological infrastructure, the digitization of collections and the budget. Though surveys may be done to consult users before the implementation of the services, libraries may not always be able to get feedback about the digital services until those services have been used for 
some time. In the interim, users may not be satisfied with their experiences of the services, and the services might not be applied and delivered in the way that the library staff expected. If not enough attention is paid to these issues, users might not make full use of the digital services.

Much research has been done to find the extent of users' satisfaction with library services. However, no research appears to have been done to investigate the differences between users and librarians in their understanding and assessment of digital services. This lack of knowledge can make it difficult for libraries to improve their services and develop new services to meet users' needs. University libraries need to identify and understand existing problems and appreciate the potential of digital services.

This research studies the preferences for specific digital services offered by a digital (hybrid) academic library by surveying the perceptions, expectations and satisfaction of users and librarians separately with the aim of delivering more satisfactory, convenient, practical and integrated services. This research reveals how well users feel their library meets their research needs, what librarians think about users' information needs and preferences, and whether users' preferences are different from librarians' preferences.

By focusing on this topic, the gaps between users and libraries in terms of perception, expectation and satisfaction can be discovered and then bridged. Bridging these gaps overcomes the drawbacks of previous research that suggested adopting technology-driven or content-driven models of library services. It is important for library managers to learn more about their users in order to improve existing services and identify needs for new services. By adopting a user-centered approach, this study aims to promote a greater understanding of the existing and potential digital services provided by academic libraries to enhance information use. 


\subsection{The Statement of Sub Problems}

The digital library has the ability to deliver various services on a network anytime and anywhere. In this research, the survey results and interview data were analyzed together to determine whether the current delivery methods for digital services were appropriate or whether there are better ways to deliver specific digital services in the academic library being investigated. The research problem is divided into the sub problems described below.

The first sub problem is to determine the users' opinions about the digital services in order to find their perceptions of the quality of the current services, expectations for future services, and to identify any barriers that may impede their use of those digital services. The evaluation dimensions and framework are derived from both user satisfaction and service quality evaluation theory. The following dimensions are investigated: the users' level of satisfaction with the digital services; the level of performance of the digital services from the users' perspectives; and the users' expectations for future services. The opinions of different user communities (undergraduates, postgraduates and academic staff) were compared to determine any divergence that may exist.

The second sub problem is to investigate the librarians' perceptions and expectations of these services. This was done by giving questionnaires to selected librarians and following up with interviews. Some of the survey questions required the respondents to describe their understanding of the users' perspective and other questions asked for their own views. Some librarians involved in implementing and planning digital services or whose work is affected by digital services were interviewed to find their opinions on digital services and their purposes.

The third sub problem is related to the Gap Model theory. From this theory we can hypothesize that users and librarians have different opinions related to the performance of digital services. This research, therefore, identifies and then compares the different perspectives to find any gaps in perceptions or expectations between users and library staff. One of the focuses of the 
interviews with library staff is to determine the reasons for any gaps. If there are obvious gaps between users' and librarians' views, these gaps need to be understood to determine whether the way in which an academic library selects and delivers specific services is appropriate to the needs of the library's users. Alternatively, if the viewpoints from the two parties are similar, the services are justified.

\subsection{The Research Questions and Hypotheses}

The overall research question is:

How and why do academic library users' preferences for specific digital services differ from the current forms of delivery?

Therefore, the following questions will be addressed:

1. What are the content and delivery formats of some specific digital services provided by academic libraries?

2. What are the profiles of the user communities and their information needs with regard to the library's digital services?

3. What are the users' perceptions of and preferences for current digital services in terms of awareness, frequency of use, importance, ease of use, usefulness, accuracy and future use?

4. What are users' expectations of future digital services?

5. What are the perceptions of the librarians concerning the current performance of the digital services?

6. What kinds of future developments do the librarians envision?

7. What are the different preferences for existing digital services among different user communities — undergraduates, postgraduates and academic staff?

8. What are the different expectations for future digital services and developments among different user communities - undergraduates, postgraduates and academic staff?

9. What are the differences in perceptions of current digital services between users and librarians? 
10. What are the different expectations for future digital services and developments between users and librarians?

11. What are the reasons given by librarians for providing some services, and what are the barriers to their provision?

The following hypotheses will be tested.

1. Different user communities have different opinions on digital services.

- Different user communities have different information needs.

- Different user communities have different perceptions on the current digital services in terms of awareness, frequency of use, importance, ease of use, usefulness, accuracy and future use.

- The different user communities are not satisfied with the digital services to the same extent.

- Different user communities have different expectations related to future digital services.

2. There is a relationship between future use of a service, and users' satisfaction with the service and perceived importance of the service.

- The more important the service is to the users, the more likely it is that users will use the service in the future.

- The more satisfied with the service the users are, the more likely it is that they will use the service in the future.

3. There are different perceptions and expectations regarding the awareness, importance, ease of use, usefulness, and future use of specific digital services between users and the librarians.

- The level of users' awareness of some specific digital services will be lower than library staff thought.

- Users have different perceptions from those of librarians on the current digital services.

- The percentage of users who are satisfied with the performance of digital services is different from that of librarians.

- Users' expectations on the importance and usefulness of future digital services differ from the expectations of librarians. 


\subsection{Definitions of Terms}

Some important terms need to be defined and explained clearly before they are used in this study.

The term digital library (DL), is used synonymously with electronic library and virtual library. According to Lary (1998), DL means the use of digital technology to acquire, store, preserve and provide access to information and materials originally published in digital form or digitized from existing print, audio-visual and other forms. For the purpose of this research, the digital services of a digital library will be emphasized.

The hybrid library, according to Brophy (1998), is an integrated system providing both electronic and print services using a range of technologies in the context of a working library. However, no library can exclude print materials completely. Therefore the hybrid library is actually the dominant form of digital library in practice today.

The academic library provides and structures instructional resources and services in support of researching, teaching and learning. Academic libraries are based in a variety of institutions including universities and polytechnics. This research focuses on the university type of academic library.

Technology driven is a type of information system which centers on size, shape, dynamics and even content (Taylor, 1986).

Content driven is another type of information system, and focuses on traditional classifications of knowledge. This kind of models provides a variety of powerful ways of dividing, organizing, and hence thinking about knowledge and perceiving the world around us (Taylor, 1986). This model provides with us a means of organizing packages (e.g., books on shelves or references in an index) and also establishes disciplined ways of perceiving knowledge and its applications. 
$I L L$ is the abbreviation of interlibrary loan. It is a service by which users can order what they want from another library when their own library does not have it.

Reference, while also a traditional service, has the further meaning in this research of assisting users in gaining information by the use of digital technologies instead of through face-to-face interviews.

Frequently Asked Questions (FAQ) is a reference list provided on a website. It combines all the common questions asked by users and gives the answers.

Virtual Reference uses videoconferencing or chat rooms in an effort to create online real time interactions so that users can ask librarians questions and get the answers immediately via the web.

Electronic Journals (E-journals) are published online. They are updated regularly and frequently.

A Current Awareness Service (CAS) aims to keep the customers of an information service informed of the latest developments in their fields.

$S D I$ is the abbreviation of selective dissemination of information. It is a proactive reference service which provides information to users according to their specifications.

Document delivery is a service responsible for transporting information to users in digital forms.

Distance learning means education for off-campus students with the aid of library online services.

Personalized service means using tools supported by DL to create a personalized library interface and keep users' individual searching strategies or topics as integrated personal information. 


\subsection{Assumptions}

This study is user-centered research rather than collection-based or technology-centered research. This research does not cover the whole life cycle of the digital academic library from creating to preserving information. The focus of this study is primarily the delivery and content of digital services tailored to users' needs, rather than the technology. The first assumption is that the cost on the services side may be high. Therefore many factors such as funding and consortia will have an impact on those services.

In order to get a scientific sample, information identifying the staff and students is required from all faculties. It is assumed that all the people listed can be contacted and will have equal chances to be selected in the sample.

Another assumption stressed here is that all the people involved including undergraduates, postgraduates and academic staff give their viewpoints objectively based on their experience. It is also assumed that all the questions on the questionnaires are comprehensible for the respondents.

\subsection{Delimitations}

In this study, a random sample is selected proportionally from all students and academic staff. General staff such as administrative staff do not normally use library services, especially digital services. They are not a typical or significant user community. The services and collections of the Library are not focused on them, therefore they are excluded from the survey population in this research. Though the users of academic libraries may also include the general public, surveying these people is difficult because they are not registered as users. Thus, this category is also excluded from the survey population. Due to limited time, technology and financial resources, this study is limited to users and staff of the Victoria University of Wellington (VUW) Library. 
This research does not cover all the digital services provided by academic libraries. For example, those services involving network support are excluded. This study does not focus on traditional services such as circulation. Instead, this study only includes digital services that have improved access to information resources.

As the qualitative investigations deal with issues that are potentially sensitive for the library, cooperation is a critical factor. The interviewees are librarians and their biases may influence their perceptions of users' satisfaction with services.

Survey questionnaires permit a wide sample of users and librarians, but suffer from some of the general limitations of quantitative research such as lack of depth. The number of questions is limited to make the survey a reasonable length. It is difficult to design a questionnaire that offers the respondents the same degree of understanding as the researcher. Thus, there is some possibility of misunderstanding the questions. It is also possible that people will apply different subjective evaluations to the Likert scales.

The study is carried out in VUW. In order to reflect most closely the overall situation in university libraries, the measures and statements used are general ones and those relating specifically to VUW Library have been kept to a minimum to allow recommendations to be made where possible, which will be of potential value to other academic libraries.

Two open-ended questions have been included to determine whether specific instances of good or bad services have affected the respondents' perceptions of the usefulness and importance of digital services. 


\subsection{Summary}

In this chapter, background information was provided to clarify the motivation behind the purpose of this research. Gaps in previous research were briefly described to delineate the objectives and importance of this research. The problem and sub problems to be dealt with in this research were explained. Several questions and hypotheses were listed. The key concepts related to this research were explained in order to make the following chapters more understandable. Some assumptions supporting this research and unavoidable limitations were also outlined. Subsequent chapters of this thesis can be broadly outlined as follows: Chapter Two introduces the existing literature regarding the development of digital services, theoretical framework, methodology and some examples of digital services. Chapter Three considers the methodology combined with qualitative and quantitative techniques for this research. Chapter Four details the current delivery of digital services provided by VUW Library by studying its website. Chapter Five presents and compares the data from the questionnaires for users and librarians. Chapter Six analyzes findings and issues arose from the comparisons and discusses the hypothesis of this research. Finally, a synthesis of the research results, issues and recommendations from the findings, an assessment of the applicability of the theory, the study's limitations, and the ramifications for future research are provided in Chapter Seven. 


\section{Chapter 2. Literature Review: A Study of the}

\section{Delivery of Specific Digital Services in Academic}

\section{Libraries}

This review begins with an overview of the literature related to a variety of services provided by digital libraries, particularly academic libraries. The topics covered are the need for digital services, the development of digital services and some specific digital services included in this research. Following that are two sections discussing the literature related to the theoretical base and methodology for this study. The final section is a summarized evaluation of the literature.

\subsection{Overview of the Development of Digital Services}

\subsubsection{Development of Digital Services}

Since the first pioneering efforts to develop automated systems were made in the $1960 \mathrm{~s}$, the computer has become a very important component within libraries. In 1961, John Kemeny wrote in A Library for the Year 2000, that the library in the future would have to make heavy use of automation (Fayen, 1983). By the end of the 1960s, a databank of photographic images of manuscripts was created to reduce wear and tear on original manuscripts (Alexander and Prescott, 1998). In the 1970s, the development of computerized catalogues, especially OPACs (Online Public Access Catalogues), resulted in research being conducted on automated library access.

New technologies, including microcomputers for processing, transmitting and storing information, presented new opportunities for librarians to provide electronic services. In the 1980s, writers in library and information science (LIS) journals began to pay more attention to the types of electronic services provided by libraries. Fayen (1983) suggested that online catalogues, searching and reference services were the main roles of electronic libraries. 
Cline (1983) proposed an online search service that would offer databases, reference help and interlibrary loans. Dowlin (1984) focused on reducing the time it took to access information. He also discussed some new ideas such as an electronic messaging system, community bulletin boards and continuing education.

In the 1990s, research on and development of digital library services increased. From that research, clear concepts of digital libraries began to emerge. Some of the research related to academic libraries aimed to support academics by providing a variety of access points to information, and became more useroriented. For some years the professional literature has been warning academic libraries and librarians of the need to change and the danger of lagging behind users' information needs. Hanson (1999, 337) felt “...the service arrangement in academic libraries needed to adapt to changes in teaching and learning methods, to the increasingly complex needs of 'networked learners', to the emerging situation of multiple information providers on campus and to the many challenges presented by the Internet."

At the start of the new millennium, Fountain (2000) observed that academic libraries were now turning their attention towards implementing and offering users a range of innovative ways to access information due to the numerous advantages of digital services. He commented on a range of these advantages. Digital services can improve the efficiency of library work, reduce duplication of effort and cost, save staff time and increase cooperation. The digital services can also improve communication between different sections of libraries and between users and libraries. Digital services can expand the functions and ability of libraries to satisfy their users' increasing information needs. Lin (1997) argued that internal and external pressures from environmental and technological changes were also forcing libraries to adopt digital services. She observed that economic constraints, such as the rising cost of publications, were changing the traditional financial base of libraries. According to Lin, the size of budgets and the number of staff in libraries have decreased. As a result, many libraries have adopted digital services to reduce costs. 


\subsubsection{Specific Digital Services}

A search of the literature has uncovered a range of services provided by digital academic libraries. Many articles have mentioned the types of digital services used in electronic library projects. Generally, academic libraries provide two types of digital services: internal services and external services (Covi and Kling, 1998). Internal digital services, for example online catalogues, help users to access the library's collections. External digital services, for example online database searching, allow users to access and obtain external information resources via the web. Some basic and widely used digital services, which have been introduced by various academic libraries and are studied in this research project, are discussed below.

\subsubsection{Catalogue}

The catalogue is a sophisticated gateway enabling users to identify relevant items and access the collections of a library. It was also the first service to be automated and is still being improved with the aid of modern computer technology.

Ekers (1998) maintained that the two main types of catalogues were traditional online public access catalogues (OPACs) and web-based catalogues. According to Hayes (1993), OPACs increase the ability to identify and retrieve materials from library collections. They can save more time and provide a wider range of access points for users than traditional manual catalogues. Lin (1997) suggested that OPACs also provided users with access to processed "backroom" information such as "on order/in" status. Thus, they became the most commonly used types of catalogues in university libraries during the late 1980s. Today, as Fountain (2000) observed, users are able to access web resources and some electronic versions of materials via the more flexible WebPACs. WebPACs are able to provide access to information that is more up-to-date than print sources. 


\subsubsection{Searching Services}

Online database searching services increase the amount of information available to users by providing online access to bibliographic and primary source databases and thus provide users with more choices.

CAS (Current Awareness Services) and SDI (Selective Dissemination of Information), in Rogers' (1986) view, essentially provide the same functions, doing what the users are unable to do for themselves - either through lack of time or lack of inclination. In their traditional form, the services consist of scanning the current literature for items of relevance to customers and notifying them immediately, either individually, or through a current awareness bulletin. Today, users can set up an online personalized alerting service that automatically repeats saved searches on specific databases. Alternatively, users can choose to put forward their requirements directly to the libraries and leave all the searching work for the librarians. The users can get the results regularly in electronic formats (Hanson, 1998).

\subsubsection{Reference}

Digital reference services offer a new model for providing answers to enquiries for users whether on or off campus. According to a 1995 survey of how well university libraries met academics' research needs conducted by Social and Community Planning Research (SCPR), reference services have improved considerably since the end of the 1980s (Erens, 1996). Hanson (1999) pointed out that a well organized website with links to local and Internet resources was a major part of such support, and subject librarians played an important role in selecting resources relevant to the users' needs for this service.

Experiments with extending reference services into the digital environment have focused on two electronic media: email and video. Online or email enquiries have become standard practice on university library web pages since 1998. Hanson (1999) observed that "virtual reference" was an attempt to provide a reactive reference service in a proactive fashion. "Virtual reference" 
service by a FAQ list is based on typical questions collected by reference staff and is structured by alphabetical order or subject. Some libraries have experimented with video. Morgan (1996) described the "See You See a Librarian" project, which is aimed to "discover whether or not video conferencing technology...could be used in libraries to enhance information/knowledge services." This service is somewhat unique in delivering services electronically in that it is not limited to a single organization (Sloan, 1998).

\subsubsection{Document Delivery}

Traditionally, users obtained materials from the library's own collections or through interlibrary loans. However, Rutstein, DeMiller, and Fuseler (1993) argued that inadequate collections and slow interlibrary loan systems had been unable to deal with the growing pressure from users for faster delivery. Today, "document delivery" service provides information to users by print, email, or other network methods. For example, as Wakeling (1999) pointed out, "document delivery" service in the form of E-journals can provide convenient and fast access to the latest developments in all kinds of research fields. Through "document delivery" services, people can access information in all formats and wherever it is located. Indeed, Layden (1994) argued that the speed of "electronic document delivery" would make it seem as if the information is local. Based on the speed and convenience of "document delivery" services, we can assume that these services will become a substitute for interlibrary loans and journals.

\subsubsection{Instruction}

Erens (1996), who found that just over half of the academic respondents in his survey were aware of the electronic services available in university libraries in the United Kingdom, suggested that it was necessary to teach students and staff basic information retrieval and management skills. Brophy (1996) contended that the skills involved in defining information needs, refining search strategies and finding and evaluating information, needed to be taught 
initially to users. Online help in the form of online tutorials or general information is becoming a key teaching resource for upgrading users' skills.

\subsubsection{Distance Learning}

Digital academic libraries have revitalized learning for the growing population of distance students. The services available in academic libraries include online course materials and electronic access to a variety of reference sources (Fountain, 2000). Hanson (1999) suggested increasing the use of electronic and printed study packs as substitutes for conventional reading lists and making them available through the university library system.

\subsubsection{Interlibrary Loan (ILL)}

The combination of deteriorating library collections and increasing amounts of online learning in universities has, according to Hanson (1998), required academic libraries to integrate access arrangements to information resources with online activities. The direct result is that scholars rely more on interlibrary loan services that can be established as a part of a suite of electronic services offered by libraries. Erens (1996) reported that over half of the academic respondents in his survey claimed they needed more and more ILL services. With this increasing reliance on interlibrary loans, many libraries have developed special online ILL request forms to streamline the process.

\subsubsection{Summary}

Covi and Kling (1998) argued that generally, there were two types of digital services in academic libraries: one focused on Internet sources and the other focused on library automation. Today, according to Brand (1994), academic libraries play a central role in a range of university activities, affecting university instruction, research, scholarship, and creative activity. Some services such as cataloguing and reference that are dependent on internal resources have been transformed and automated with the aid of modern technology. More services offering users access to external information sources have become available. 


\subsection{Theoretical Framework}

The section outlines the literature on the theories supporting this research.

\subsubsection{The Development of Theories before the Mid-1980s}

Prior to 1980 s, there were few user-centered approaches used in library services research. Most of the research during this period was technologydriven or content-driven. Dervin and Nilan (1986) pointed out that in the early 1980s, many researchers and survey designers began to assess information needs and users. Garvey (1979) said that better information services were more likely to be achieved through adjusting the services to meet the specific needs of an individual rather than trying to adapt the individual user to match the wholesale output of an information system. Mick (1980) suggested changing the focus of information systems from technology and content to users. Wilson (1981) identified the imbalance in information flows to underserved users and hoped to decrease the marginality of many information services to increase use. By the mid 1980s, both the research literature and professional literature were looking at users as the most important aspect for analysis in research about the effectiveness of information services.

\subsubsection{Taylor's User-Centered and Value-Added Theory}

After Taylor's (1986) theory was introduced, researchers began to pay more attention to information use. The most important theory used in this thesis is user-centered and value-added theory. Taylor (1986) emphasized that the main input into the design of information systems must come from an analysis of information use. According to Taylor, the technology-driven model had essentially prescribed the size, shape, dynamics and even the content of information systems, while the content-driven model was derived from traditional classifications of knowledge. These two models were no longer enough to deal with the information explosion, therefore Taylor (1986) argued that research on the delivery of electronic services should be user-oriented. This point of view suggests that surveys of users and library staff can be a basic foundation for research on the performance of library services, since 
users are the best judges of service quality. Since the mid-1980s, the user-driven model, which is rooted in an analysis of information use, has become an essential part of information system design and evaluation.

The inclusion of users and their needs is also the main strength of the valueadded model of information systems, which is another important aspect of Taylor's work. According to this theory, electronic services should provide enhancements to add value to the information sources. Taylor $(1986,41)$ said that information system problems did not just require answers, but rather solutions, resolutions, clarifications and options.

In Taylor's value-added theory, the criteria that could be used as evaluation measures for electronic information services included ease of use, noise reduction, service quality and adaptability. When conforming to the above criteria, electronic information services and systems will be accessible, flexible and stimulating. Unfortunately, many of the early electronic information systems were designed using a technology-centered or contentcentered model. The research used to design these systems ignored user input, reducing the practical value of that research. The importance of the usercentered approach in the design of current digital information resources is highlighted by writers such as Sloan (1998). Sloan explained that digital library proponents must consider the role of people if the digital library was to be truly beneficial.

\subsubsection{Parasuraman's Gap Model}

Other theories are also needed to thoroughly evaluate digital services. The Gap Model of Parasuraman et al. (1988) is another key theory. This model was influenced by disconfirmation theory, an approach that has been widely used by libraries to examine the differences between the users' expectations of service quality and their perceptions of the actual quality. Thus, the service quality in this research project is to be determined based on the users' perceptions of the service quality rather than any objective standard. 
The Gap Model, however, develops disconfirmation theory further and takes the perspectives of library management staff into consideration. Hernon and Nitecki (2001) argued that the Gap Model reflected an important perspective on service quality and offered a framework to identify those services meeting or exceeding users' expectations. Five gaps are put forward in the original theory in terms of customers' expectations, management's perceptions and service quality specifications:

1. Customers' expectations and management's perceptions of these expectations;

2. Management's perceptions of customers' expectations and service quality specifications;

3. Service quality specifications and actual service delivery;

4. Actual service delivery and what is communicated to customers about it; and

5. Customers' expected services and perceived services delivered.

The first four gaps contribute to the fifth gap, which also follows the usercentered theory to define service performance and quality by examining the discrepancy between expectations and actual service delivery. A large gap between what is preferred by users and what is delivered by libraries results in poor service. In the research project undertaken here, the first gap is broadened to include the differences between users' assessments of services and library staff's perceptions of these assessments. The second and the third gaps are not the domains of this research considering that this current research project focuses on users' perceptions and expectations rather than libraries' specifications of service quality.

\subsubsection{Service Quality Model and User Satisfaction Model}

Using the Raizen and Rossi's (1981) model for evaluative research, this current research is an evaluation of the impact of digital library services. In order to do this, the complex relationship between service quality and users' satisfaction needs to be explored in advance. 
The service quality model examines the organization from the users' perspective and considers users' needs as paramount. Hernon and Nitecki (2001) stated that assessing service quality involved a range of methods for surveying users. SERVQUAL, a standardized instrument based on the fifth gap, has been widely used in a range of situations. It consists of 22 pairs of statements about a delivered service identifying five interrelated dimensions of performance:

- Tangibles: the appearance of physical facilities, equipment, personnel, and communication materials;

- Reliability: the ability to perform the promised service dependably and accurately;

- Responsiveness: willingness to help customers and provide prompt service;

- Assurance: the knowledge and courtesy of librarians and their ability to inspire trust and confidence; and

- Empathy: the caring, individualized attention that a firm providers its customers.

The LibQual+ instrument developed by Fred Heath et al. (1999) contains 41 statements examining four dimensions (effect of service, reliability or service efficiency, tangibles, and resources).

User satisfaction, as another evaluation framework, has two levels. The micro level focuses on whether individual services conform to the previously mentioned dimensions of service quality. The macro level integrates the five dimensions and gives the overall level of users' satisfaction. In this kind of evaluation, users give their preferences and perceptions of the delivery of services.

Each is worthy of consideration as a framework for evaluating library services from the perspectives of users. Service quality addresses cognitive judgments and specific attributes of services, while the satisfaction model focuses on cumulative judgments based on encounters and transactions. The evaluation of user satisfaction provides channels for users to rate service delivery in a few 
specific areas. Through this kind of survey, libraries can learn about their users and how they use the services.

\subsubsection{The Preliminary Integrated Theory Model Supporting This Research}

Using the above theories, a preliminary integrated theoretical model was developed to use in this research. Considering that the focus of this research is to examine the different perceptions and expectations of digital services between users and library staff, this research is rooted in user satisfaction and preference evaluation. Nevertheless, this research incorporates some unique attributes of service quality evaluation. It focuses on the users' cumulative judgments based on their personal experiences. Some dimensions and measures of service quality evaluation are used in this research. Statement questions which are aimed at getting users' perceptions of services based on factors, such as usefulness and importance, are employed in this study. These types of questions are widely used in service quality evaluation. The instrument for this research is based on the first and fifth gaps of Parasuraman's Gap Model (1988).

Parasuraman (1988) identified two research domains of customers and management in his gap model of evaluating library services. In the academic setting, the customers are academics and students, and the management are librarians (Choudhury et al., 2002). Based on that theory, this research domain can be broken down into users, services, and library staff, as shown in the following figure: 
Figure 2. Research domains

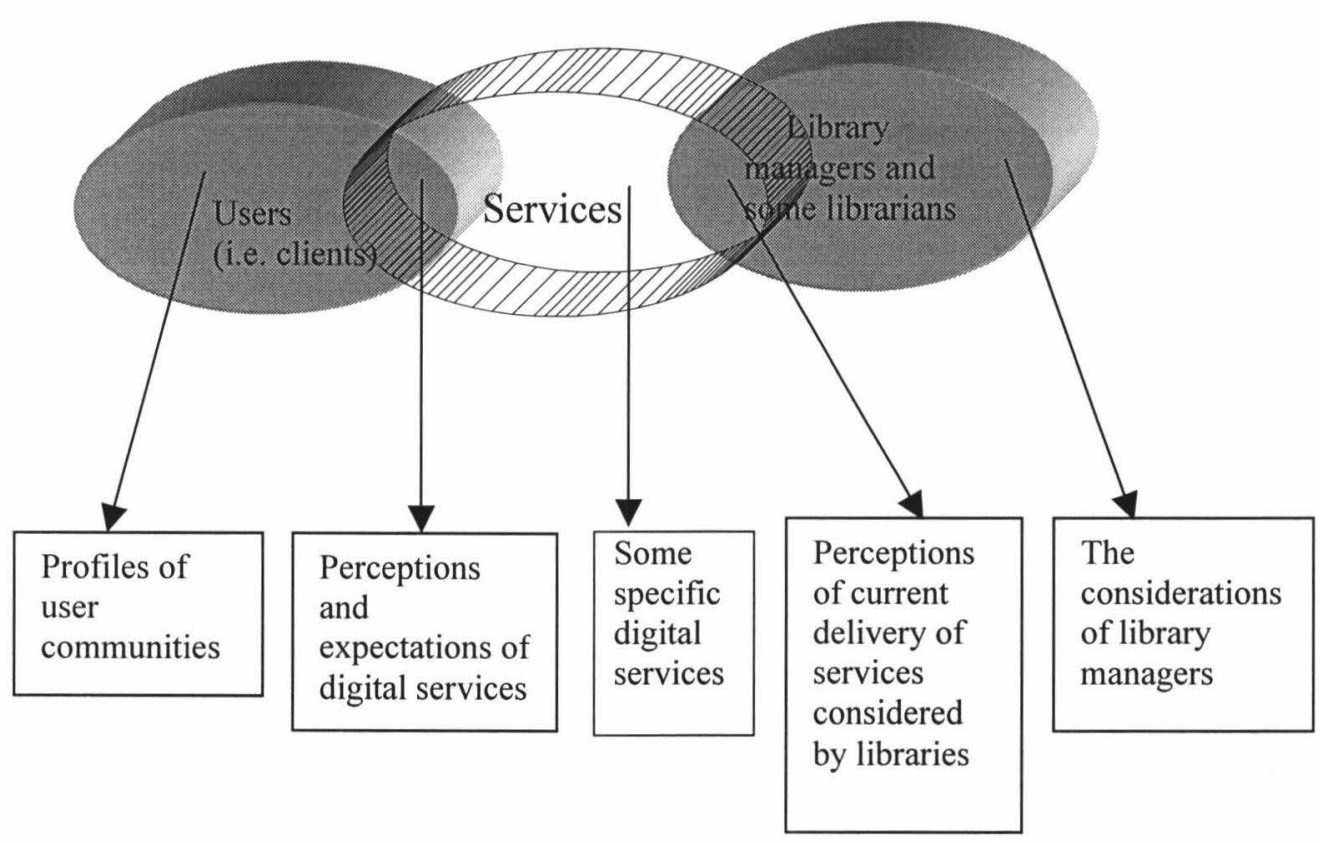

The domains provide the evaluation dimensions that are used in this research:

- Various user communities;

- Specific digital library services;

- Management (some planning, governance and fiscal aspects considered by library staff);

Under the dimension of user communities, the measures of information needs and behaviors from different communities are examined. This part of the research project focuses on the users, their reasons for using these digital services and the frequency of use. The digital services dimension comprises the evaluation of eight services including document delivery, the catalogue, searching, reference, distance learning, instruction, interlibrary loan, and other selected Internet sources. The justifications for providing or not providing some specific digital services — such as funding, consortia and technology belong to the dimension of management and are also examined in the research.

A set of measures (see Chapter 3) appears under every dimension and is used to assess individual digital services. The relationships between dimensions and measures can be seen in Figure 3. 


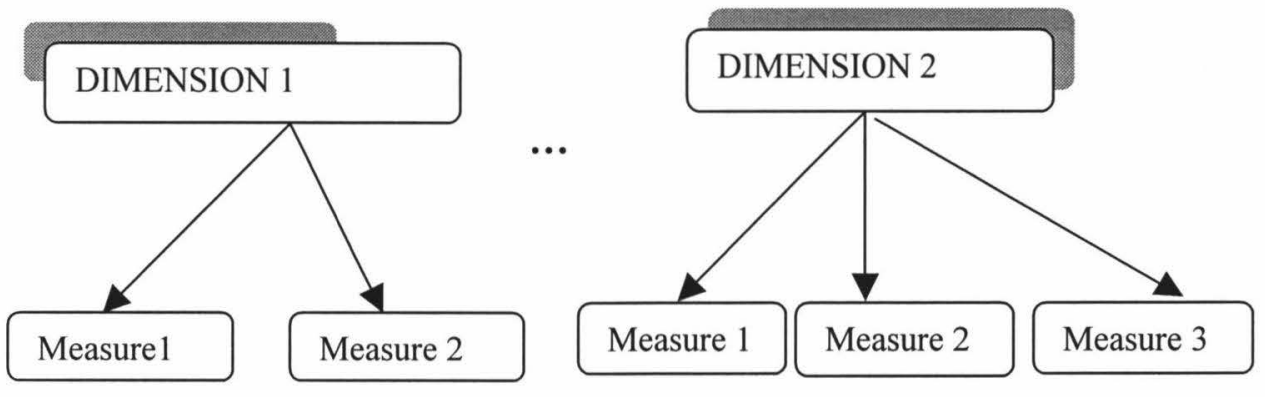

\subsection{Literature on Methodology}

Porter (1998) listed three steps for doing research similar to this current research. The first step is to provide user-based qualitative assessments of how digital services are used and what the users expect of them in the future. The second step is to offer a summary statement of what users require in order to

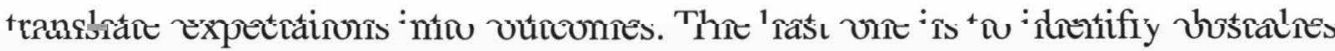
impeding use and to make practical suggestions. The first step is the most important foundation for the success of this kind of research. As Atkinson (1996) pointed, it is vital to review and define the core qualities of those services as libraries prepare to convert an increasing proportion of their services to online formats. Thus qualitative and quantitative evaluations are the core methodological framework for studying the digital services provided by academic libraries.

Raizen and Rossi's (1981) model of evaluation research included fiscal accountability, coverage accountability, implementation accountability, impact assessment and economic analyses. Raizen and Rossi suggested specific evaluation methods for each model. For example, administration records, special surveys and ethnographic surveys are the methods recommended for research on implementation accountability.

Some of the research literature describes methods for evaluating library services in terms of performance, satisfaction and effectiveness (Crawford, 1996). Orr (1968) was among the first to standardize a method for comparing 
a specific range of services offered by libraries. Although it was published over 30 years ago, his study remains the most comprehensive of its kind (Crawford, 1996). In Orr's inventory, the services included interlibrary loan (ILL), cataloguing and binding, exchange services, and the provision of training and management services. The methodology and theory developed by Orr were only used for evaluating traditional services and did not consider users' subjective opinions.

Some other experts took into account users' needs for comfort, information, convenience, and cooperation ${ }^{2}$ (Crawford, 1996). Attkisson and others (1978) proposed four levels of evaluation of library services including systems resource management, client utilization, outcome of intervention, and community impact. The evaluation of libraries changed its focus to output rather than input. Outcome of intervention concerned the effectiveness of the service program from the individual client's point of view, including satisfaction with the services used. The quantity and quality of service delivery and the level of use by clients were the focus of client utilization evaluation. During the following years, three evaluation models of library services appeared including the goal model (Cameron, 1981), open systems (Scott, 1987) and the multiple constituencies approach (Zammuto, 1984). Cameron (1981) further defined the domains within which the organizations operated as population, technology and services. When explaining the open systems model, Scott (1987) suggested that organizations should respond to the demands of their external environment. The multiple constituencies approach defined effectiveness as the degree to which needs and expectations were met (Childers and Van House, 1989).

McElroy (1982) described a project which sought to evaluate the full range of services and activities of a research library, and their impact on users, quality of collections and internal efficiency. However, electronic services are just one of the library activities evaluated, which also include acquisitions, circulation, stock, services and use of staff.

\footnotetext{
${ }^{2}$ Cooperation is defined as the cooperative attitudes of the library staff.
} 
Crawford's work $(1996,2000)$ is highly relevant to this current research. He focused on describing the range of library services by using surveys and interviews. He mainly measured general satisfaction, not dividing it into specific aspects such as awareness, usefulness and so on.

In addition to looking at the digital services, Erens (1996) also dealt with users' opinions of them. He provided the results of the survey carried out in 1995. The survey examined the availability and use of services, the importance of services for academics and the potential consequence of recent library developments. However, the services investigated included many general and traditional services such as reshelving, collecting and ordering books and journals. The measurement framework he used in that research was basic and only included the factors of awareness, familiarity and general satisfaction. He did not discuss the effectiveness, usefulness and future use of digital services. Moreover, the report was purely descriptive and had no recommendations.

Bertot et al. (2000) went further in developing a quality measurement framework for networked library services. They identified four models audience, technology infrastructure, network component, and composite - for determining library network statistics and performance measures. Each model presents a different angle for evaluating service performance. The primary focus of the audience model is the consumer of the network. In the technology infrastructure model, the measures are driven by existing information technology architecture. The network component model focuses on several dimensions: technical infrastructure, information content, information services, support and management. The composite model incorporates aspects of the other models. Evaluation dimensions and measures in these models, especially the last two, are used in the current research. 


\subsection{The Evaluation of the Literature}

There is a considerable amount of research on digital libraries, mainly focusing on technology or collection criteria. The services themselves, and the needs of users, are discussed less frequently. The researcher's study integrates previous theories and methodology and focus on users' perceptions and expectations.

The few papers that provide an overview show a range of digital services provided by academic libraries. Many cases can be found to support authors' opinions about the practicality of digital services. Brophy's (2000) model was based on case studies and can be used by libraries when planning digital services. However, there are also some weaknesses in the literature.

Firstly, Taylor (1986) emphasized that analysis of the information use environment should be central in the design of information systems, and the Gap Model (Parasuraman et al., 1988) also focuses on users. Many other researchers have not understood that data gathered from the perspective of users and library staff are a necessary part of service analysis. Ignoring users' feedback leads to a disproportionate reliance on technology-centered or content-centered theory. As well as gaps between the perceptions and expectations of users, there may be gaps between those of the users and library staff. None of the evaluation literature examines the gaps between service receivers and service providers in addition to the gaps between users. Moreover, historically, there has been a greater emphasis on measuring the costs associated with libraries. However, currently there is a growing trend toward examining and emphasising potential benefits associated with libraries determined by patrons and users. The Association of Research Libraries acknowledged through the "New Measure Initiative" that more attention needed to be paid to services outcome, impacts etc., based on user satisfaction (Blixrud,1999).

Kyrilliidou (1998) has provided compelling reasons for evaluating libraries based on user feedback even without considering digital library services. 
Choudhury et al. (2002) demonstrated an increasing emphasis on a usercentric perspective when evaluating digital services. Thus, user-centred research may identify the gaps in digital library services and then provide the means for prioritising services to address users' needs. In reality, resource constraints require a ranking of priorities, so it is not possible to provide a full range of digital library services to all users. Researchers such as Brophy (2000) focus on evaluation methodologies that consider the outcomes, impacts, or benefits of library services. They evaluate current services to prioritise the development of new digital library services within an institution, based on users' preferences. According to Choudhury et al. (2002), decision-makers need to consider insights and perspectives regarding user preferences from a variety of sources to ensure that future digital services serve the needs of that community.

Although SERVQUAL and other user satisfaction literature provides general guidelines for evaluating libraries, the statements from SERVQUAL are rather sweeping and not appropriate for digital services. Some of the evaluation dimensions in SERVQUAL include library equipment, personnel, communication materials, and politeness of librarians, which are more useful for evaluating traditional library services rather than digital services. In this research, those dimensions are of little relevance and are not included.

Erens (1996) combined quantitative and qualitative methods to evaluate some digital services provided by university libraries, but made no recommendations. In reporting on the effect of recent developments in university libraries on the research process, Erens stated that the results from the survey would feed into the decision-making process concerned with the future level of provision of university library services. In his report, he found that some electronic services were perceived to be more important than others. Views of academic staff about the usefulness of electronic services varied across different services. The overwhelming majority of those staff who had access to online services were satisfied with the facilities and support from the library. Erens also found that as a result of recent developments in library 
services, all academics now made greater use of electronic services because access to information was now easier.

Without a clear theoretical framework and appropriate methodology, research is of little value with regard to providing useful suggestions to help library staff improve their services. When recommending any future services, it is important to undertake surveys to understand how well university libraries meet students' and academic staff's teaching, learning and research needs. Choudhury et al. (2002) stated that the broad aims of a user survey of academic libraries are to examine:

- The importance of university libraries for academic research, teaching and learning, and how well they meet research needs;

- The availability and use of information technology and electronic services by academics and students;

- Consequences of recent library developments for students and academic staff.

A second weakness in the literature is that there is insufficient research on digital services offered by academic libraries. Instead, most studies focus on national digital libraries or public libraries. As a result, the suggested evaluation models for service quality introduced earlier in this chapter are not fully appropriate for evaluating digital services in academic libraries without any revision. The majority of the literature examines one or two aspects of digital services, such as reference or training services, instead of a fully integrated package. The research done by Jones (1998), for example, only focused on searching services.

Another weakness is that most research has been done by analyzing examples in the United States, United Kingdom or Australia. No case studies have been made of New Zealand university libraries. Due to differences in the cultural and economic environment, the findings and recommendations of the other studies may not be fully applicable. 
Some of the literature focuses on new developments of advanced electronic services projects in specific universities and institutions. Nevertheless, some of these projects only exist in the form of software rather than being used in the real world. Only a few studies investigate digital services currently used regularly in university libraries. This research project addresses the models, performance criteria, measures, methods, and results of studies evaluating digital services. There are several good sources offering evaluation measures, but almost none of them can be used unchanged for evaluating the digital services provided by academic libraries. There are few studies giving measurement frameworks and methods to study the performance of digital services from the perspectives of users. It is this lack of research into users' and librarians' opinions of digital services that attracted the researcher's attention and ultimately led the researcher to do this research.

\subsection{Summary}

This chapter reviewed the literature on digital services in academic libraries, focusing on their development, theoretical frameworks, and methodology. In this online age, digital services can provide information faster than libraries can acquire and organize it (Lin, 1997). Libraries are also linking users to more information sources. Users are becoming more proactive in choosing which kind of information they need instead of passively receiving it. In this sense, libraries can take the role of delivering the information sources and allow users to link to them directly. This research is innovative in not only identifying the gaps between the perceptions and expectations of users but also in revealing the gaps between users and library staff. Thus, the results of this study lead to useful suggestions for decision-makers. Academic libraries are in a good position to improve access for both faculty and students to online information (Fountain, 2000). Proactive libraries will be able to provide access to an enormous amount of information whatever their size and budget. 


\section{Chapter 3. Research Design}

This chapter begins with an introduction to the research methodology and details the procedure applied in this research. Following that is information about the survey sample and instrumentation used in this research. The pilot study is then described, and the chapter concludes with a discussion of the data collection and analysis methods used in this research.

\subsection{Research Methodology}

Of the four evaluation levels identified by Attkisson (1978) et al. and discussed in the previous chapter, this research project is mainly on the outcome of intervention level. It is concerned with the clients' level of satisfaction with the digital services in an academic library setting. The research also includes evaluation of client utilization of those services, and the quality and quantity of the service delivery from the clients' perspectives. In addition, the perceptions of library staff about users' preferences for some services are investigated and then compared with those of users.

For this research, a number of detailed evaluation models have been developed based on the theories outlined in the previous chapter: Orr (1968), Crawford (1990), McElroy (1982), Cameron (1981), Zammuto (1984) and Scott (1987).

This research is user-centered, so the results provide a basis for developing better service delivery. Because library services are multi-dimensional, no single method or measure of satisfaction and performance can describe all services and users. Therefore, measures from several models are combined according to the special characteristics of user-centered services. A number of approaches have recently been used to develop a quality measurement framework for digital library services. One of the approaches is the composite model identified by Bertot et al. (2000). This approach incorporates models varying from the audience model to the network component model. The users of digital services, the services themselves and resource dimensions are 
evaluated according to a number of measures regarding service performance and user satisfaction. This is a strong evaluation framework model.

The measures used in this research determine the value and importance of the features of specific digital services from the perspectives of the users. Evaluation measures vary according to which service is involved. Some measures from Bertot's audience, network and composite models have been revised for use in this research. In addition, measures from the goal model (Cameron, 1981) stressing the range and quality of services, have been combined with measures from the multiple constituencies approach (Zammuto, 1984) for user satisfaction. This combination of measurement methods enables different preferences between users and libraries to be identified more strongly. Qualitative and quantitative methods both support this research.

The research comprises five stages. Firstly, the literature review has helped to identify a range of evaluation measurements and research methodologies appropriate to this research. The following list provides the measures that have been applied ${ }^{3}$.

- The demographic profiles of each user community;

- The reason for using various digital services;

- To what extent digital services are provided;

- The use frequency of various digital services;

- Awareness and adoption of the service delivery format;

- The importance of various services;

- Convenience of access;

- Ease of use;

- Usefulness and accuracy;

- Satisfaction;

- Influence on future use.

\footnotetext{
${ }^{3}$ A variety of different measures have been used for evaluating and assessing the features of some specific services such as electronic databases and electronic journals. For example, the measures of range of content, availability of searching options, currency of the databases, ease
} 
Secondly, an inventory of the digital services to be investigated was compiled in advance. This inventory includes services that are currently provided as well as some not provided but which are thought desirable judging by the reviewed literature and case studies of other libraries. Thirdly, separate quantitative assessments on users and library staff, and follow-up qualitative investigations are employed to determine users' preferences for the current delivery of digital services and library staff's perceptions about those preferences. The survey results are designed to make library managers aware of current services that would benefit from promotional efforts and to identify others which should be added or dropped. Next, the reasons for the different preferences among users and librarians are summarized. Lastly, negative factors that affect users' satisfaction with the digital services are identified from the interviews, and some recommendations to improve the delivery of digital services are given.

Surveys are the foundation for this research. Library services are a user-centered and value-added information system. The delivery of digital services should be based on analysis of the information use environment, which is essential to describe information needs and the interface between systems and users. Objective data has identified services that are not being delivered to the standard expected by users. The purposes of using surveys in this research, therefore, are:

- To define the characteristics of users and their needs and organize this information to influence the structure of services;

- To provide information about the users' opinions of the services;

- To compare users' preferences for specific digital services with the perceptions of librarians about what they believe are the preferences of users;

- To compare the assumptions of the librarians about the implementation and effects of digital services delivery;

- To indicate problems; and

- To suggest solutions.

of choosing a relevant database and response time are used when considering the importance of the features of electronic databases. 
Different classes of users require different types and delivery formats of information services. The users and their environment are necessary components of analysis for the eventual improvement of the system (Taylor, 1986). Therefore, during the survey, different users are asked what they want that would improve the services, and then on what basis they make choices when being presented with large numbers of potentially relevant services. The viewpoints of the library manager and librarians are also investigated.

The user preferences survey is the first step in this research and is used for quantitative analysis. The questionnaires distributed to users include both open-ended and closed questions. There are more closed questions than openended questions in the survey in order to get a high response ratio. The answers to the closed questions are on a Likert scale. Users are asked to rate the services according to extensiveness, awareness, frequency of use, importance, convenience of access, ease of use, usefulness, accuracy, satisfaction, and influence. A pilot study was used to trial the questionnaires to make sure the questions were clear to the users. The questionnaires were redesigned according to the results of the pilot study to make them more comprehensible and representative.

The questions on the librarians' questionnaires aim to identify current problems with the digital services and the librarians' views about these problems. The staff chosen for interviews are some key librarians involved in implementing and planning digital services or whose work is impacted by digital services. This selection provides the perspective of service providers, helping to identify problems in existing service delivery. In the light of suggestions from Crawford (1996), the interviews were semi-structured and were based on a list of issues related to various services offered to users and the library's strategies regarding these services.

This research has been designed using ethical guidelines laid down by the Human Ethics Committee of Faculty of Commerce and Administration and I have obtained the necessary ethical approval. The research involves human subjects giving their demographic details, personal perceptions and 
expectations. The user survey and librarian survey is strictly anonymous and an information sheet was supplied for participants about filling out the questionnaire. The librarians' interviews are confidential and informed consent was obtained through a signed consent form (Appendix C). Both the questionnaire survey and interviews have been conducted in accordance with ethical principles. Access to all the survey results and interview tapes and transcripts are restricted to the researcher and the supervisor.

From the survey data, preferences expressed by different user communities are compared to identify the communities' different information needs, perceptions and expectations. The combined opinions of the users are compared with the librarians' perspectives on the various services using a set of evaluation measures to identify any differences among the different user communities or between users and the library staff. The aim of the librarian interviews is to determine reasons for the gaps, which should help to identify existing problems and lead to constructive suggestions for improvements.

\subsection{Procedure}

The procedures that have been followed in this research are summarized in sequential order below ${ }^{4}$.

- Investigate some techniques of service measurement and identify possible research methodology and theoretical framework.

- Design questionnaires and interview checklists.

- Choose an appropriate sample, time and place.

- Conduct pilot study.

- Revise the structure and content of questionnaires and interview checklists in the light of the results of the pilot study.

- Arrange the interviews and questionnaire survey by contacting participants in advance by email or phone.

- Survey users with questionnaires.

- Analyze users' profiles and information demands.

\footnotetext{
${ }^{4}$ For a flow chart of the procedure, refer to Appendix A.
} 
- Assess current digital services offered by academic libraries from the perspective of users.

- Compare perceptions and expectations of different user communities.

- Survey librarians with questionnaires.

- Analyze the library manager's and librarians' perceptions of users' preferences for current delivery of digital services.

- Compare different opinions of users and librarians.

- Interview the key librarians whose work is closely related to digital services.

- Find the reasons for the different preferences between users and library staff.

- Consider some suggestions to improve current digital services and identify new needs.

These procedures are designed in the sequence of the research process and are based on the data flow produced in the research.

\subsection{Research Sample}

This research focuses on the Victoria University of Wellington (VUW) Library. Library users, the manager and some librarians are the survey subjects.

The samples of users and librarians were determined as follows. The selected librarians were surveyed and interviewed to determine their perspectives on the Library's digital services. The librarians were selected on the basis that they were involved in implementing and planning digital services or their work is affected by digital services.

For the user survey, the sample population consists of all the users of VUW Library, especially those who have experience in using digital services. The sample unit is individual users. Proportional stratified sampling was used in selecting the sample for this research. The aim of the stratified sample is to ensure that all major areas involved in digital services are represented. The 
proportional stratified model is more scientific than the simple randomization model (Leedy, 1997). The user community was divided into three strata of undergraduates, postgraduates and academic staff with a proportional distribution between them. The university library must balance the needs and viewpoints of each group. As mentioned before, non-academic staff and the general public are excluded from this study. After the whole body of users was stratified, a random sample was proportionately selected from each group. The following figure shows the sample design. 


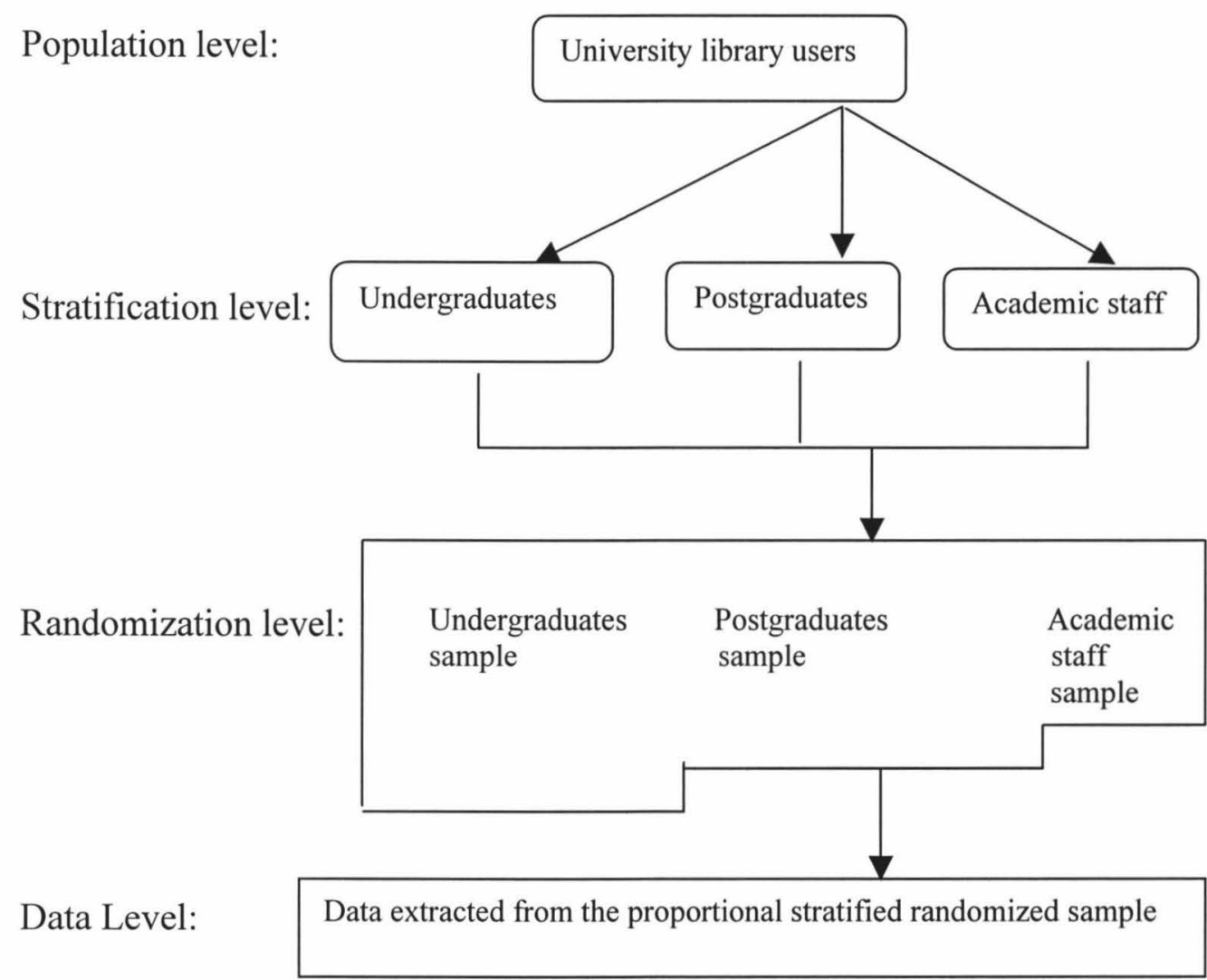

Sample size is worth considering carefully. Smaller samples are more likely to be different from the population than are larger ones, and therefore less representative. This means that the smaller the sample is, the lower the reliability of the data. Thus the sample size must be of a certain percentage in order to reach a given level of confidence. However, according to Alreck and Settle (1980), it is seldom necessary to sample more than 10 percent of the population. If the population is 10,000 or more, most experienced researchers will probably consider a sample size of between 200 and 1000 respondents. The maximum practical size of a sample has no relation to the size of the population. Gay (1996) suggested that the larger the population size, the smaller the percentage of the population needed to get a representative sample. Guided by these theories and the table from Krejcie and Morgan (1970) on sample size required for given population sizes, in the case of the Victoria University of Wellington, a $2.5 \%$ sample of each individual stratum was drawn from the population, which was further divided into the following strata: 
10,480 undergraduates, 1912 postgraduates and 812 academic staff (VUW statistics of 2001). Consequently, in this research, the total sample of users was approximately 325 including 262 undergraduate students, 48 graduate students and 20 academic staff.

VUW has five faculties: Architecture and Design, Commerce and Administration, Humanities and Social Sciences, Law, and Science. Academic staff were chosen randomly by a SPSS tool after setting up a database for all academic staff from different faculties.

Undergraduates form the majority of the whole sample. By contacting faculty offices and by searching the timetable information online, the researcher chose tutorials in every faculty according to the number of students enrolled. A range of 100, 200 and 300 level papers were included. Assuming the number of students per tutorial ranged from 15 to 20 , the expected sample size of undergraduates was close to 264 (2.5\% of all whole undergraduates). By using the random case selection function of SPSS, 15 tutorials were selected to comprise the undergraduate sample. This was broken down into five tutorials each from the Faculty of Commerce and Administration and the Faculty of Humanities and Social Sciences, three tutorials from the Faculty of Science, one from the Faculty of Law and one from the Faculty of Architecture and Design. All the students in these tutorials were surveyed.

A random sample of postgraduates was chosen when the questionnaires were distributed into the envelopes or pigeonholes in their schools by school administrators. The number of distributed questionnaires was proportional to the number of graduates in the corresponding schools. The expected sample size of postgraduates was around 48.

The sample of academic staff was chosen randomly from the academic staff list of VUW. The expected sample size of academic staff was 20. 


\subsection{Instrumentation}

Questionnaires and interview checklists are the main instruments used in this research. Designing them was a difficult task as no research has been done on the comparison of different preferences for digital services. The questionnaires were designed with the objective of obtaining information in the areas of users' demographic information, their perceptions of current digital services and the expectations for future possible services from the perspectives of both users and librarians.

The questionnaire for users fit on three double-sided sheets of A4 paper (including screenshots) in order to appear short and quick to complete. The questionnaires included both closed and open-ended questions. The openended questions allowed respondents to express their views and their experiences of using digital services. The closed questions used multiple choice and Likert scales (five responses ranging from negative to positive in relation to the question statement). These questions allowed respondents to make comparative ratings of each service in terms of frequency of use, awareness, importance, convenience, ease of use, usefulness, accuracy, satisfaction and influence. The questionnaires asked for general information about the respondent, their reasons for using the digital services, and their opinions on the delivery of specific digital services. Various indicators used in the questionnaires recognized users' needs and adapted the services to those needs. Questions investigating users' experiences with digital services were also included to distinguish the actual users of digital services from the rest of the research population.

The questionnaire for users was made up of three parts. The questions in the first part covered general background information about the user's field, status and their information needs. In part two, the questions were designed to discover the perceptions and expectations of users regarding current digital services and possible future services. Questions 3 to 9 were based on seven digital services: the Library website, online catalogue, electronic databases, electronic journals, electronic reference, selected Internet sources and online 
request forms. For each service, respondents were asked to state frequency of use, awareness, importance, convenience of access, ease of use, usefulness, accuracy, satisfaction and influence. These statements were much the same for every service, except where they would be inapplicable, in which case they were replaced with appropriate substitutes. For instance, the online catalogue service includes an online tutorial via the website, but no similar online instructions accompany the other services. Thus the statement, "online tutorial is helpful in using this service", was not valid for any other question. The multiple-choice questions were designed to elicit users' preferences among various forms of service delivery. Question 10 asked about users' expectations of future services. Current awareness services, virtual reference and electronic closed reserve service were discussed at the end of part two. For these services, the measures of importance, usefulness and influence were explored. Part three was an overall assessment. Question 11 investigated users' satisfaction with digital services at the macro level. Question 12 established what kind of services users thought needed to be improved first. The last two were openended questions to encourage extra comments and suggestions.

The questionnaire for librarians fit on two double-sided sheets of A4 paper. To a large extent, it was the same as that for users. One difference is that the background information was reduced to the librarian's division and status in the Library. The question regarding future services included one more statement about the possibility of new applications. The open-ended question was intended to elicit further comments. The interviews were semi-structured and based on a prepared list of issues. The questions on the interview checklist addressed some positive and negative factors that might influence the implementation of digital services, in order to find some reasons for the gaps between users and librarians. The interviews were recorded and transcribed by the researcher. The topics ranged from budget allocations, and views on providing some services, to future plans.

Cover letters were included when distributing questionnaires to participants. The letter included information about the survey and appreciation to the interviewee for their assistance. 
Specialized software, specifically Excel and SPSS, were used for data analysis.

\subsection{Pilot Study}

A pilot study for this research was carried out from March 22nd to March 29th in 2002 after the first trimester started. The targets of this pilot study were student users of the Library, whose reactions to the questionnaires would prove useful for determining if any revisions were needed, and some university librarians, who could provide expert advice to the researcher. Around 30 questionnaires for users were distributed in tutorials to Victoria University students and 10 questionnaires for librarians were distributed to staff of the Massey University (Wellington) Library. The users involved in the pilot study were not also selected for the final sample of the research in VUW. The questionnaires were revised based on the information provided by the participants in the pilot study. Some of the terminology was modified to improve respondents' comprehension, and several questions which were unclear or ambiguous to the respondents were eliminated.

\subsection{Data Collection Strategies}

The common method of using transaction or log records to study digital services has not been used here since the focus of this study is to collect detailed opinions and to analyze the preferences of users, the manager and librarians for specific digital services.

Primary data were gathered through interviews and questionnaire surveys. In this research, data were collected by mailed and personally delivered surveys, and interviews, in order to reach a satisfactory response rate. To increase the reliability of the data, a wide range of input was sought through the survey instrument. For example, the sampling method ensured that undergraduates, postgraduates and academic staff at different levels and from different schools, and similarly, librarians from different branches and in different types of positions relevant to digital information resources, were surveyed. For 
undergraduates and postgraduates respectively, the questionnaires were distributed to them in person at tutorials or in their envelopes/pigeonholes by school administrators, and returned by the respondents within a prescribed time span. The questionnaires for academic staff and some librarians were posted to them through the internal mail system, and returned the same way. Follow-up interviews were carried out on the subset of librarians in the sample whose positions were most related to the delivery of digital services. By comparing data from the interviews and the questionnaires, different preferences for the delivery of digital services between users and providers or even between different user communities and the reasons for these gaps were found.

The surveys were conducted from 8 April 2002 to 10 May 2002. The data collection methods varied for different user communities. Because postal surveys have a potentially low response rate, the surveys were personally delivered to and collected from the students. For undergraduates, questionnaires were distributed at the beginning or the end of tutorials. The information letters explaining how to fill in these questionnaires and how to return them were attached. In order to improve students' motivation, when they delivered the questionnaires to the designated location at the appointed time, rewards in the form of chocolate bars were given to them. For postgraduates, the questionnaires were placed into their personal envelopes or pigeonholes in their schools by the school administrators. Information regarding when and where these questionnaires would be collected was attached to the questionnaires. They also received the same rewards as the undergraduates for their cooperation. As mentioned above, academic staff and librarians received and returned the questionnaires through the University's internal mail system. After the completed questionnaires were received, letters were sent to the respondents to express the researcher's appreciation. In some cases, reminder letters and additional copies of questionnaires needed to be sent to those participants who had not returned their questionnaires in order to improve the response rate. 
Before the interviews took place, emails including the information sheet and consent letter were sent to the selected librarians, asking for their agreement. Then after the appointments were made, the interviews were carried out one at a time.

\subsection{Treatment of the Data}

This research includes both primary data and secondary data. Primary data were gathered from questionnaires and interviews. Some questionnaires were incoherent or incomplete and therefore could not be used. These were subtracted from the number of returns when determining the response rate. Unanswered questions were considered missing. "Other" answers were coded to fit existing categories. If a respondent gave multiple answers to a question that should have had only one, the question was considered unanswered, and therefore missing. The data were processed by accurately tabulating all of the responses to the questionnaires and transcribing the recording and notes of the interviews. The secondary data were found on the VUW Library website, and in Library policies, statistical records and annual reports.

\subsubsection{Treatment of the Data for the Preliminary Problem}

As a basis for the ensuing study of various sub problems, the preliminary problem was to identify the existing digital services offered by the VUW Library. The data for solving the first research question were the categories and delivery methods of specific digital services provided by the Library, which were located in online documents from the Library website and some secondary resources such as Library policies and annual reports.

\subsubsection{Treatment of the Data for Sub Problem One}

The first sub problem was to analyze the users' (undergraduates, postgraduates and academic staff) opinions concerning the performance, satisfaction and their expectations of the digital services. The responses to research questions 2 , 3 and 4 (covering the users' profiles, perceptions and expectations) and 
research questions 7 and 8 (on the differences in perceptions and expectations between user communities) provided the data used to solve this sub problem.

The data were the responses received from undergraduates, postgraduates and academic staff. The data were divided into two types: descriptive and rating. Descriptive data comprised the profiles and information needs of the user communities, which answered the second research question. Rating data gave the opinions of the various user communities on the delivery of specific services, answering the third and fourth research questions. The answers to research questions 7 and 8 were based on comparing the answers to the second, third and fourth research questions.

All the information from the returned questionnaires was organized using a spreadsheet. The results were tabulated and analyzed by the statistical tools, Excel and SPSS. Statistics were used to analyze the data in order to measure the performance of digital services. Ratios, percentages and portions, central tendency, standard deviation, correlation, and analysis of significance of variance were applied in the data analysis.

The second research question was answered by summarizing information about users' characteristics and purposes. With the aid of the statistical results, the perceptions of all three user communities relating to the third research question were shown (awareness, frequency, importance, etc.). Users' expectations and opinions of future services were also revealed.

Comparisons between three different user communities were carried out for each service. The users' perceptions and expectations of current services were the first areas explored. For statements about each service, the percentages of respondents who agree, agree somewhat, are neutral, disagree somewhat or disagree, were compared between undergraduates, postgraduates and academic staff. As mentioned before, these statements covered measures of frequency, awareness, importance, convenience, ease of use, usefulness, accuracy and influence. In addition to the percentages, the mean and standard deviation (SD) of every statement about every service were compared among 
different user communities to determine the general opinions and the dispersal of the opinions. Users' opinions on the future possible services were the next area examined. The expectations of three forthcoming services within each user community were compared to see which service was most welcomed by each type of user. Moreover, for each future service, the expectations from several communities were compared to indicate the different information needs and ascertain the chief beneficiary of each service.

\subsubsection{Treatment of Data of Sub Problem Two}

The second sub problem was to find the library staff's perceptions of these services. Key librarians' viewpoints on existing and future digital services delivery were obtained. Research questions 5 and 6, covering the opinions of librarians about existing and future services are linked to this sub problem.

The responses were available from the questionnaires completed by the librarians before the interviews. In addition, some important information was obtained by interviewing the manager and librarians. Both qualitative and quantitative data were needed to solve the second sub problem. The librarians' answers to the questionnaires were handled in the same way as the quantitative data used to solve the first sub problem. As for the qualitative data, the interview notes and transcripts were divided into several segments, each containing an important aspect. All the segments were sorted into piles of similar materials and it could then be decided what important aspects differentiated them. Notes and transcripts were carefully read to find common themes as well as unexpected deviations to see where there were obvious redundancies and categories that could be combined.

\subsubsection{Treatment of the Data for Sub Problem Three}

The third sub problem was to compare the different perspectives of users and library staff and find reasons for any gaps in their perceptions and expectations. Research questions 9-11 are closely connected with this sub problem. 
The data needed for sub problem three were used in previous sub problems. The answers to research questions 9 and 10 on differences of opinion between user communities, and the answers to research question 11 on the barriers and reasons resulting in any gaps between users and library staff were approaches to this sub problem.

At this stage, some further analysis took place. The first step was to determine to what extent the evaluation results revealed different preferences for digital services. Similar and different preferences, perceptions and expectations between users and library staff were identified.

The perceptions and expectations of current services were compared first. For each service, the percentages of agreement on the Likert scale, the mean and standard deviation of every statement were compared between overall users and librarians. Then the expectations of three forthcoming services were compared between users and librarians to identify whether it was worth providing these services. For some specific services, it was necessary to compare the opinions of librarians with the main beneficiary of this service. For example, academic staff and postgraduates are the most frequent users of electronic journals and as such, are the main beneficiaries. The librarians' opinions needed to be compared with the main beneficiaries as well as with general users. It made most sense to pay more attention to the opinions of the people who use a service most often (unless asking why some users do not use the service). The analysis of this data answers research question 7. For some digital services where there are no apparent differences in the evaluation between users and librarians, the librarians have presumably taken the users' preferences and needs into consideration when providing these services. In circumstance such as these, the current forms of service delivery should be retained to keep users satisfied with the services.

The interview data was also used to identify reasons for any barriers that have negative effects on the delivery of the digital services in the VUW Library. In addition, this data helped reveal factors resulting in the gaps between 
librarians' and users' views relating to the Library's provision of those services. By analyzing the comparisons between the various survey data and interview results, the last research question was answered.

The last step of the analysis was to examine the data in order to make recommendations to improve the delivery of the digital services to increase their use.

\subsection{Summary}

In this chapter, the research methodology, which includes both qualitative and quantitative aspects, has been explained. The quantitative models and measures involved the use of a questionnaire to survey users and librarians of VUW Library to determine any differences in their preferences for the delivery of digital services and in the information needs of the different user communities. The qualitative method took the form of interviews, which allowed the researcher to get in-depth information from the librarians to investigate reasons for any differences between users' and librarians' preferences. This chapter explained the structure of the research sample. Stratified random sampling was used to select users, while simple random sampling was used to select librarians. This chapter also provided details of the aims and considerations in designing the questionnaire. The pilot study was described, as were the data collection strategies and treatment of data. The techniques used to analyze the data were introduced in the order of the research problems. 


\section{Chapter 4. Investigation of Digital Services}

\section{Provided by the Victoria University of}

\section{Wellington Library}

This chapter describes the digital services provided by the Victoria University of Wellington (VUW) Library and seeks to answer Research Question 1. I found that the best way to find information about those services was to search the Library website, a method which was more efficient than using print documents. The investigation of digital services currently provided by the VUW Library was done in November 2001, as the first step of this research. In this chapter, information about these services is presented in detail. While the website was used to obtain information to describe the services, VUW Library documents were used to identify the Library's reasons for delivering the digital services, and to provide details of the access to those services.

\subsection{Introduction}

The VUW Library exists to support study and research by university students and staff. In the late 1990s, the Digital Service Group was set up to be responsible for administering digital services. Its tasks are listed below (ftp://aida.its.vuw.ac.nz/policy/General_Statute_-_Library_Statute.doc):

- the evaluation, negotiation, purchase of, and access to electronic resources in the Library;

- the maintenance, upgrading and quality control of the online catalogue;

- the planning and implementation of new IT developments in the Library;

- liaison with Information Technology Services (ITS);

- desktop support for all Library staff; and

- the management of the Library's WWW pages.

Digital services and electronic information are provided via the Library's website, which is being developed as the main gateway for access to electronic 
journals and other datasets. Over the years, these services have been used by more and more students and staff (Smith, 2000). Although digital services are unlikely to replace all of the traditional physical services, it is likely that they will become the predominant activities of the VUW Library.

The researcher investigated the following digital services: the online public access catalogue (OPAC), databases, reference, electronic journals, instruction services, distance learning, selected Internet resources, interlibrary loan and current awareness service.

\subsection{Catalogue Services}

The original card catalogue system of the VUW Library is no longer used for the main collections except for some special collections such as rare books, archives and manuscripts. At the time of this research, the OPAC was still the main electronic catalogue service used in the Library. It still can be accessed via workstations located in the Library, terminals in the computer labs or on the website via telnet. Consequently, users can search collections any time and anywhere. During the writing stage of this thesis (mid-2002), the Library has started to provide access to IPAC ${ }^{5}$ with its advantages of flexibility and ease of access.

The OPAC has various functions. It allows users to search by browse or keyword, for example. A browse search produces a list that can be scrolled through forwards or backwards. The search result in the entry that most closely matches the search request is displayed as item number 3. Personal name, corporate name, subject and series searches are also available. The index for closed reserve and three-day loan items is also a kind of browse search resulting in the alphabetic listing of all course codes from which the required code can be selected. Keyword search offers retrieval from keyword indexes for titles, corporate names, subjects, series and contents. Common variant spellings and truncated keywords can be used to widen the search. The

\footnotetext{
${ }^{5}$ Internet Public Access Catalogue
} 
more specific the words are, the faster the search results will appear. Keyword search can be narrowed or widened by linking the key words with AND or OR. It is also possible to view groups of records and find related works. In addition to the above main functions, OPAC services also allow users to obtain online help, place a hold on a book or review their personal records. Overseas library catalogues including the National Library of Australia, Australian Libraries Gateway, COPAC (Consortium of University Research Libraries Online Public Access Catalogue), Library of Congress, University of California and Worldwide Library OPACs have links from the Library website.

\subsection{Electronic Journals (E-Journals)}

The E-journals web page provides a search engine for searching by subject or discipline. Thirty-six categories of E-journals are listed. There is also a master E-journal list in alphabetical order. At the end of 2001, this master list was no longer updated when titles were added to the catalogue. If the user's academic field is not included in the subject categories or in the databases, this list can be used as a last resort.

The Library provides comprehensive access to the electronic journals which it acquires as individual subscriptions or in full text databases. Most web-based journals and newspapers listed on the website are licensed for the use of VUW students and staff. The ones freely available on the web are indicated as free. At the time the data were being gathered for this study, five full-text databases or database packages were provided: ABI Inform, Expanded Academic ASAP, Health Reference, LegalTrac and ProQuest. The Library has an increasing number of E-journal subscriptions covering most academic disciplines. Most databases can be searched from anywhere on campus, including the Student Computing Suite, by both students and staff. Remote access is available both for staff and students with different Internet service providers. Students can register to have off-campus access to most of the Library's E-journals via the Library databases page on the SCS portal. E-journals can be accessed by selecting the relevant database or publisher. If the E-journal provider is not listed on the database page, then off-campus access is not available for that E- 
journal. VUW staff with a VUW dial-up account off campus are able to access all the Library's E-journals directly via the VUW electronic journals page or catalogue.

\subsection{Electronic Databases}

The Library offers free access to a range of databases in electronic format. Some are available only in the Library, while others are networked externally. They include full-text databases, and indexing and abstracting databases. The full-text databases are considered electronic journal services and have been discussed in the previous section. The indexing and abstracting databases cover most subjects and can be searched by subject, keyword, author and journal. Records include full bibliographic details and often abstracts. The main database packages are OCLC, ProQuest, ASAP, and International Bibliography of the Social Sciences ${ }^{6}$.

The databases exist in two electronic formats: CD-ROM and networked. Databases in CD-ROM format on the online list are indicated as such and are only available in the area adjacent to Reference \& Research, on level 2 of the main Library. Remote access to the Library databases via the SCS portal can be obtained by any registered student, as mentioned above.

According to the Library's annual reports, collaboration with other university libraries in New Zealand and Australia through the $\mathrm{CAUL}^{7}$ Electronic Information Resources Committee (CEIRC) has achieved substantial price reductions for online data. All the New Zealand university libraries negotiated for increased access for users to the Te Puna national online systems run by the National Library of New Zealand. Now, the VUW Library provides its users with unlimited use of the index to New Zealand periodicals.

\footnotetext{
${ }^{6}$ In addition, three free trial electronic databases - Zentralblatt MATH, Linguistic and Language Behaviour Abstracts, and INSPEC-Institution of Electronic Engineers - were provided for a limited time during the writing of this thesis. The last two trial databases are directly linked to the Library website and the first needs to be visited from its own website.

${ }^{7}$ Council of Australian University Librarians
} 
During the online investigation, the researcher found it difficult to get a precise number of online databases provided by VUW Library since there is overlapping coverage of some databases in aggregate packages. This is a matter of cost. If a Library subscribed to the databases separately in order to avoid repetition, it would be charged more in total than for the aggregated packages.

\subsection{Reference Service}

Reference services and collections are important sections of a university Library. Traditional reference collections are kept in the reference room and contain biographic and language dictionaries, thesauri, general and subject encyclopedias, directories, yearbooks, bibliographies, indexes and abstracts. These materials can only be used in the reference room. Accompanying these collections are traditional reference services such as face-to-face or phone consultations with librarians.

Reference collections on the VUW Library website include electronic journals, the electronic reference shelf and some subject-based resources. The electronic reference shelf is a combination of useful Internet resources. These are divided into the following categories: academic Internet directories; biography; dictionaries and encyclopedias ${ }^{8}$; geographic/country information; New Zealand material; quotations; statistics; style guides; telephone directories; and weights, measures, and calendars. The content of the individual categories includes links to useful websites. The "Resources by Subject" heading links to a liaison librarian page that provides information covering databases, Ejournals, course information, various print collections and useful websites for specific research areas. By clicking on these sub categories, users can access the information related to the selected subject directly and conveniently.

\footnotetext{
${ }^{8}$ This resource includes language dictionaries, general encyclopedias, and subject dictionaries and encyclopedias.
} 
Online reference services exist in three forms: FAQ (frequently asked questions), email reference and liaison librarians. The FAQ list on the website provides general information ranging from access to the collection to the Library schedules. "Ask a Reference Librarian" is a quick-reference email service available for VUW staff and students. This service answers four types of questions: assistance with the Library catalogue or other online services; information about the Library's services and facilities; verification of references or publisher details; and advice on where to find information for a particular topic. On weekdays, users will get a response to their queries within 24 hours. "Liaison librarians", an integrated innovation in reference work, were introduced in 1999. In order to promote better use of the Library's resources, some librarians have designated as the provider of liaison services for users in some subjects. Users can contact these librarians by email or telephone.

\subsection{Instruction Service}

Instruction services such as online help and training in information searching skills are necessary supplements to other digital services. Effective instruction services reduce users' difficulties with digital services. The online instruction services are often the first point of contact for a new user. More experienced users may also, at times, need instruction services. If users cannot find solutions to their information problems with digital services, they might stop using them.

"About the Library" appears on the first page of the Library website. Information about the Library including hours, staff, department information, and Compass (a Library tutorial program) are listed there. Photos of the Library, a brief description of the Library's development, the mission statement, Library statute and the annual report are also provided. The Compass section lists the schedules for specific tutorials and training sessions designed to enhance information retrieval skills. Moreover, it also provides links to the following items: Library liaison service; timetable information; resources by subject; online tutorials; printed resources; and useful links. 
Online help is provided for some digital services, for example the catalogue. There is a guide to the online catalogue, called "VUWCAT tutor", on the website. This guide shows how to search for and locate material in the Library.

\subsection{Distance Learning Service}

The Library plays an important role in supporting the distance-learning programs at VUW. Any VUW student enrolled in an approved distance course is eligible for distance library services. Current students living outside the Wellington region can also use this service with the approval of the Library. Distance learning services have expanded and the number of transactions in distant learning services grew by $22 \%$ from 1998 to 1999 .

On the Library homepage, "Distance Education" is listed as a Library service. The distance services link is always provided on almost every page of the Library website, especially the pages for E-journals, databases and electronic reference shelf. On the SCS portal for remote students, the Library website and databases are the two main links from the first page. Users can request materials by filling in the electronic form on the website, emailing or faxing the Library. The Library can lend books to distance-learning students from its own collections or it can obtain books and articles from other libraries on their behalf. The Library can also send students photocopies of journal articles and book chapters. Books can be reserved for remote users. If students log on to the Library website on campus through the internal VUW communication network, they can access all the networked databases using their SCS accounts. If using other Internet service providers, students need to register to use the University Library portal, but not all the databases can be accessed through the portal.

\subsection{Other Selected Internet Resources}

In addition to the digital services based on the Library's collections or those of cooperating libraries, some services derived from external Internet resources 
are also provided. These include the electronic reference shelf, general index sites, useful websites and resources by subject.

The electronic reference shelf is a selection of subject related websites. Webbased encyclopedias, dictionaries, directories, biographies, quotations, and guides are made accessible via links from the VUW Library website. The electronic reference shelf aims to assist the teaching and researching needs of VUW staff and students with websites which have been evaluated and selected by Library staff. The websites are classified into 40 subjects. No extra charges apply for browsing these websites apart from the usual Internet charges. Users can suggest other useful websites by email. "Resources by subject" is a collection for digital reference services. It combines the internal and external resources together by subject.

\subsection{Interlibrary Loan (ILL)}

The Library is moving to use the online New Zealand interloan system fully. This system is one of the online services provided by the National Library's Te Puna system. Consequently, there has been a large increase in the amount of items supplied to other New Zealand libraries. At the same time, the Library is dependent on access to other libraries' collections through interloan (Smith, 2000). The Library's goal is to deliver access to the total worldwide resource of published information (http://www.ac.nz/Library/about/general.html).

The link to electronic interloan forms can be found on the page called online electronic forms. Although the form is available online, most items are still delivered on paper due to copyright issues.

\subsection{Current Awareness Service}

Current awareness service (CAS) and selective dissemination of information (SDI) are proactive services offered by many libraries and information service providers. However, the VUW Library website does not list these services. 
The introduction page for the Library liaison program is the only page that mentions CAS, and the names and email addresses of liaison librarians are listed by subjects. Most liaison librarians provide access to current awareness service in their subjects in the form of an "Auto Alert" service. It is likely that most users do not know what the term "current awareness service" means, so they cannot make full use of it. On the liaison librarian page of the website, the Library explains the service in detail. Auto Alerts are (usually) e-mails containing tables-of-contents pages from specific journals. Some Auto Alert providers also allow for search updates to be sent out regularly in the same way. Most academic publishing houses and some database providers provide some sort of Auto Alert. Thus users can set up a personalized alerting service that will automatically re-run saved searches, by journal title or subject, against database updates. Results are sent by email. The reference and research staff can help new users in setting up these types of services.

\subsection{Closed Reserve}

The VUW Library web page offers access to electronic forms via a link called "E-forms". One form is for academic staff to email requests for materials to be placed on Closed Reserve or 3-Day Loan. In addition, if users want materials that are in Closed Reserve or 3-Day Loan, they can request "holds" to be placed on them online via the OPAC. From the OPAC, users can also book closed reserve materials after checking the available times.

\subsection{Summary}

The university is a knowledge-based community. The amount of new materials acquired in electronic (online or disk) format is growing constantly. The ratio of the Library investment in print versus online resources is gradually declining (Smith, 2000). With the increase of electronic resources, the core business of the Library is becoming more dependent on computers as it becomes more capable of serving more and more users. The detailed description of digital services provided by the VUW Library, which has been 
provided in this chapter is the foundation for the following research in this project. 


\section{Chapter 5. Dote Interpretetion and Analyysifs}

This chapter presents the data from the responses to the questionnaire survey. Firstly, an overview is presented of results from the survey. These include the following: users' reasons for visiting the Victoria University of Wellington (VUW) Library website and using digital information services; users' perceptions of current digital services; the importance of the features of current digital services; and expectations of future services. Further comparisons between different user communities, and between users and librarians are analyzed in terms of response rate, frequency of use, perceptions and expectations of digital services.

\subsection{Data Analysis Overview}

This part presents an overview of data from the user and librarian surveys and seeks to answer Research Questions (RQ) 2 to 6:

RQ 2 "What are the profiles of the user communities and their information needs with regard to the library's digital services?"

RQ 3 “What are the users' perceptions of and preferences for current digital services in terms of awareness, frequency of use, importance, ease of use, usefulness, accuracy, and future use?"

RQ 4 "What are the users' expectations of future digital services?"

RQ 5 "What are the perceptions of the librarians concerning the current performance of the digital services?"

RQ 6 "What kinds of future developments do the librarians envision?"

\subsubsection{User Survey}

The user survey assessed service quality and user satisfaction. This survey was piloted from 21 to 28 March 2002 with a group of students from VUW and librarians from Massey University (Wellington). The survey was then revised based on the information provided by these students and librarians in the pretest. Questions that were unclear or ambiguous to the respondents were revised 
or expanded to give more detailed explanations. The final versions of the questionnaires were distributed to a random and stratified sample of users ${ }^{9}$.

Users of library services were divided into three communities with different information needs: undergraduates, postgraduates, and academic staff. Two hundred and seven questionnaires were distributed to undergraduates in 15 tutorials covering papers from the 100 level to the 300 level in five different faculties: Architecture and Design; Commerce and Administration; Humanities and Social Science; Law; and Science. One hundred and fortynine questionnaires for undergraduates were collected. Two hundred and fifty questionnaires were placed in the mailboxes or pigeonholes for postgraduates in individual schools with the aid of school administrators and seventy-six responses were received. Thirty-eight questionnaires were posted through the university internal mail system to academic staff selected randomly from the sample and after two weeks, 19 questionnaires were returned to the researcher through the internal mail system.

Overall, of 495 questionnaires distributed to users, 231 valid responses were received. The general response rate was $46.7 \%$, which is high compared to similar surveys. Most respondents were from the Science, Humanities and Social Science, and Commerce and Administration Faculties.

\subsubsection{Users' Purposes for Visiting the Library Website and Using Digital Information Services}

Table 1 gives the detailed information about users' reasons for visiting the library website and using digital information services. The vast majority of respondents chose two or more reasons. As shown in Table 2, most respondents visited the website to search for library resources (68\%).

\footnotetext{
${ }^{9}$ Refer to Chapter 3 for the information on sample size and sample selection method. Considering different distribution methods for different communities, the expected return rate varies. The number of questionnaires distributed to postgraduates was based on an expected $20 \%$ return rate. The numbers of questionnaires distributed to academic staff and librarians were based on an expected $50 \%$ return rate.
} 
Table 1. Reason for using the library website and information services (general users)

\begin{tabular}{|l|l|}
\hline Reasons & Percent \\
\hline Browse casually & 32.5 \\
\hline Check and review my personal records & 29.0 \\
\hline Search for library resources & 68.0 \\
\hline Look for literature related to my interests or latest development in my field & 46.3 \\
\hline For reasons relating to assignments & 62.8 \\
\hline For reasons relating to the research in my field & 37.7 \\
\hline Review newly arrived items (books, journals, or videos) & 10.0 \\
\hline Looking for information about the library & 8.7 \\
\hline Other & 4.8 \\
\hline
\end{tabular}

\subsubsection{Perceptions of Current Digital Services}

The frequency of use responses is presented in Table 2. There is some variation in the frequency of use across different digital services. The OPAC and databases have the highest frequency of use. The OPAC is definitely the most frequently used online service and more than half of the users stated that they used it weekly or more. The second most used service is "electronic databases", which was used monthly or more often by $61.5 \%$ of the users. In contrast, "email reference" and "online request forms" were used less than the others with approximately $80 \%$ of the users using them very infrequently or having never tried those services before. It is therefore worth considering whether those services are justified given the cost of staff and other resources required to implement and maintain them.

Table 2. Frequency of use of current services (general users)

\begin{tabular}{|l|l|l|l|l|l|}
\hline & $\begin{array}{l}\text { Daily } \\
(\%)\end{array}$ & $\begin{array}{l}\text { Weekly } \\
(\%)\end{array}$ & $\begin{array}{l}\text { Monthly } \\
(\%)\end{array}$ & $\begin{array}{l}\text { Quarterly } \\
(\%)\end{array}$ & $\begin{array}{l}\text { Very infrequently/not at al } \\
(\%)\end{array}$ \\
\hline OPAC & 11.3 & 46.3 & 15.6 & 6.5 & 20.3 \\
\hline Databases & 7.4 & 32.5 & 21.6 & 7.8 & 30.7 \\
\hline E-journals & 2.6 & 15.6 & 16.9 & 10.8 & 54.1 \\
\hline Email reference & 3.9 & 9.1 & 6.9 & 1.7 & 78.4 \\
\hline $\begin{array}{lllll}\text { Other selected Internet } \\
\text { sources }\end{array}$ & 3.9 & 12.1 & 13.4 & 6.9 & 63.6 \\
\hline Online request forms & 0.0 & 8.2 & 9.1 & 7.8 & 74.9 \\
\hline
\end{tabular}


Table 3 and Figure 5 present the assessment of current services. On the whole, users moderately concurred that the majority of digital services were important to them. The exceptions were the "email reference" and "other selected Internet sources" services. More than $20 \%$ of the users disagreed with the statement that "email reference" and "online request forms" were important. The OPAC is the most important service with a mean rating of 3.99 followed by "databases" and "E-journals". The least important service for users is "email reference" and only $21.3 \%$ of the users thought that it was important.

User satisfaction differed significantly across the services. Around $60 \%$ of the users were satisfied with the "databases" and the "OPAC". Less than $40 \%$ of the users were satisfied with the "E-journals" and "online request forms". "Email reference" had a low mean satisfaction rating of 3.12 and did not appear to meet users' needs. The "OPAC" and "databases" had the highest frequency of use and accordingly received high satisfaction ratings compared to other services. "Email reference", "other selected Internet sources" and "online request forms" were given the lowest satisfaction ratings. This could be due to the low frequency of use and the low perception of importance. It is worth noting that responses to overall level of satisfaction with digital services are not closely correlated to the satisfaction with individual services. Eighty percent of the users were satisfied with digital services overall, and this percentage is significantly higher than for individual services. In this sense, the overall rating given for users' satisfaction indicates something other than the sum of the satisfaction ratings for individual services.

More than $70 \%$ of the respondents indicated that in the future they would be willing to use the "OPAC" and "databases", the two services that were given higher satisfaction ratings by users than other services. "E-journals" is another service that most respondents (59.3\%) said that they would use again in the future. However, most users stated that they did not plan to use the other three services ("email reference", "other Internet sources" and "online request forms") again in the future. The results show that the future use of these services is likely to be low. Responses to this survey suggest that only a few services are likely to be used frequently in the future. 
Table 3. Assessment of current digital services (general users)

\begin{tabular}{|c|c|c|c|c|c|}
\hline & \multicolumn{5}{|l|}{ Percent } \\
\hline & 5 (agree) & 4 & 3 (neutral) & 2 & 1 (disagree) \\
\hline \multicolumn{6}{|l|}{ OPAC } \\
\hline Importance of the service & 32.1 & 39.4 & 24.0 & 4.1 & .5 \\
\hline Satisfaction with this service & 14.9 & 45.7 & 33.5 & 3.6 & 2.3 \\
\hline Willingness to use this service again in the future & 48.4 & 32.1 & 18.1 & .9 & .5 \\
\hline \multicolumn{6}{|l|}{ Databases } \\
\hline Importance of the service & 32.5 & 30.1 & 30.1 & 3.9 & 3.4 \\
\hline Satisfaction with this service & 17.5 & 35.9 & 37.4 & 6.8 & 2.4 \\
\hline Willingness to use this service again in the future & 38.3 & 32.0 & 22.3 & 3.9 & 3.4 \\
\hline \multicolumn{6}{|l|}{ E-journals } \\
\hline Importance of the service & 21.0 & 26.5 & 39.5 & 8.0 & 4.9 \\
\hline Satisfaction with this service & 11.1 & 27.2 & 45.1 & 11.7 & 4.9 \\
\hline Willingness to use this service again in the future & 30.2 & 29.0 & 30.9 & 6.2 & 3.7 \\
\hline \multicolumn{6}{|l|}{ Email reference } \\
\hline Importance of the service & 6.6 & 14.7 & 53.7 & 11.0 & 14.0 \\
\hline Satisfaction with this service & 5.1 & 18.4 & 64.7 & 6.6 & 5.1 \\
\hline Willingness to use this service again in the future & 7.4 & 19.9 & 58.1 & 10.3 & 4.4 \\
\hline \multicolumn{6}{|l|}{ Other selected Internet sources } \\
\hline Importance of the service & 13.2 & 26.5 & 43.7 & 9.3 & 7.3 \\
\hline Satisfaction with this service & 6.6 & 32.5 & 53.6 & 6.0 & 1.3 \\
\hline Willingness to use this service again in the future & 17.2 & 23.8 & 52.3 & 4.6 & 2.0 \\
\hline \multicolumn{6}{|l|}{ Online request forms } \\
\hline Importance of the service & 22.7 & 18.9 & 37.9 & 10.6 & 9.8 \\
\hline Satisfaction with this service & 17.4 & 19.7 & 50.8 & 9.8 & 2.3 \\
\hline Willingness to use this service again in the future & 26.5 & 12.1 & 50.8 & 6.8 & 3.8 \\
\hline
\end{tabular}

Figure 5. Assessment of current services based on the mean ratings (general users)

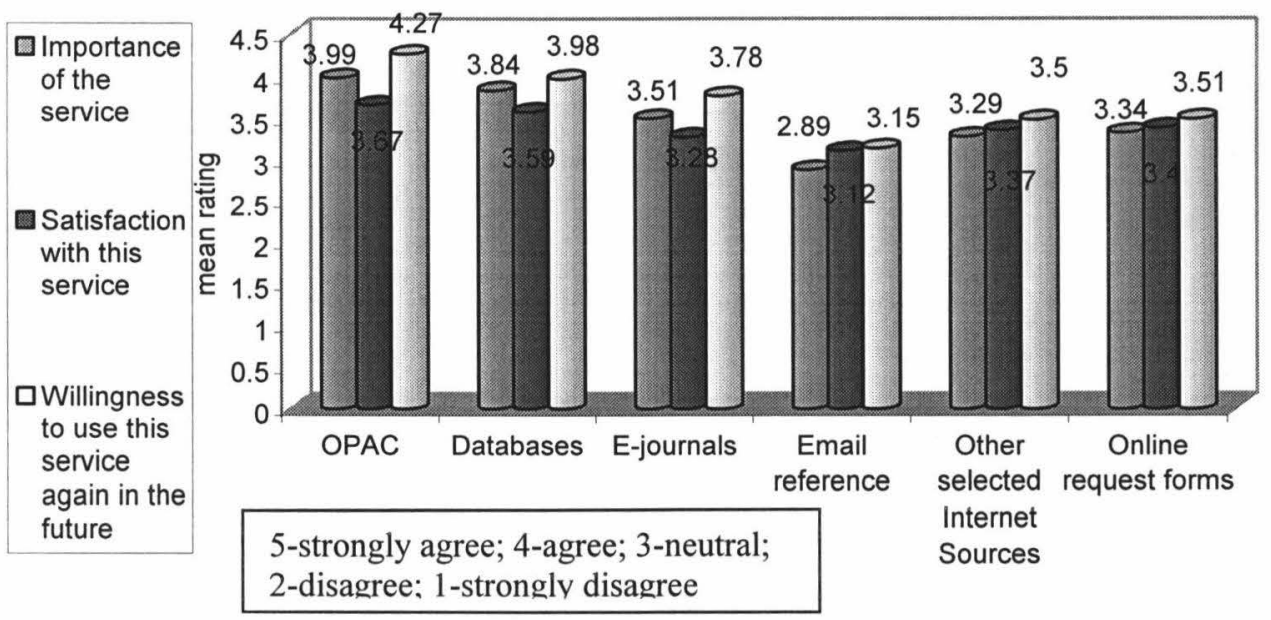


The survey included one question about the users' level of satisfaction with the digital services as a whole. Respondents who were satisfied with the whole range of digital services were frequent users and were satisfied with more services, thought highly of the importance of the services and indicated that they would use the digital services again in the future.

The assessment of these current services can be indirectly ascertained from Q12 in the questionnaire regarding selecting and rating five services that need improving. It is very interesting that even though users gave the highest satisfaction ratings to the "OPAC" and "databases", these two digital services were ranked the highest priorities for the library to improve by $56.7 \%$ and $35.1 \%$ of the users respectively. "E-journals", "electronic reference" and "digital closed reserve" are the other services in order of priority. The reasons for this will be more apparent in the discussion of users' assessment in terms of importance and usefulness of the services, which will be dealt with in the next chapter.

\subsubsection{Importance of the Features of Services}

In Question 3 about the library website, "reliability of information" was thought important by $93.4 \%$ of the respondents. "Ease of navigation" and "friendly interface" are the second and the third most important features of the website. Almost $90 \%$ of the users of every group gave high ratings to the importance of every feature of the library website, which is a gateway to various digital services.

Table 4 gives the users' ratings for the importance of the features of different services. Generally, users appreciated "convenient and easy access", "easy to use" and "useful information provided by this service", giving mean ratings over 4. One interesting finding is that only half of the respondents thought that "availability of information about this service" was important.

For the "OPAC", the most important features users emphasized were "convenient and easy access", "easy to use" and "useful information provided 
by the service". "Accurate source of information about the materials held by the library" is another important feature of the "OPAC" with a mean rating of 4.55. "Quick response time", as a feature for "email reference" and "online request forms", were considered important by around $70 \%$ of the users. "Range of content" of "E-journals" and "other selected Internet sources" were mildly important. For the "OPAC" and databases, the respondents $(45.2 \%$ and $49.1 \%$ respectively) thought "online help or some training" were the least important factors. "Useful information" and "convenient access" were the two most important features of database services, followed by "easy to use", "precision of the results" and "various searching options". The importance of "convenient and easy access" and "easy to use" suggest that users experience difficulties in searching databases. Frustrated users will be less satisfied and may not use the service again in the future. 
Table 4. The importance of the features of the digital services (general users)

\begin{tabular}{|c|c|c|c|c|c|c|c|c|}
\hline & \multirow{2}{*}{ Mean } & \multirow{2}{*}{ Median } & \multirow{2}{*}{$\begin{array}{l}\text { Standard } \\
\text { Deviation }\end{array}$} & \multicolumn{5}{|l|}{ Percent } \\
\hline & & & & (important) & 4 & $\begin{array}{l}3 \\
\text { (neutral) }\end{array}$ & 2 & $\begin{array}{l}1 \\
\text { (unimportant) }\end{array}$ \\
\hline \multicolumn{9}{|l|}{ OPAC } \\
\hline $\begin{array}{l}\text { Availability of information about } \\
\text { this service }\end{array}$ & 3.96 & 4.00 & .936 & 33.9 & 34.3 & 27.4 & 2.6 & 1.7 \\
\hline Convenient and easy access & 4.53 & 5.00 & .665 & 61.7 & 31.3 & 5.7 & 1.3 & 0.0 \\
\hline Easy to use & 4.53 & 5.00 & .691 & 62.2 & 30.0 & 6.1 & 1.7 & 0.0 \\
\hline $\begin{array}{l}\text { Useful information provided by } \\
\text { this service }\end{array}$ & 4.52 & 5.00 & .652 & 60.9 & 30.4 & 8.7 & 0.0 & 0.0 \\
\hline $\begin{array}{l}\text { Helpful online tutorials for } \\
\text { catalogue service }\end{array}$ & 3.43 & 3.00 & .968 & 14.8 & 30.4 & 41.3 & 10.4 & 3.0 \\
\hline $\begin{array}{l}\text { Accurate source of information } \\
\text { about the materials held by the } \\
\text { library }\end{array}$ & 4.55 & 5.00 & .727 & 66.5 & 23.5 & 8.7 & .9 & .4 \\
\hline \multicolumn{9}{|l|}{ Databases } \\
\hline $\begin{array}{l}\text { Availability of information about } \\
\text { this service }\end{array}$ & 4.08 & 4.00 & .845 & 36.0 & 38.7 & 22.5 & 2.3 & .5 \\
\hline Convenient and easy access & 4.46 & 5.00 & .703 & 57.2 & 33.3 & 8.1 & 1.4 & 0.0 \\
\hline Easy to use & 4.44 & 5.00 & .739 & 57.7 & 30.2 & 10.8 & 1.4 & 0.0 \\
\hline $\begin{array}{l}\text { Useful information provided by } \\
\text { this service }\end{array}$ & 4.55 & 5.00 & .689 & 66.2 & 23.4 & 9.9 & .5 & 0.0 \\
\hline Number of databases & 3.91 & 4.00 & .862 & 28.4 & 37.8 & 31.1 & 1.8 & .9 \\
\hline Range of content & 4.31 & 4.00 & .782 & 49.1 & 33.8 & 15.8 & 1.4 & 0.0 \\
\hline $\begin{array}{l}\text { Precision of the searching } \\
\text { results }\end{array}$ & 4.48 & 5.00 & .735 & 62.2 & 24.3 & 13.1 & .5 & 0.0 \\
\hline $\begin{array}{l}\text { Availability of various searching } \\
\text { options }\end{array}$ & 4.43 & 5.00 & .756 & 57.2 & 29.7 & 12.2 & .5 & .5 \\
\hline Currency of the databases & 4.23 & 4.00 & .860 & 48.6 & 27.9 & 21.2 & 2.3 & 0.0 \\
\hline $\begin{array}{l}\text { Easy for users to choose a } \\
\text { relevant databases }\end{array}$ & 4.19 & 4.00 & .813 & 40.5 & 41.4 & 14.4 & 3.6 & 0.0 \\
\hline Response time & 4.05 & 4.00 & .878 & 35.6 & 38.7 & 21.2 & 4.1 & .5 \\
\hline Availability of some training & 3.54 & 3.00 & .977 & 18.9 & 30.2 & 39.2 & 9.5 & 2.3 \\
\hline \multicolumn{9}{|l|}{ E-journals } \\
\hline $\begin{array}{l}\text { Availability of information about } \\
\text { this service }\end{array}$ & 4.02 & 4.00 & .893 & 34.9 & 37.6 & 22.8 & 4.2 & .5 \\
\hline Convenient and easy access & 4.32 & 5.00 & .810 & 51.9 & 30.2 & 16.9 & .5 & .5 \\
\hline Easy to use & 4.31 & 5.00 & .851 & 52.4 & 29.1 & 15.9 & 2.1 & .5 \\
\hline $\begin{array}{l}\text { Useful information provided by } \\
\text { this service }\end{array}$ & 4.48 & 5.00 & .755 & 61.4 & 26.5 & 11.1 & .5 & .5 \\
\hline Range of content & 4.31 & 5.00 & .876 & 54.0 & 26.5 & 16.4 & 2.6 & 5 \\
\hline Currency of the content & 4.26 & 5.00 & .918 & 53.4 & 22.8 & 21.2 & 1.6 & 1.1 \\
\hline
\end{tabular}


Table 4. The importance of the features of the digital services (general users) (continued)

\begin{tabular}{|c|c|c|c|c|c|c|c|c|}
\hline & \multirow[b]{2}{*}{ Mean } & \multirow[b]{2}{*}{ Median } & \multirow{2}{*}{$\begin{array}{l}\text { Standard } \\
\text { Deviation }\end{array}$} & \multicolumn{5}{|l|}{ Percent } \\
\hline & & & & (important) & 4 & $\begin{array}{l}3 \\
\text { (neutral) }\end{array}$ & 2 & (unimportant) \\
\hline \multicolumn{9}{|l|}{ Email reference } \\
\hline $\begin{array}{l}\text { Availability of information about } \\
\text { this service }\end{array}$ & 3.82 & 4.00 & .866 & 26.3 & 32.2 & 39.2 & 1.8 & .6 \\
\hline Convenient and easy access & 4.01 & 4.00 & .898 & 35.1 & 35.1 & 25.7 & 3.5 & .6 \\
\hline Easy to use & 4.04 & 4.00 & .939 & 39.8 & 28.7 & 28.1 & 2.3 & 1.2 \\
\hline $\begin{array}{l}\text { Useful information provided by } \\
\text { this service }\end{array}$ & 4.04 & 4.00 & .929 & 39.8 & 29.2 & 26.9 & 3.5 & .6 \\
\hline Friendliness of the response & 3.73 & 4.00 & .940 & 24.6 & 31.0 & 38.6 & 4.1 & 1.8 \\
\hline Quick response time & 4.05 & 4.00 & .975 & 42.7 & 25.1 & 27.5 & 3.5 & 1.2 \\
\hline \multicolumn{9}{|c|}{ Other selected Internet source } \\
\hline $\begin{array}{l}\text { Availability of information about } \\
\text { this service }\end{array}$ & 3.88 & 4.00 & .922 & 30.9 & 31.5 & 33.7 & 2.8 & 1.1 \\
\hline Convenient and easy access & 4.02 & 4.00 & .902 & 37.6 & 30.3 & 29.2 & 2.2 & .6 \\
\hline Easy to use & 4.06 & 4.00 & .900 & 39.3 & 30.3 & 27.5 & 2.2 & .6 \\
\hline $\begin{array}{l}\text { Useful information provided by } \\
\text { this service }\end{array}$ & 4.14 & 4.00 & .925 & 46.6 & 24.2 & 26.4 & 2.2 & .6 \\
\hline Range of content & 4.02 & 4.00 & .950 & 41.6 & 23.0 & 32.0 & 2.8 & .6 \\
\hline \multicolumn{9}{|l|}{ Online Request forms } \\
\hline $\begin{array}{l}\text { Availability of information about } \\
\text { this service }\end{array}$ & 3.86 & 4.00 & .960 & 32.2 & 28.1 & 34.5 & 4.1 & 1.2 \\
\hline Convenient and easy access & 4.15 & 4.00 & .905 & 46.2 & 24.6 & 27.5 & 1.2 & .6 \\
\hline Easy to use & 4.13 & 4.00 & .958 & 46.8 & 25.1 & 24.0 & 2.9 & 1.2 \\
\hline $\begin{array}{l}\text { Useful information provided by } \\
\text { this service }\end{array}$ & 4.06 & 4.00 & .965 & 42.1 & 28.7 & 24.0 & 4.1 & 1.2 \\
\hline
\end{tabular}

Figure 6 shows that almost half of the users preferred printing from E-journals or electronic databases to downloading or emailing. 
users)

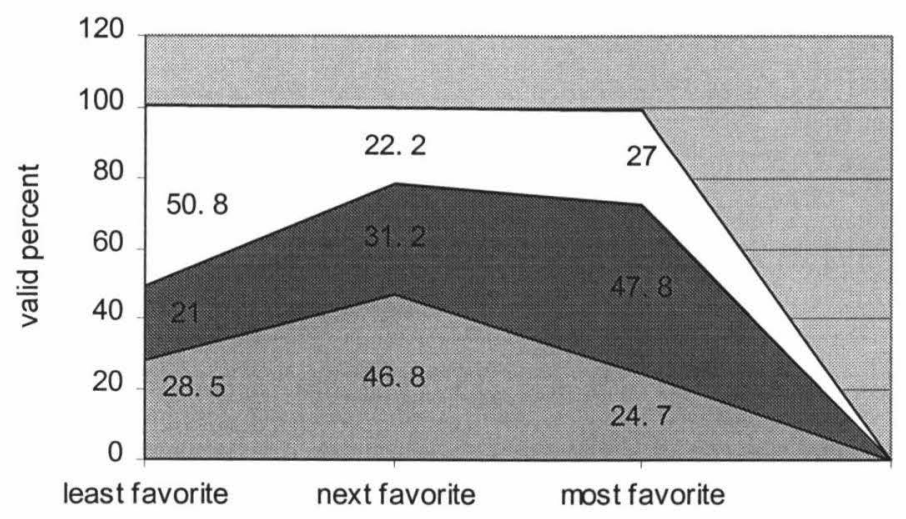

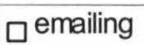

printing

$\square$ dow nloading

\subsubsection{Expectations of Future Services}

The users' opinions about future services are inconsistent. On the whole, the assessment ratings for future services in terms of importance, usefulness and future use are not as high as for current services. "Electronic closed reserve" is the most important future service according to $59.8 \%$ of the users. Sixty-seven percent of the users would use "electronic closed reserve" given their high perceptions of its usefulness with the mean rating of 3.86. "Virtual

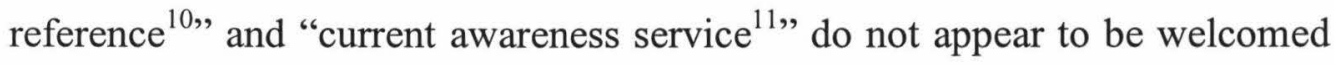
by users, having lower ratings of importance and usefulness. Figure 7 compares the three future services:

\footnotetext{
${ }^{10}$ Use of videoconferencing or chat rooms for online interactions so that users can ask librarians questions and get the answers immediately via the web

${ }^{11}$ You ask the VUW Library to retrieve information for you based on a profile of your personal information needs and to send the results to you on a regular basis.
} 

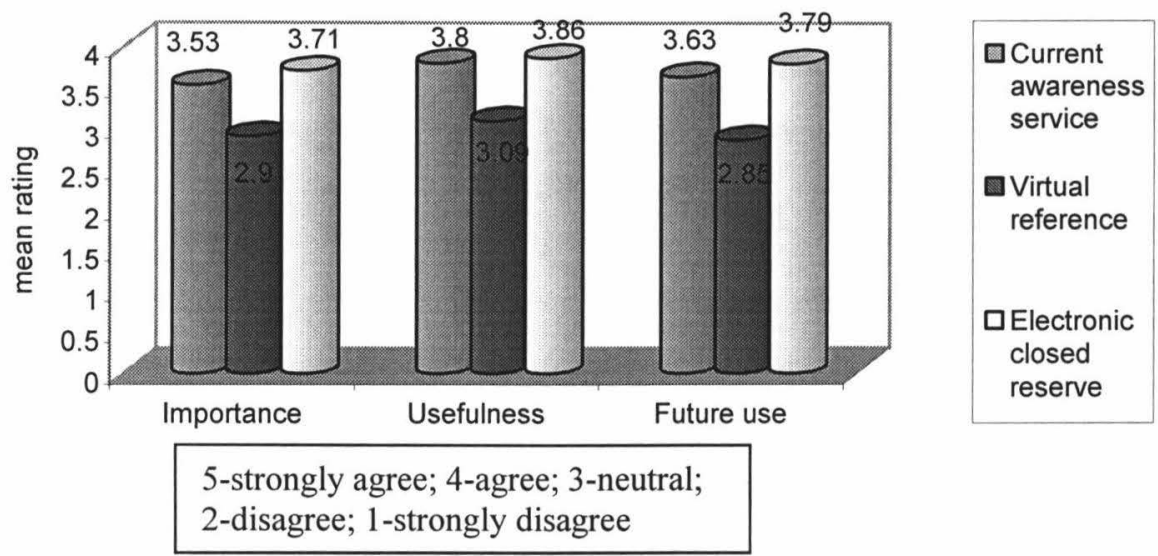

For the first open-ended question investigating users' experiences that affect their use of library services, most responses mentioned the "OPAC", "databases" and "E-journals". "Ease of access", "response time" and "searching options" were mentioned as having negative impact on their use of digital services, while "helpful instruction", "holding books online" and "requesting interlibrary loan online" had a positive impact on use of library services. Users definitely wanted easier access to digital services. Users also recommended "improving awareness of the existence of the digital services", "electronic document delivery" and "help functions".

\subsubsection{Correlation Test of Two Relationships}

A correlation test was used to test two relationships. The first test was whether there was a relationship between users' saying that they would use the service in the future and the level of importance that the users attributed to the service. The second test was to determine whether there was a relationship between users' saying that they would use the service in the future and the level of their satisfaction with the service. A two-tailed Spearman Correlation Test was used in each case. When the correlation between variables is confirmed, the possibility of either a negative or a positive relationship exists depending on the value of the correlation coefficient ${ }^{12}$. These correlation tests were carried out for each service. The relationships vary from service to service. As would

\footnotetext{
${ }^{12}$ If the value is positive, a positive relationship exists. The increase or decrease of one variable will result in a corresponding increase or decrease of the other variable. Equally, if the value is negative, a negative relationship exists.
} 
be expected, both the importance of the service and the users' satisfaction with the service have a significant effect on the future use of the services.

Table 5. Spearman Correlation Test results across different services (general users)

\begin{tabular}{|c|c|c|c|c|}
\hline & \multicolumn{2}{|c|}{ Importance of this service } & \multicolumn{2}{|c|}{$\begin{array}{l}\text { Satisfaction with this } \\
\text { service }\end{array}$} \\
\hline & $\begin{array}{l}\text { Correlation } \\
\text { Coefficient }\end{array}$ & Significance & $\begin{array}{l}\text { Correlation } \\
\text { Coefficient }\end{array}$ & Significance \\
\hline Users would like to use OPAC in the future & .544 & .01 & .458 & .01 \\
\hline Users would like to use databases in the future & .656 & .01 & .551 & .01 \\
\hline Users would like to use E-journals in the future & .683 & .01 & .559 & .01 \\
\hline $\begin{array}{l}\text { Users would like to use email reference in the } \\
\text { future }\end{array}$ & .783 & .01 & .740 & .01 \\
\hline $\begin{array}{l}\text { Users would like to use other selected Internet } \\
\text { services in the future }\end{array}$ & .734 & .01 & .795 & .01 \\
\hline $\begin{array}{l}\text { Users would like to use online request forms in } \\
\text { the future }\end{array}$ & .855 & .01 & .803 & .01 \\
\hline
\end{tabular}

Note: All significance tests are two-tailed tests.

At the same significance level, the higher the correlation coefficient, the stronger relationships.

From Table 5, it is obvious that the correlations are very strong with regard to the "online request forms" service. There are strong relationships between the users' rating of the importance of "online request forms" and whether they would use this service in the future, with a correlation coefficient of 0.855 , and the level of users' satisfaction with the forms and whether they would use this service in the future, with a correlation coefficient of 0.803 . Both of the two correlations are significant at the 0.01 level of confidence.

A strong correlation also exists in "email reference": a coefficient of 0.783 between the ratings of the importance of the service and whether users would use this service in the future, and 0.74 between the ratings of users' satisfaction with the service and whether they would use it in the future. There are significant correlations between the ratings of the importance of "other Internet source" and whether users would use this service in the future, and the ratings of users' satisfaction and whether they would use it in the future. For the "databases" and "OPAC", the importance of the service and users' 
satisfaction does not influence users' future use to the same extent as other services.

On the whole, a positive correlation exists both between the ratings of future use of a service and its importance, and between the ratings of the future use and users' satisfaction with the service. The more important the service is from the users' perspective, the more likely it is that users will use it in the future. The more satisfied users feel with a service, the more likely it is that they want to use it again. The importance that users attributed to the service has a more significant influence on whether users would use the service in the future. The findings suggest the Library needs to increase users' awareness of the importance of digital services and provide more satisfactory services in order to attract more users and increase the frequency of use. Users who say that they would use digital services in the future also considered them important for their information retrieval strategy and were satisfied with the services. However, only a mild positive relationship exists between users' satisfaction with the "OPAC" and future use of this service. A large amount of users would use the "OPAC" again in the future although they were not satisfied with it. Users cannot necessarily be satisfied with all the services and they cannot avoid such a necessary service as the "OPAC" if they do not like it, because there is no alternative to searching for necessary information.

\subsubsection{Librarian Survey}

The librarians in the sample are from different departments of the Library including Administration, Architecture and Design, Collection services, the Commerce Library, Digital Services, Law Library, Lending Services and Reference \& Research. The librarians include the university librarian, heads of groups, senior librarians and assistant librarians. Thirty-eight questionnaires were posted to a random sample of the librarians through the university's internal mail system. By the end of April, 13 questionnaires were returned to the researcher. The response rate of librarians, after several reminders from the researcher, was $34.2 \%$. 
The questionnaires for librarians asked about their understanding of users' perceptions and expectations of digital services. Table 6 presents the librarians' assessments of current digital services. More than $80 \%$ of the librarians gave high ratings to the assessments of the "OPAC", "databases" and "E-journals" in the areas of importance, users' satisfaction and users' likelihood to use these services in the future. Less than half of the librarians thought "email reference" and "other selected Internet sources" were important.

Table 6. Assessment of current digital services (librarians)

\begin{tabular}{|c|c|c|c|c|c|c|}
\hline & \multirow{2}{*}{ Mean } & \multicolumn{5}{|l|}{ Percent } \\
\hline & & 5 (agree) & 4 & 3 (neutral) & 2 & 1 (disagree) \\
\hline \multicolumn{7}{|l|}{ OPAC } \\
\hline Importance of the service & 4.09 & 27.3 & 54.5 & 18.2 & 0.0 & 0.0 \\
\hline Satisfaction with this service & 3.09 & 0.0 & 36.4 & 45.5 & 9.1 & 9.1 \\
\hline Would use this service again in the future & 3.91 & 9.1 & 72.7 & 18.2 & 0.0 & 0.0 \\
\hline \multicolumn{7}{|l|}{ Databases } \\
\hline Importance of the service & 4.64 & 72.7 & 18.2 & 9.1 & 0.0 & 0.0 \\
\hline Satisfaction with this service & 3.80 & 0.0 & 80.0 & 20.0 & 0.0 & 0.0 \\
\hline Would use this service again in the future & 4.50 & 60.0 & 30.0 & 10.0 & 0.0 & 0.0 \\
\hline \multicolumn{7}{|l|}{ E-journals } \\
\hline Importance of the service & 4.00 & 27.3 & 54.5 & 9.1 & 9.1 & 0.0 \\
\hline Satisfaction with this service & 3.40 & 0.0 & 50.0 & 40.0 & 10.0 & 0.0 \\
\hline Would use this service again in the future & 3.80 & 20.0 & 50.0 & 20.0 & 10.0 & 0.0 \\
\hline \multicolumn{7}{|l|}{ Email reference } \\
\hline Importance of the service & 3.56 & 11.1 & 33.3 & 55.6 & 0.0 & 0.0 \\
\hline Satisfaction with this service & 3.22 & 0.0 & 22.2 & 77.8 & 0.0 & 0.0 \\
\hline Would use this service again in the future & 3.56 & 11.1 & 33.3 & 55.6 & 0.0 & 0.0 \\
\hline \multicolumn{7}{|l|}{ Other selected Internet sources } \\
\hline Importance of the service & 3.56 & 11.1 & 33.3 & 55.6 & 0.0 & 0.0 \\
\hline Satisfaction with this service & 3.33 & 0.0 & 33.3 & 66.7 & 0.0 & 0.0 \\
\hline Would use this service again in the future & 3.44 & 11.1 & 22.2 & 66.7 & 0.0 & 0.0 \\
\hline \multicolumn{7}{|l|}{ Online request forms } \\
\hline Importance of the service & 3.89 & 11.1 & 66.7 & 22.2 & 0.0 & 0.0 \\
\hline Satisfaction with this service & 3.56 & 0.0 & 55.6 & 44.4 & 0.0 & 0.0 \\
\hline Would use this service again in the future & 3.67 & 0.0 & 66.7 & 33.3 & 0.0 & 0.0 \\
\hline
\end{tabular}

Survey question 11 for librarians asked for their opinions as to what extent users were satisfied with the digital services as a whole. Half of the librarians agreed that users were generally satisfied with the digital services, which was lower than the satisfaction percentages for individual services. 
Regarding document delivery from "databases" or "E-journals", most librarians $(54.5 \%)$ thought that users prefer printing out their search results to the other two formats of downloading and emailing.

The possible future services were also listed in the questionnaires for ratings from librarians in terms of importance, usefulness, possibility of implementation, and future use. The majority of librarians (more than 70\%) consistently agreed with the importance, usefulness and future use of "electronic closed reserve". The surprising finding is that a minority of the librarians (less than 30\%) believed that these three future services were likely to be provided. Only $10 \%$ of the respondents thought "current awareness" and "virtual reference" would be provided at VUW.

Figure 8. Assessment of three future services (librarians)

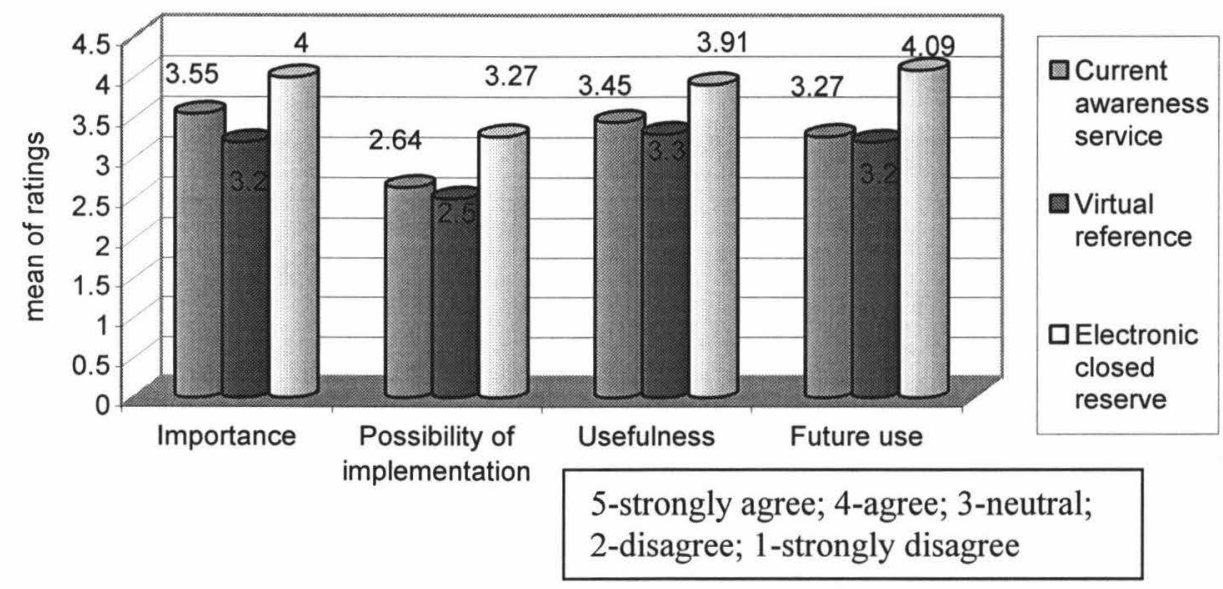

Librarians were also asked to select and rate five services that they thought the library should improve. The "OPAC" was considered to be the most important service for improving by half of the respondents. "E-journals" were considered to need improvement by $25 \%$ of the librarians. The other services that the librarians thought should be improved, in order of priority, were "digital closed reserve", "databases" and "electronic reference".

The answers given by the librarians to the last open-ended question covered services, the library system, staff and budget issues. The comments on digital 
services are grouped together into thematic areas as follows, with the percentage of librarians who made the comments in parentheses:

- A large amount of resources in terms of capital, knowledge and staff are needed to provide services such as CAS/SDI and virtual reference service. $(33.3 \%)$

- The implementation of some services is constrained by the allocation of limited budgets. (26.7\%)

- The "OPAC" plays a vital role in the provision of digital services to clients of the library. However, the current "OPAC" is unsatisfactory with regard to its interface, speed and content (20\%). Several librarians suggested that more information from the databases and E-journals needed to be put on the "OPAC".

- More convenient and streamlined access to "databases" and "Ejournals" both on campus and off campus needs to be provided (13.3\%). Moreover, the range of "databases" and "E-journals" also needs to be expanded according to some librarians' opinions.

- "Electronic document delivery" in the form of email needs support from the computer system (13.3\%). Additionally, copyright issues are also involved when delivering documents by email, which was mentioned by some librarians.

\subsection{Comparative Results}

The results from the survey show significant variations between different user communities in response rate, frequency of use, assessments of current services, importance of different features of services, opinions about future services and overall assessment. The academic library user communities are not homogeneous in the way they use libraries or in their needs for library resources and information services. There can also be significantly different perceptions and expectations between users and librarians. An investigation of these differences is important for identifying users' information needs, perceptions and expectations. 
Correlation tests were used to analyze relationships between users who said that they would use the service in the future and the level of importance users attributed to this service, and between users' saying that they would use the service in the future and the level of their satisfaction with it. Those areas are often used as barometers of perceptions and expectations of stakeholders.

The discussion in this part covers the users' responses, some significant comparative findings and the summary of the findings. This comparative analysis provides answers to the following research questions:

Research Question 7: What are the different perceptions and opinions on current digital services from the perspectives of different user communities?

Research Question 8: What are the expectations and preferences for future services from the perspectives of different user communities?

Research Question 9: What are the differences in perceptions and opinions on current digital services between users and the librarians?

Research Question 10: What are the differences in expectations and preferences for future services between users and the librarians?

\subsubsection{Comparisons of Different User Communities}

\subsubsection{Response Rate}

The response rate from different user communities ranged from $30.4 \%$ of postgraduates, and $50 \%$ of academic staff, to $72 \%$ of undergraduates. The varying response rate could be due to the different distribution methods. The high response rate of the undergraduates can be attributed, in part, to the fact that most of the responses were collected in the tutorials. Students could not delay, set aside or lose the questionnaires. The tutors were very cooperative and asked the students to fill in the questionnaires before they started their tutorials. Their response rate may also be due to the chocolate bars presented as rewards to those who completed their questionnaires. The questionnaires for postgraduates were dropped into their pigeonholes and it was possible that some postgraduates checked their mailboxes infrequently so they did not receive the questionnaires during the survey period. Emails giving information about this survey were sent to the academic staff in the sample. Reminder 
emails were sent to the academic staff again during the week before the deadline for collecting the responses. The variations in response rate can also be attributed, in part, to the fact that undergraduates, postgraduates and academic staff have different experiences of digital services and different levels of interest in participating in this survey.

\subsubsection{Purposes for Visiting Library Website and Using Digital Services}

Table 7 shows the distribution of reasons for using the library website and information services in different user communities. Undergraduates were most likely to visit the website in order to finish assignments $(83.2 \%)$ and search for library resources $(59.1 \%)$; postgraduates focused on searching for library resources $(82.7 \%)$ and doing some research (68\%). Academic staff mainly searched for library resources $(73.7 \%)$ and looked for literature related to their personal interests or research $(73.3 \%)$. Nearly $3 \%$ of the undergraduates chose "other reasons" and specified the reasons as lending issues, for example renewing books or reserving online. Almost $10 \%$ of the postgraduates specified other reasons for visiting the library website, mainly relating to circulation, for example submitting interloan requests. Their different reasons influence their assessments of current services in terms of importance, satisfaction and future use.

Table 7. Purposes for using the library website and information services

\begin{tabular}{|c|c|c|c|}
\hline & $\begin{array}{l}\text { Undergraduates } \\
(\%)\end{array}$ & $\begin{array}{l}\text { Postgraduates } \\
(\%)\end{array}$ & $\begin{array}{l}\text { Academic staff } \\
(\%)\end{array}$ \\
\hline Browse casually & 32.8 & 32.0 & 31.6 \\
\hline Check and review my personal records & 22.6 & 40.0 & 31.6 \\
\hline Search for library resources & 59.1 & 82.7 & 73.7 \\
\hline $\begin{array}{l}\text { Look for literature related to my interests or latest } \\
\text { developments in my field }\end{array}$ & 32.8 & 62.7 & 73.7 \\
\hline For reasons relating to assignments & 83.2 & 40.0 & 5.3 \\
\hline For reasons relating to the research in my field & 16.8 & 68.0 & 68.4 \\
\hline $\begin{array}{l}\text { Review newly arrived items (books, journals, or } \\
\text { videos) }\end{array}$ & 5.8 & 17.3 & 10.5 \\
\hline Looking for information about the library & 5.1 & 14.7 & 10.5 \\
\hline Other & 2.9 & 9.3 & 0.0 \\
\hline
\end{tabular}




\subsubsection{Frequency of Use}

Table 8 presents the frequency of use of various digital services. In general, academic staff used all the digital services listed in the questionnaires more frequently than the other two communities of postgraduates and undergraduates, especially the "OPAC", electronic "databases" and "Ejournals". The general frequency of use of the postgraduates is a little higher than that of the undergraduates. The "OPAC" and databases are the most frequently used services for every user community. In particular, more than $90 \%$ of postgraduates and academic staff used these two services at least quarterly. Postgraduates were more used to submitting interloan requirements with "online request forms" than academic staff and undergraduates. Undergraduates used the "email reference" and "other selected Internet sources" more frequently than any other communities. The difference of frequency of use is significant at the .05 level of confidence. 
Table 8. Frequency of use of current services

\begin{tabular}{|c|c|c|c|c|c|}
\hline & $\begin{array}{l}\text { Daily } \\
(\%)\end{array}$ & $\begin{array}{l}\text { Weekly } \\
(\%)\end{array}$ & $\begin{array}{l}\text { Monthly } \\
(\%)\end{array}$ & $\begin{array}{l}\text { Quarterly } \\
(\%)\end{array}$ & $\begin{array}{l}\text { Very infrequently/not at all } \\
(\%)\end{array}$ \\
\hline \multicolumn{6}{|l|}{ Undergraduates } \\
\hline OPAC & 5.8 & 37.2 & 18.2 & 8.8 & 29.9 \\
\hline Databases & 2.9 & 25.5 & 24.8 & 8.8 & 38.0 \\
\hline E-journals & 0.0 & 11.7 & 12.4 & 8.8 & 67.2 \\
\hline Email reference & 3.6 & 12.4 & 6.7 & 2.2 & 75.2 \\
\hline $\begin{array}{l}\text { Other selected Internet } \\
\text { sources }\end{array}$ & 3.6 & 11.7 & 17.5 & 6.6 & 60.6 \\
\hline Online request forms & 0.0 & 5.1 & 4.4 & 6.6 & 83.9 \\
\hline \multicolumn{6}{|l|}{ Postgraduates } \\
\hline OPAC & 20.0 & 56.0 & 14.7 & 2.7 & 6.7 \\
\hline Databases & 13.3 & 41.3 & 20.0 & 5.3 & 20.0 \\
\hline E-journals & 5.3 & 18.7 & 22.7 & 16.0 & 37.3 \\
\hline Email reference & 4.0 & 4.0 & 9.3 & 1.3 & 81.3 \\
\hline $\begin{array}{l}\text { Other selected Internet } \\
\text { sources }\end{array}$ & 5.3 & 10.7 & 9.3 & 9.3 & 65.3 \\
\hline Online request forms & 0.0 & 13.3 & 17.3 & 9.3 & 60.0 \\
\hline \multicolumn{6}{|l|}{ Academic staff } \\
\hline OPAC & 15.8 & 73.7 & 0.0 & 5.3 & 5.3 \\
\hline Databases & 15.8 & 47.4 & 5.3 & 10.5 & 21.1 \\
\hline E-journals & 10.5 & 31.6 & 26.3 & 5.3 & 26.3 \\
\hline Email reference & 5.3 & 5.3 & 0.0 & 0.0 & 89.5 \\
\hline $\begin{array}{l}\text { Other selected Internet } \\
\text { sources }\end{array}$ & 0.0 & 21.1 & 0.0 & 0.0 & 78.9 \\
\hline Online request forms & 0.0 & 10.5 & 10.5 & 10.5 & 68.4 \\
\hline
\end{tabular}

\subsubsection{Perceptions of the Current Digital Services}

Different perceptions of importance of, satisfaction with, and future use of digital services are shown in Figures 9-11.

The assessment of the importance of the digital services is shown in Figure 9. Overall, the "OPAC" and "databases" were the two most important services with ratings higher than 4, followed by "E-journals". Academic staff, however, thought "E-journals" were more important than the "OPAC" but less important than "databases". Postgraduates gave much higher ratings than undergraduates and academic staff to the importance of "online request forms". The least important services for academic staff were "email reference" and "other selected Internet sources". Undergraduates, however, did not give 
the same low ratings to these two services as other user communities. "Online request forms" were given high ratings by postgraduates but got the lowest ratings from undergraduates. The different assessments of the importance of the services result from different roles of undergraduates, postgraduates and academic staff in universities. Undergraduates mainly use resources closely related to their courses. Postgraduates search for academic information for their research as well as the materials relating to their study. The major responsibility for academic staff is teaching and research which depend heavily on information services from university libraries.

Figure 9. Importance of the current services (academic staff VS. postgraduates VS. undergraduates)

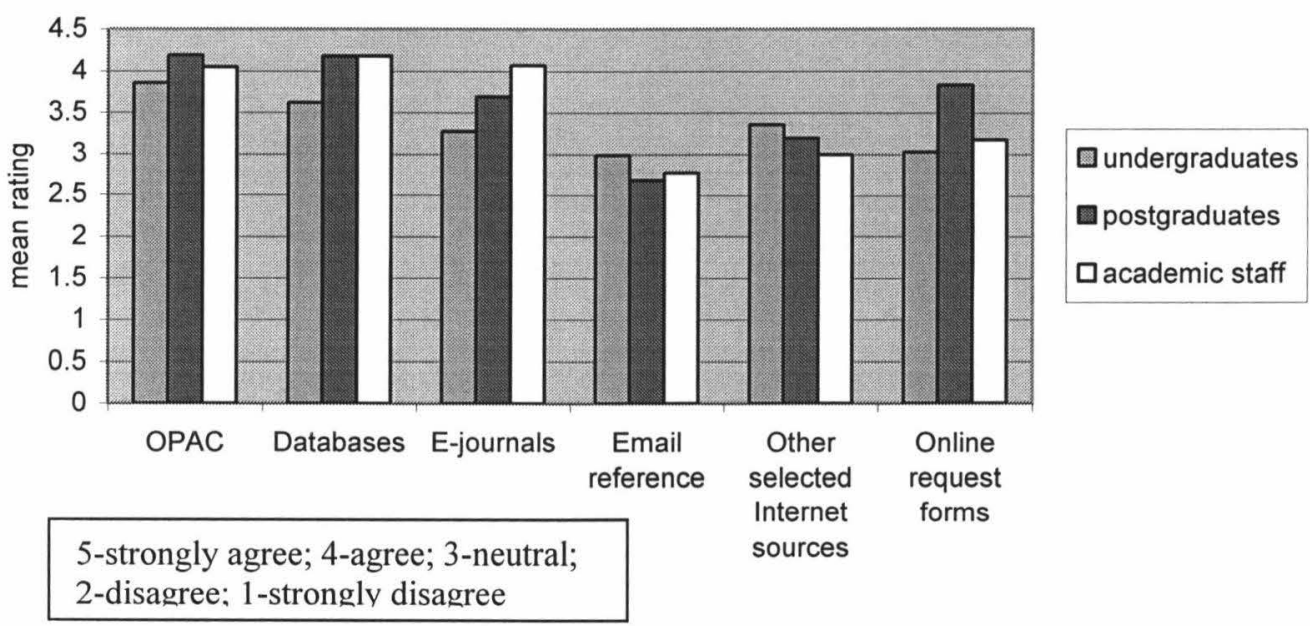

Responses to user survey Question 12 about the overall level of satisfaction with digital services, while showing some variations, generally do not differ significantly by different user communities. Approximately $70 \%$ of every community was satisfied with the digital services provided by the University Library. 
Satisfaction with specific services, on the other hand, clearly does vary, as shown in Figure 10:

Figure 10. Satisfaction with current services (undergraduates VS. postgraduates VS. academic staff)

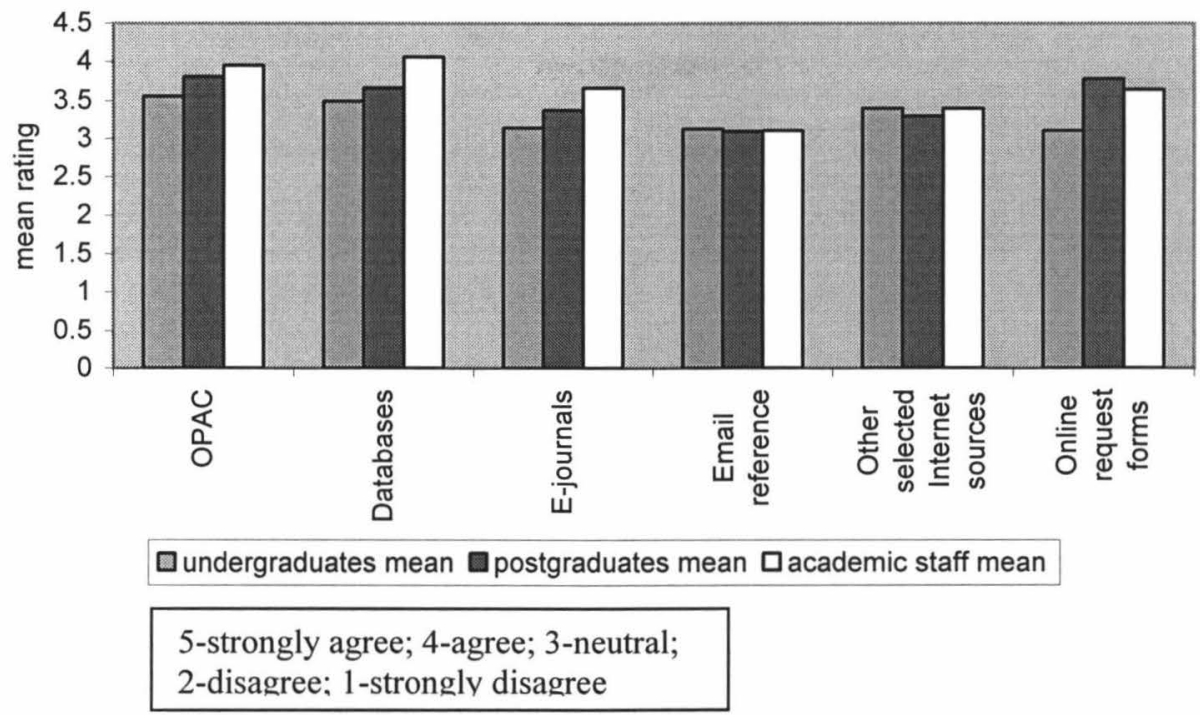

Respondents overall seemed to have been satisfied with both the OPAC and databases but not with "email reference". The "OPAC" and "databases" were the most frequently used information services and correspondingly got high satisfaction ratings from all user communities. Undergraduates gave high ratings to "other selected Internet sources", while around $70 \%$ of the postgraduates and the academic staff thought it was one of the most unsatisfactory services. The lowest satisfaction rating was given to "online request forms" by undergraduates, and "email reference" by postgraduates and academic staff. "Online request form" was one of the most satisfactory services for postgraduates. 


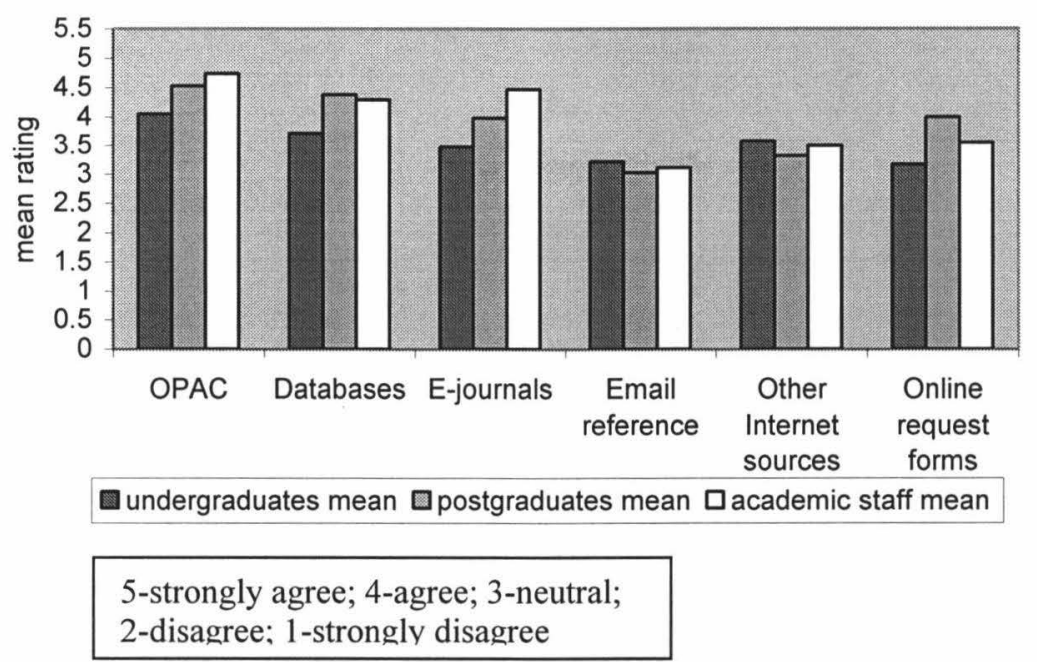

The assessment of future use of current services is shown in Figure 11. In general, more than $70 \%$ of the users would like to use the "OPAC" again in the future, followed by "databases". Almost half of the undergraduates indicated that they would want to use the "other Internet sources" that they felt most satisfied with. Postgraduates would want to use "online request forms", unlike undergraduates. Academic staff and postgraduates would more emphatically like to use "E-journals" again compared to undergraduates. The future of use of "email reference' is clearly the lowest among all user communities.

\subsubsection{The Importance of the Features of the Services}

The importance of various features of digital services was rated in order to find users' preferences and thus improve the quality of the digital services. Undergraduates, postgraduates and academic staff felt "easy to use" and "useful information provided by this service" were the most important features, followed by "convenient and easy access". The comparison of four general features ("availability of information about this service", "convenient and easy access", "easy to use", and "useful information provided by this service") are shown in Figures 12-15: 
Figure 12. Assessment of "availability of information about this service" (three user communities)

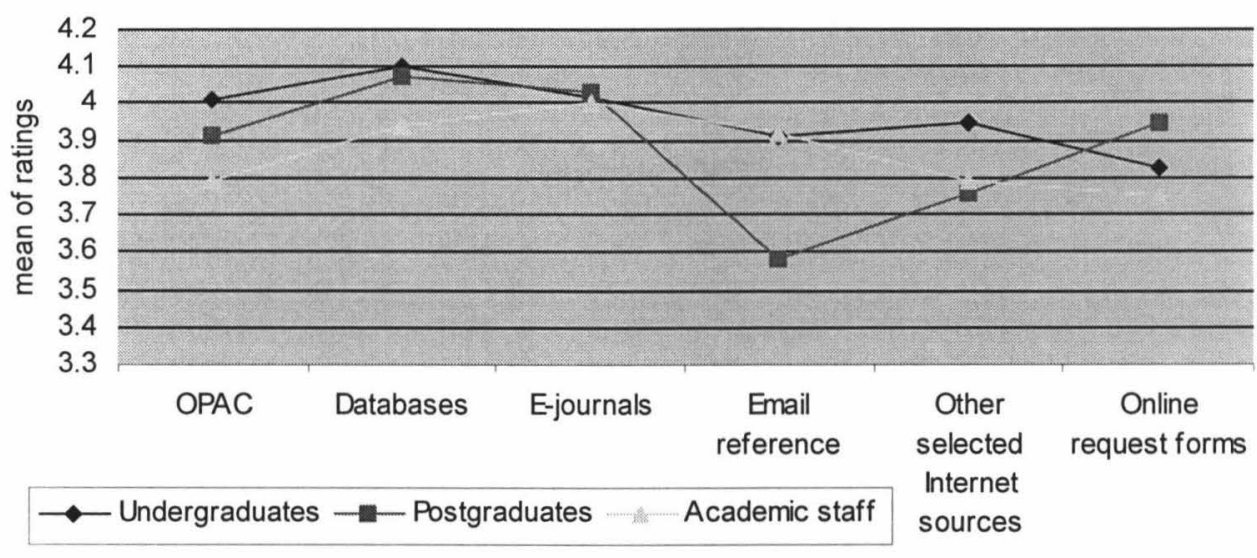

Figure 13. Assessment of "convenient and easy access" (three user communities)

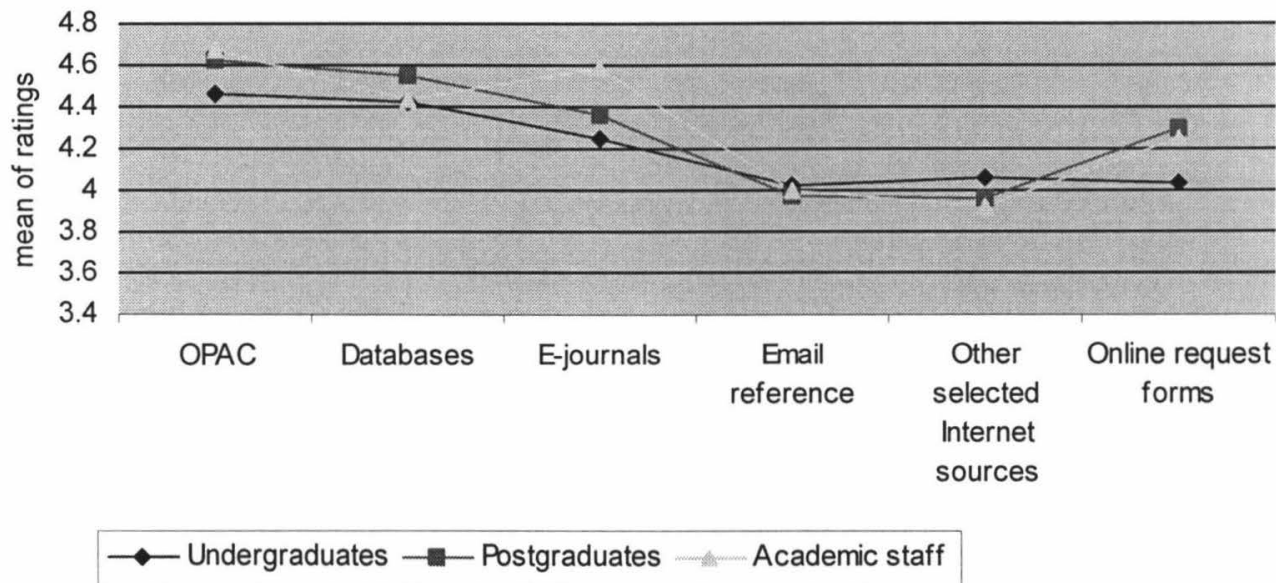

5-strongly agree; 4-agree; 3-neutral; 2-disagree; 1 -strongly disagree 
Figure 14. Assessment of "easy to use" (three user communities)

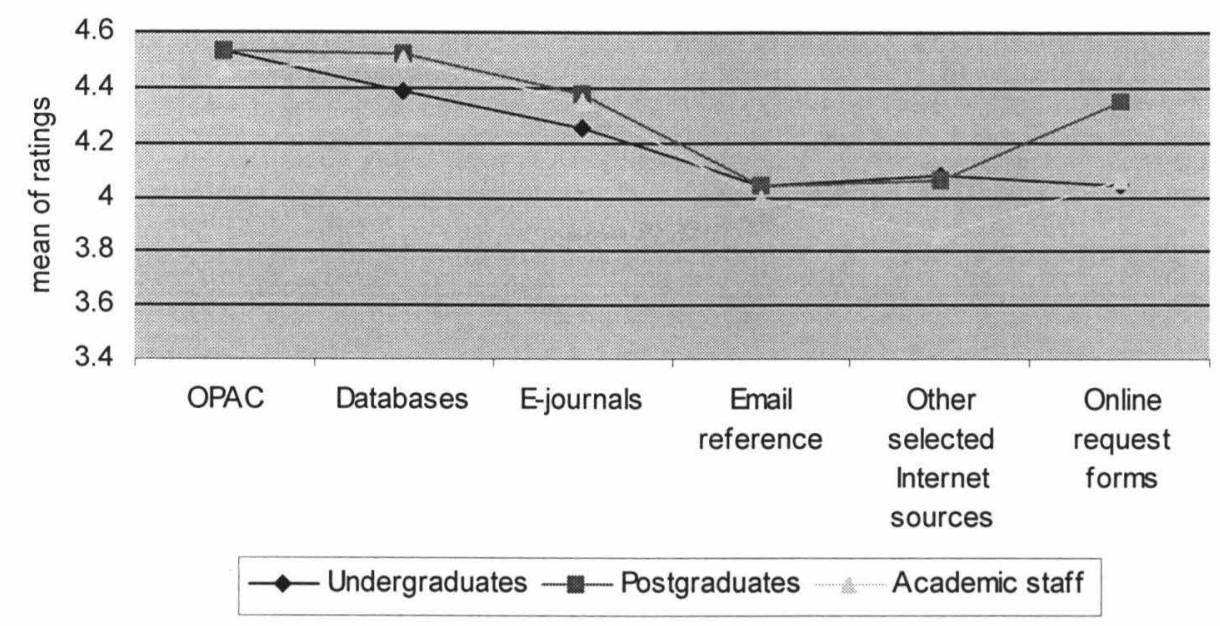

Figure 15. Assessment of "useful information provided by this service" (three user communities)

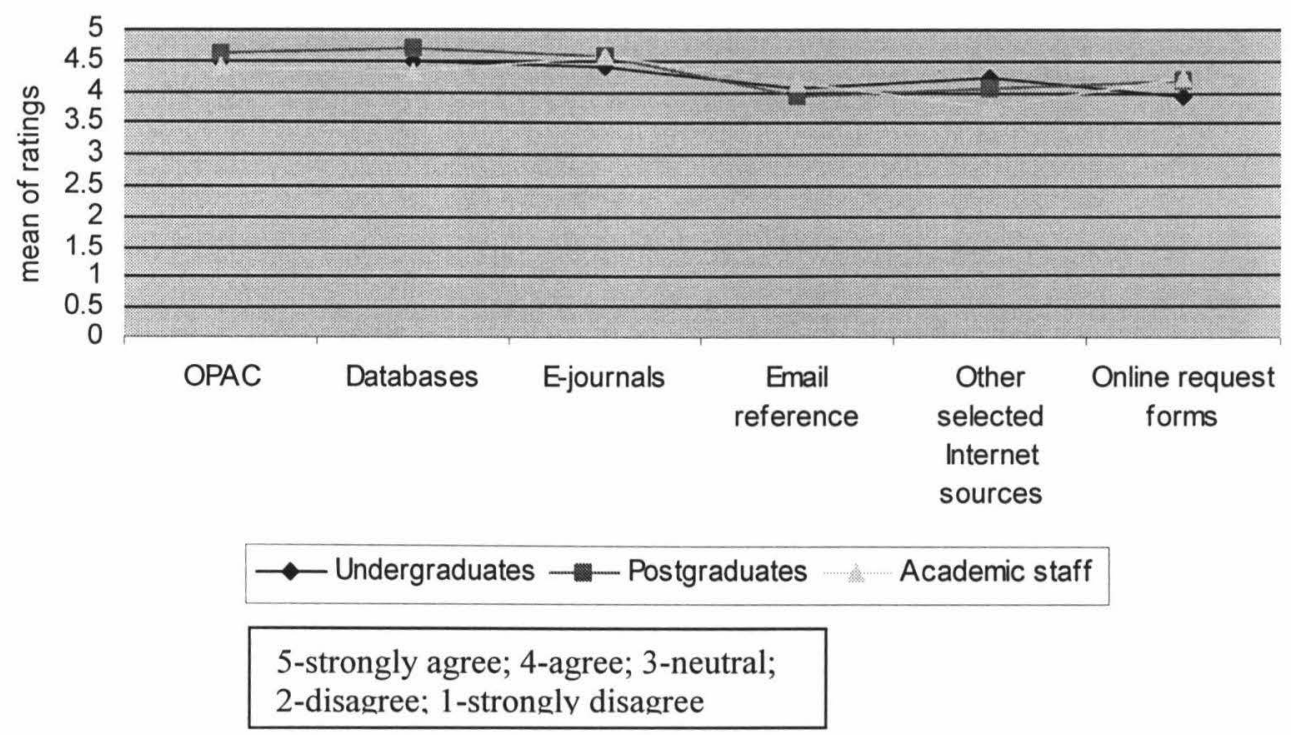

For the "OPAC", the most important feature for undergraduates was "easy to use" (91.9\%), "accuracy of the information" by postgraduates (96\%) and "convenient and easy access" by academic staff (100\%). "Online tutorials" were considered the least important feature of the "OPAC".

"Availability of training" was the most important feature of databases for users followed by "availability of information about this service" and "number 
of the databases". "Currency of the databases", was important for the academic staff and postgraduates, but not for undergraduates. The students' rating of the importance of "useful information provided by this service" was higher than for academic staff.

Figure 16. Location when using databases (undergraduates VS. postgraduates VS. academic staff)

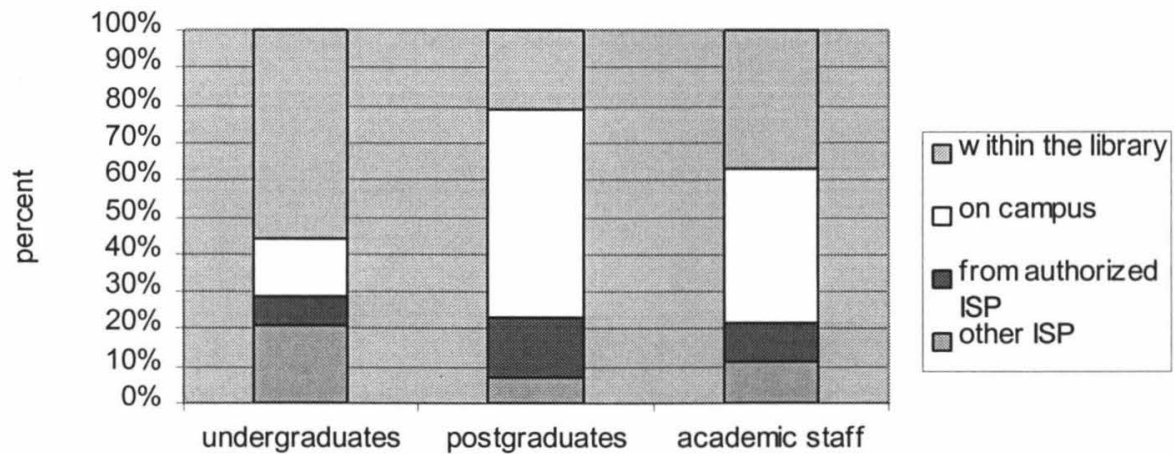

Note: If the users use authorized ISP (Internet Service Provider) for example VUW and Paradise, they can access all the databases from the Library website.

Figure 16 shows the locations where users use databases. Both postgraduates $(56 \%)$ and academic staff (41\%) mainly used databases on campus (e.g., in computer labs or offices). Users did not have to visit the library building in order to access the library's resources. Postgraduates particularly preferred using databases in labs, offices, or at home instead of within the library. Undergraduates mostly (56\%) used databases within the library.

Over $80 \%$ of the users agreed that "useful information provided by this service" was the most important feature of E-journals and less than $20 \%$ of the users thought "availability of information about this service" was the least important. Academic staff and postgraduates gave high ratings to "currency of the content" while undergraduates gave high ratings to "easy to use". Undergraduates and academic staff also preferred "convenient and easy access". For delivery of the results from "E-journals" or "databases", the unanimous preference was to print out the articles rather than have the full-text emailed to users, as shown in Table 9. Academic staff were also interested in downloading the articles from the web. 
Table 9. The percent of the preferences of delivery format of results from databases/E-journals

\begin{tabular}{|l|l|l|l|l|l|l|l|l|l|l|}
\hline & \multicolumn{3}{l}{ Undergraduates } & \multicolumn{2}{l|}{ Postgraduates } & \multicolumn{2}{l|}{ Academic staff } \\
\hline & Emailing & Printing & Downloading & Emailing & Printing & Downloading & Emailing & Printing & Downloading \\
\hline $\begin{array}{l}\text { Least } \\
\text { favorite }\end{array}$ & 51.9 & 17.3 & 31.7 & 52.3 & 24.6 & 23.1 & 35.3 & 35.3 & 29.4 \\
\hline $\begin{array}{l}\text { Next } \\
\text { favorite }\end{array}$ & 19.2 & 29.8 & 51 & 24.6 & 32.3 & 43.1 & 35.3 & 35.3 & 29.4 \\
\hline $\begin{array}{l}\text { Most } \\
\text { favorite }\end{array}$ & 28.8 & 52.9 & 17.3 & 23.1 & 43.1 & 33.8 & 31.3 & 31.3 & 37.5 \\
\hline
\end{tabular}

"Email reference", "other selected Internet sources" and "online request forms" are the most infrequently used services (Figure 5 in 5.1.1.2). "Email reference" service received identical responses for "easy to use" and "convenient and easy access". "Response time" of "email reference" is considered important, rating higher than 4 for all users. "Other select Internet sources", "convenient and easy access" and "useful information" are more important for students than for academic staff. "Range of content" is mildly important for students. "Online request forms", "useful information" and "response time" were thought more important by postgraduates and academic staff than by undergraduates. The importance of access to the online request forms was agreed to by all user groups.

The differences between undergraduates' and postgraduates' perceptions of the "OPAC" and "databases" are significant at the .001 level, but are significant at the greater .01 level between staff and students ${ }^{13}$. The differences in "E-journals" are significant at the .001 level between each pair of user communities except for satisfaction assessment. The different levels of satisfaction with "E-journal" service are significant at the .1 level for different user communities. The differences for "online request forms" between postgraduates and undergraduates are significant at the .001 level, and at the .01 level between academic staff, undergraduates and postgraduates. For "other selected Internet resources", the differences are significant at the 1

\footnotetext{
${ }^{13}$ The smaller the number of the significant level, the more significant the comparison results. In details, if the comparison results are significant, it is able to reflect the whole survey population from the sample data and suggests that the survey results are typical for the survey population.
} 
level between each pair of user communities. There are no significant differences for "email reference".

\subsubsection{Expectations of Future Digital Services and Improvements on Current} Services

The respondents' opinions are inconsistent regarding several possible future services. Figures 17-19 show the importance, usefulness and future use of three services: "electronic closed reserve"; "virtual reference"; and "current awareness service".

Figure 17. Importance of three future services (three user communities)

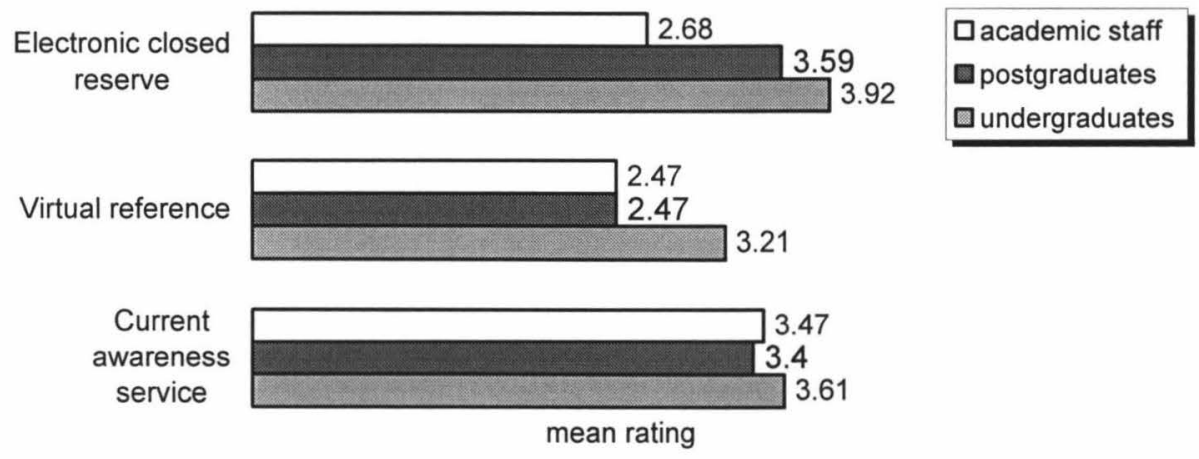

Figure 18 Usefulness of three future services (three user communities)

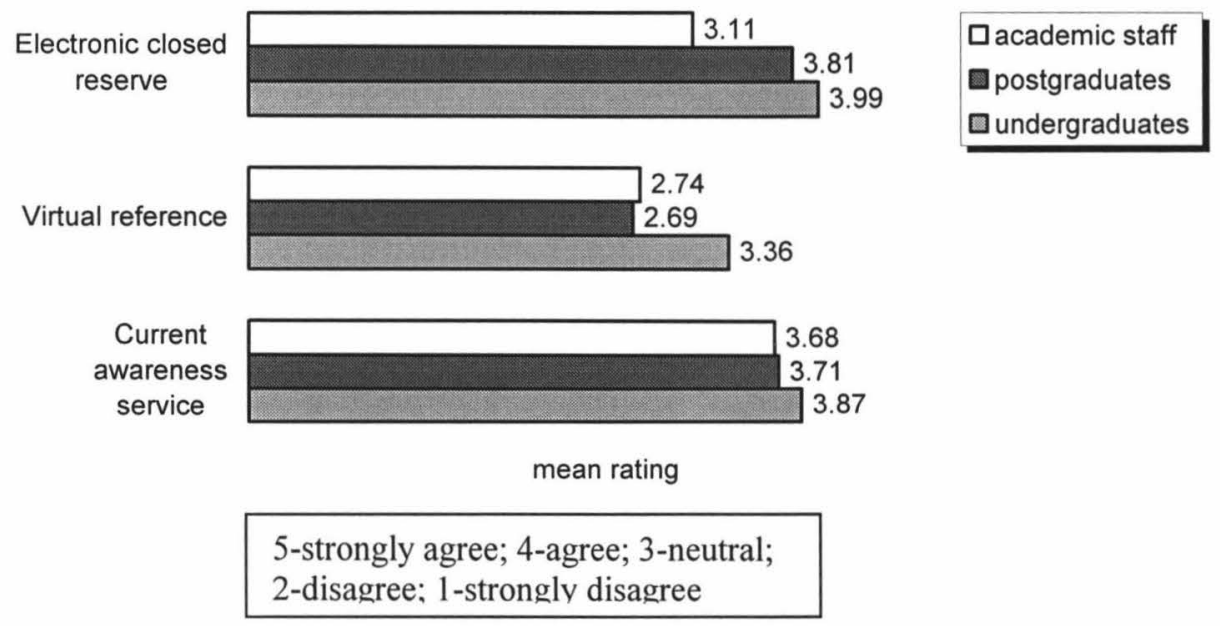


Figure 19. Future use of three future services (three user communities)

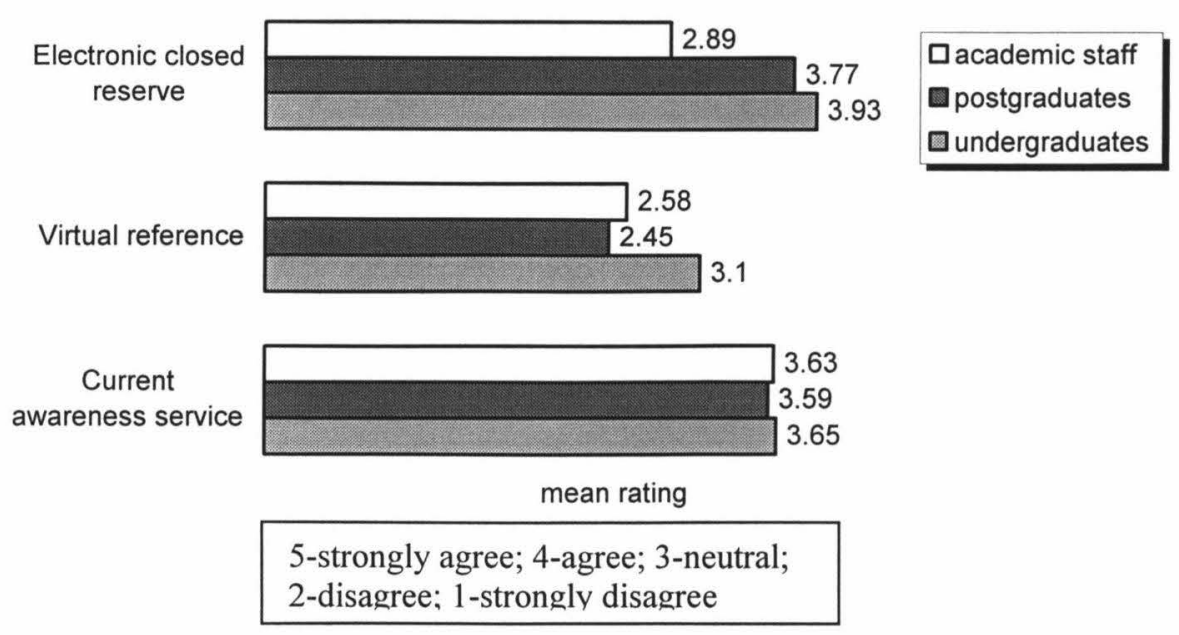

"Current awareness" was the most important future service for academic staff $\left(3.47^{14}\right)$ compared to "virtual reference" (2.47) and "electronic closed reserve" (2.68). Students were looking forward to "electronic closed reserve" by giving higher ratings to the importance, usefulness and future use of the service. Undergraduates gave much higher ratings to the "virtual reference service".

Table 10 shows the different selections and ratings by users of five services that need to be improved by the library. All three communities rated the "OPAC" and "databases" as the first two services that the library should improve. There were dramatic differences in the order of priority for the remaining services. Both academic staff and postgraduates chose "E-journals" as the third priority while undergraduates chose "electronic reference". "Electronic document delivery" needed to be improved according to academic staff and postgraduates but not undergraduates. "Electronic closed reserve" was excluded from the list of priorities by academic staff.

\footnotetext{
${ }^{14}$ The figures in parenthesis in this paragraph are the mean rating where the scale is: 5 -agree; 4 - somewhat agree; 3 - neutral; 2 - somewhat disagree; 1 - disagree.
} 
Table 10. The five choices for improvements

\begin{tabular}{|l|c|l|c|c|c|}
\hline & First choice & $\begin{array}{c}\text { Second } \\
\text { choice }\end{array}$ & Third choice & Fourth choice & Fifth choice \\
\hline Undergraduates & $\begin{array}{c}\text { online } \\
\text { catalogue }\end{array}$ & databases & $\begin{array}{c}\text { electronic } \\
\text { references }\end{array}$ & $\begin{array}{c}\text { digital closed } \\
\text { reserve }\end{array}$ & E-journals \\
\hline Postgraduates & $\begin{array}{c}\text { online } \\
\text { catalogue }\end{array}$ & databases & E-journals & $\begin{array}{c}\text { electronic } \\
\text { document delivery }\end{array}$ & $\begin{array}{c}\text { digital closed } \\
\text { reserve }\end{array}$ \\
\hline Academic staff & $\begin{array}{c}\text { online } \\
\text { catalogue }\end{array}$ & databases & E-journals & $\begin{array}{c}\text { electronic } \\
\text { references }\end{array}$ & $\begin{array}{c}\text { electronic } \\
\text { document delivery }\end{array}$ \\
\hline
\end{tabular}

Compared to postgraduate and academic staff, undergraduates gave more answers to the first open-ended question about their experiences of using digital services. They mentioned the connections between branch libraries and the main campus library, the quality of computers in the library, and access issues concerning the catalogue, databases and E-journals. The responses were divided into broad categories. The 32 responses from undergraduates generally included the following comments on the delivery of digital services provided by the university library:

- Users were not aware of the existence and use of some online services (40.6\%). Some of respondents learned about some services for the first time when filling in the questionnaires.

- The computers and printers in the library did not always work smoothly, which affects the use of digital services. (18.8\%)

- They found it hard to navigate the databases to find useful information. $(12.5 \%)$

- The information on the library website needed to be updated more frequently. (12.5\%)

- They found it difficult to access E-journals and databases. (9.4\%)

- The OPAC interface and the accuracy of its information were not satisfactory. $(6.3 \%)$

Postgraduates had more problems with the searching options of databases, the range and currency of "databases" and "E-journals", and the external access to online resources of "databases" and "E-journals". Thirty-three percent of the postgraduates in this research sample made comments about digital services. 
- More than a third of the comments related to the "OPAC" (44\%). Some users thought the interface of the current "OPAC" via telnet was unattractive and the layout looked out-dated. The searching options provided by the "OPAC" were not useful enough and users could not refine their search results.

- The searching options in databases were also an important issue (36\%). Respondents found it difficult to choose a relevant database and to use proper searching terms.

- They gave feedback on the range of the "E-journals" and data export from "E-journals", "databases" and the "OPAC" to other software such as Endnote. (28\%)

- The information on the library website needed updating. (12\%)

- Online requests for inter-loans were thought helpful, fast and useful. $(12 \%)$

- The help from library staff was commended. (8\%)

- Document delivery by email was acknowledged by some respondents. $(4 \%)$

Academic staff commented on the "OPAC" and "E-journals". They did not feel comfortable when using these services. One professor described the OPAC as a terrible dinosaur.

The differences between undergraduates and postgraduates, postgraduates and academic staff, and undergraduates and academic staff are significant at least at the .05 level for current awareness services and digital closed reserve services, but there were no significant differences for virtual reference services.

\subsubsection{Correlation Test of Two Relationships}

Correlation tests were calculated for the two relationships for each community. Strong correlation indicates that the increase or decrease of one variable in the relationship leads to a corresponding increase or decrease of the other variable. 
Table 11. Spearman Correlation Test results across different services

\begin{tabular}{|c|c|c|c|c|}
\hline & \multicolumn{2}{|c|}{ Importance of the service } & \multicolumn{2}{|c|}{ Satisfaction with the service } \\
\hline & $\begin{array}{l}\text { Correlation } \\
\text { Coefficient }\end{array}$ & Significance & $\begin{array}{l}\text { Correlation } \\
\text { Coefficient }\end{array}$ & Significance \\
\hline \multicolumn{5}{|l|}{ Undergraduates } \\
\hline $\begin{array}{l}\text { Users would like to use OPAC in the } \\
\text { future }\end{array}$ & .601 & .01 & .406 & .01 \\
\hline $\begin{array}{l}\text { Users would like to use databases in } \\
\text { the future }\end{array}$ & .547 & .01 & .626 & .01 \\
\hline $\begin{array}{l}\text { Users would like to use E-journals in } \\
\text { the future }\end{array}$ & .636 & .01 & .606 & .01 \\
\hline $\begin{array}{l}\text { Users would like to use email } \\
\text { reference in the future }\end{array}$ & .790 & .01 & .813 & .01 \\
\hline $\begin{array}{l}\text { Users would like to use other selected } \\
\text { Internet services in the future }\end{array}$ & .790 & .01 & .693 & .01 \\
\hline $\begin{array}{l}\text { Users would like to use online request } \\
\text { forms in the future }\end{array}$ & .829 & .01 & .813 & .01 \\
\hline \multicolumn{5}{|l|}{ Postgraduates } \\
\hline $\begin{array}{l}\text { Users would like to use OPAC in the } \\
\text { future }\end{array}$ & .369 & N/A & .515 & .01 \\
\hline $\begin{array}{l}\text { Users would like to use databases in } \\
\text { the future }\end{array}$ & .806 & .01 & .509 & .01 \\
\hline $\begin{array}{l}\text { Users would like to use E-journals in } \\
\text { the future }\end{array}$ & .639 & .05 & .639 & .01 \\
\hline $\begin{array}{l}\text { Users would like to use email } \\
\text { reference in the future }\end{array}$ & .655 & N/A & .737 & .01 \\
\hline $\begin{array}{l}\text { Users would like to use other selected } \\
\text { Internet services in the future }\end{array}$ & .272 & N/A & .832 & .01 \\
\hline $\begin{array}{l}\text { Users would like to use online request } \\
\text { forms in the future }\end{array}$ & .944 & .01 & .790 & .01 \\
\hline \multicolumn{5}{|l|}{ Academic staff } \\
\hline $\begin{array}{l}\text { Users would like to use OPAC in the } \\
\text { future }\end{array}$ & .403 & .01 & .036 & $\mathrm{~N} / \mathrm{A}$ \\
\hline $\begin{array}{l}\text { Users would like to use databases in } \\
\text { the future }\end{array}$ & .511 & .01 & .621 & .01 \\
\hline $\begin{array}{l}\text { Users would like to use E-journals in } \\
\text { the future }\end{array}$ & .352 & .01 & .482 & $\mathrm{~N} / \mathrm{A}$ \\
\hline $\begin{array}{l}\text { Users would like to use email } \\
\text { reference in the future }\end{array}$ & .739 & .01 & 1.000 & .01 \\
\hline $\begin{array}{l}\text { Users would like to use other selected } \\
\text { Internet services in the future }\end{array}$ & .600 & .01 & .986 & $\mathrm{~N} / \mathrm{A}$ \\
\hline $\begin{array}{l}\text { Users would like to use online request } \\
\text { forms in the future }\end{array}$ & .745 & .01 & .947 & .01 \\
\hline
\end{tabular}

Table 11 shows a strong correlation between users saying that they would use the service in the future and the level of importance users attributed to it, and between the level of users satisfaction with the service and whether users would use it in the future for "email reference", "other selected Internet 
sources" and "online request forms" (more than .7 individually). Both correlations are significant at the 0.01 level. For postgraduates, the strongest correlations were for "email reference" and "online request forms" (more than .800 individually), also significant at the .01 level. For academic staff, the strongest correlations involved "online request forms". There were absolute positive relationships — with both correlation coefficient values more than .9 - between the importance of this service and users saying that they would use it in the future, and the users' satisfaction with the service and the future use of this service. In comparison with the previous correlations, the weakest

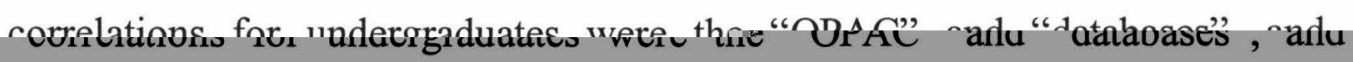
"OPAC" and "E-journals" for postgraduates. Compared with students, the levels of importance and satisfaction of the services do not obviously influence the academic staff's future use of some services (e.g., "OPAC" and "E-journals").

It is interesting that satisfaction with "email reference" and "other Internet sources" has a close relationship with users' future use although there is no obvious relationship between the importance of these two services and users' future use. Academic staff did not think "email reference" and "other Internet sources" were important. However, when they were satisfied with these services they would likely use them again. As for "online request forms", the influence of the importance of this service on the users' future use of this service is stronger than any other service in every user community.

For students, the importance of the services is more influential than satisfaction. So even though the users may not be satisfied with the service, they will still use it again. Their information needs and the importance of the service determine the users' intentions to use a digital service in the future. Academic staff think about importance as well as satisfaction when deciding whether to use services again in the future. Although some services are not necessary, they still would like to use the services as long as they are satisfied with them. 


\subsubsection{Comparison between Users and Librarians}

\subsubsection{Response Rate}

The general user response rate $(46.7 \%)$ was much higher than for librarians $(34.2 \%)$. Librarians were presumably not as interested in responding to a survey in this subject or they were too busy to spend time in filling in the questionnaires. While the response rate was particularly good for the undergraduates, it was only modest for the academic staff, and it was on the low side for the postgraduates and the librarians. Although the response rate was lowest for the librarians, it is important to realize that this particular group is the most knowledgeable about the concepts being surveyed, and as a result, the data obtained from the librarians will likely not suffer from any misunderstandings of what was being asked. Similarly, the data from postgraduates are also able to reflect their understandings of surveyed topics. Nonetheless, it is important to note that the variability of the response rate across the different groups may have impacted on the reliability of the data.

\subsubsection{Perceptions of the Current Digital Services}

The importance of the current services from the perspectives of the librarians and the users is shown in Figure 20. In the librarians' opinions, "databases" and OPAC were the two most important services, which is consistent with the users' opinions. However, the ratings of importance from librarians were much higher than those from users.

Figure 20. Importance of the services (librarians VS. general users)

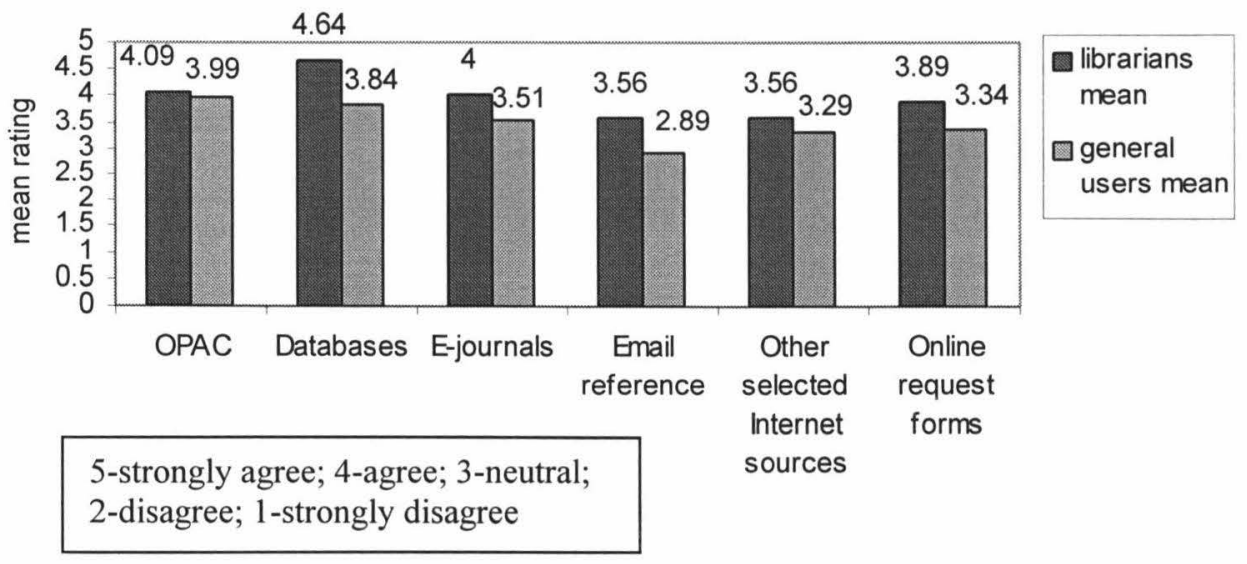


The most important service according to the librarians was "databases" followed by the "OPAC" and "E-journals", while users chose the "OPAC" followed by "databases". "Email reference" was the least importance service for both librarians and users.

Figure 21. Satisfaction with the services (librarians VS. general users)

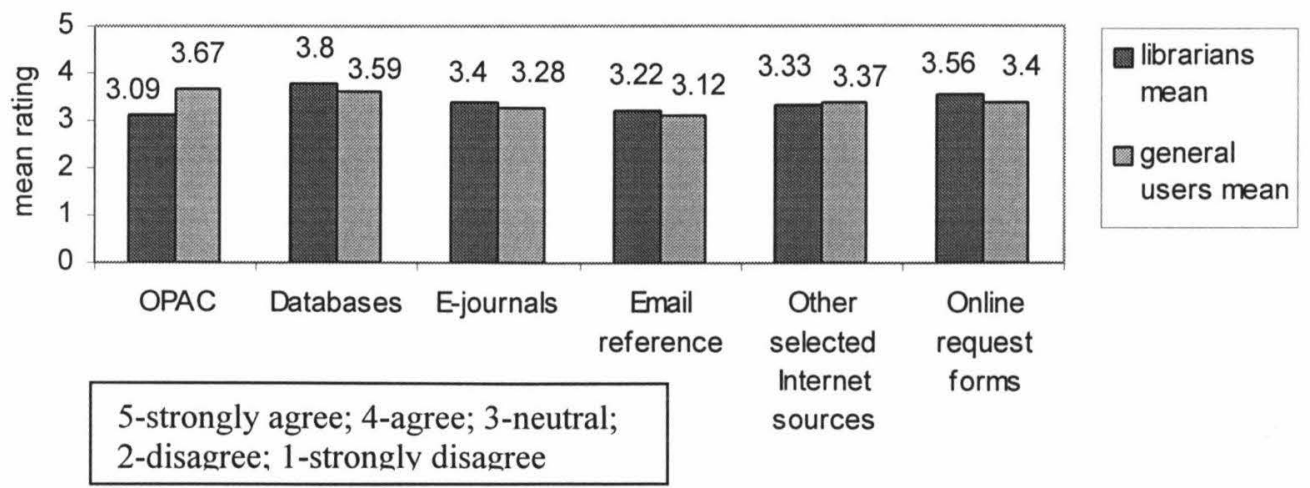

Figure 21 shows that the librarians perceived the users' satisfaction with the "OPAC" to be low and that they considered it the least satisfactory service for users. However, users were more satisfied with this service than was believed by the librarians, although the users complained about the interface and some other aspects. Unlike the librarians, users were not satisfied with the "databases", "E-journals" and "online request forms", though they gave high ratings to the statements that they would use the service in the future. Figure 22 presents future use of the services from librarians' and users' perspectives.

Figure 22. Future use of the services (librarians VS. general users)

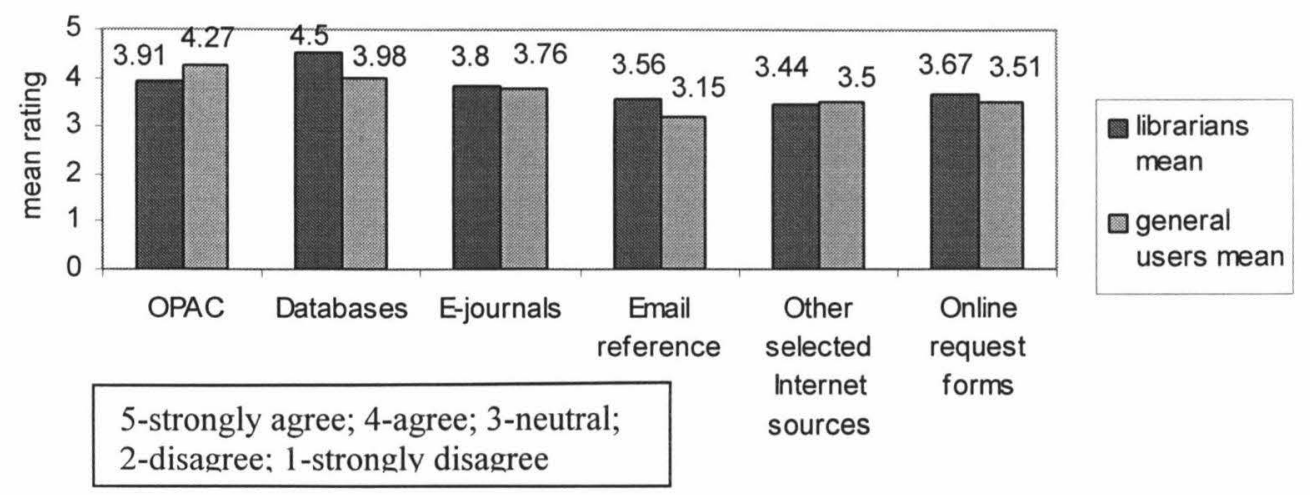

The "OPAC", "databases" and "E-journals" are the services which would most likely be used in the future. The different expectations of future use 
between librarians and users are apparent in the results for "databases" and "email reference service". The librarians overestimated the future use of these two digital services. More users intend to use the "OPAC" than librarians thought.

Some services obviously have key beneficiaries who are their most frequent users. The comparison between the main beneficiaries including academic staff, postgraduates, and librarians is shown in Figure 23. "E-journals" are convenient information sources for academic staff and postgraduates. "Ejournals" were thought to be very important by librarians, but not to the same degree by users, especially students. As a group who use this service relatively frequently, academic staff still did not display their satisfaction and readiness to use this service to the same extent as the librarians' assessment. Other user communities only gave mildly positive assessments of "E-journals", with much lower ratings than librarians. Therefore, when making decisions about this service, library staff should pay attention to the information needs of academic staff and postgraduates, who gave it high ratings of importance and future use.

Figure 23. Assessment of E-journals (librarians VS. academic staff VS. postgraduates VS. undergraduates)

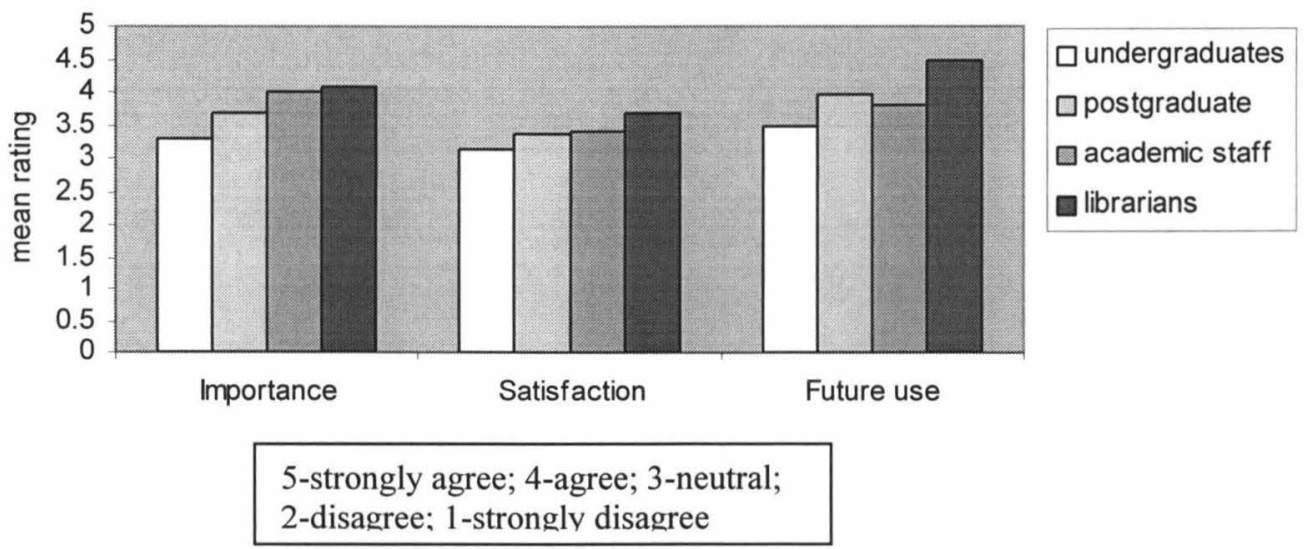

For "online request forms", there is consistency between users and librarians except in two cases. The assessment of "online request forms" is shown in Figure 24 . 
Figure 24. Assessment of online request forms (librarians VS. academic staff VS. postgraduates VS. undergraduates)

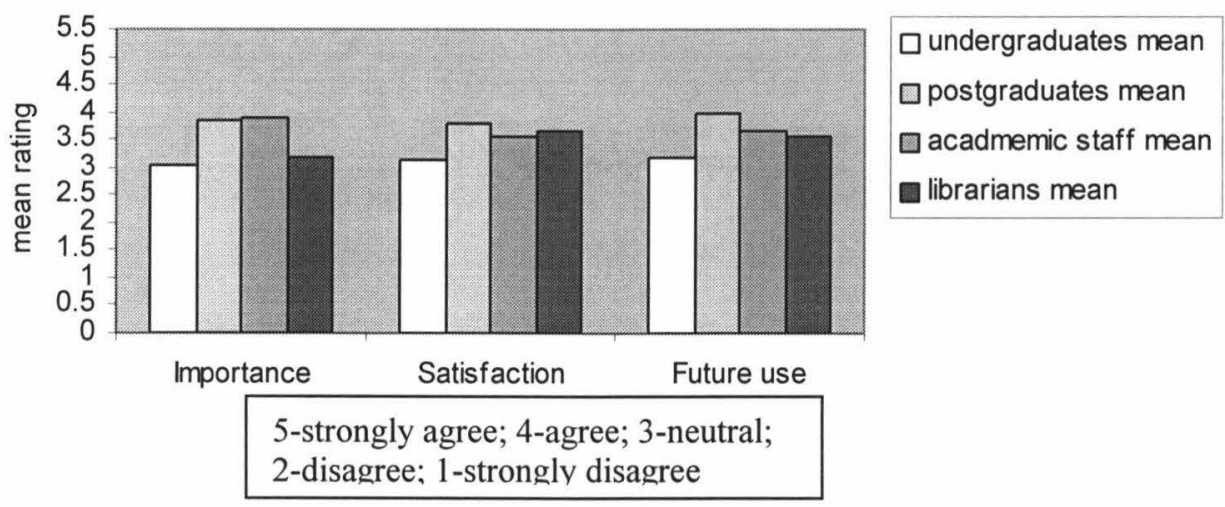

One case is that undergraduates, who are not a key beneficiary of the "online request forms" service, gave lower ratings to this service than the librarians. The other case is that postgraduates and academic staff, who are frequent users, agreed on the importance of the service and would like to use this service more than was expected by the librarians. The librarians underestimated that a larger proportion of postgraduates would use online request forms in the future. Although undergraduates are not key users of the above two services, undergraduates at different levels (e.g., first year, second year and third year) have different needs. It is possible that undergraduates in the third year are also a potential user group of this service.

"Email reference" and "other selected Internet sources" are two less important services for both general users and librarians. "Email reference" service was thought more important and satisfactory by librarians than by any user community. Nearly half of the librarians estimated that the users would like to use this service again in the future but less than $30 \%$ of the users agreed. Even though undergraduates are frequent users of "other selected Internet sources", they were not satisfied with this service to the level that the librarians thought they were.

In terms of overall satisfaction, users were satisfied with digital services by giving a rating of 4 compared to 3.5 from librarians' expectations. More users were satisfied overall with digital services than the librarians had expected. 
From the users' perspectives, the digital services provided by the VUW Library are, overall, able to meet their needs.

\subsubsection{The Importance of the Features of the Services}

Both users and librarians felt "easy to use" and "convenient and easy access" were the most important features, followed by "useful information provided by this service". The importance of these three features can be seen in Figures 25-27:

Figure25. Importance of "convenient and easy access" (librarians VS general users)

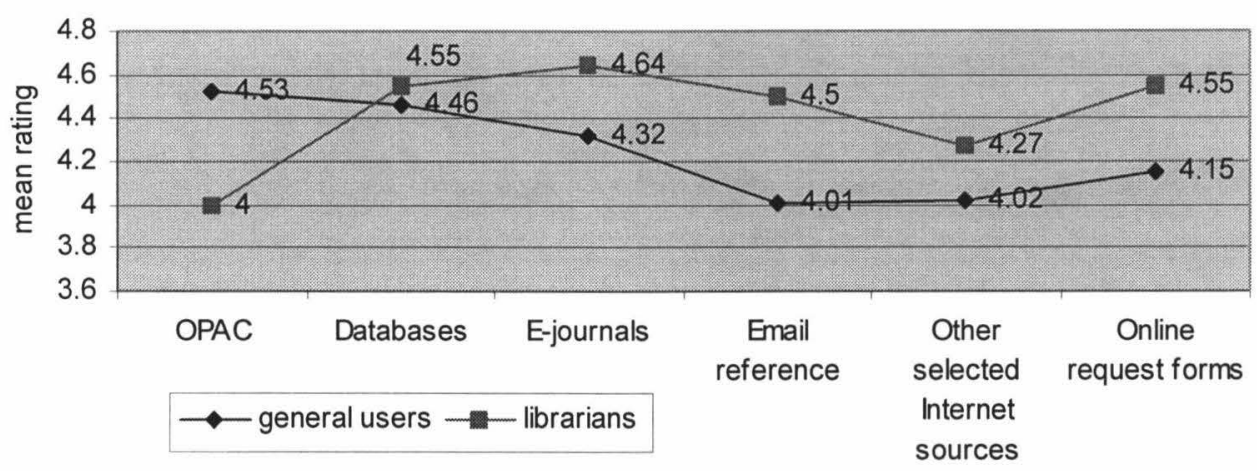

Figure 26. Importance of "easy to use" (librarians VS general users)

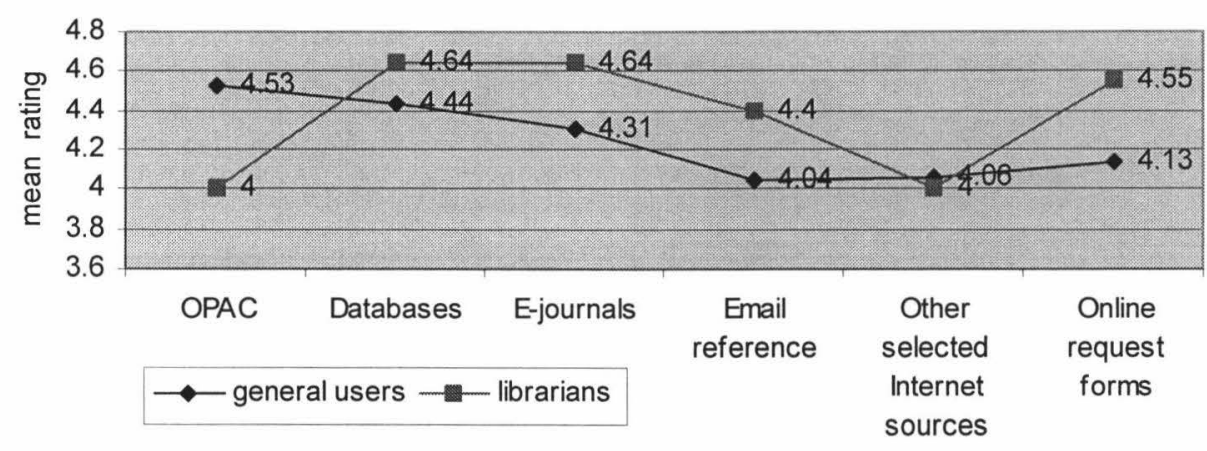

5-strongly agree; 4-agree; 3-neutral; 2-disagree; 1 -strongly disagree 
Figure 27. Importance of "useful information provided by this service" (librarians VS general users)

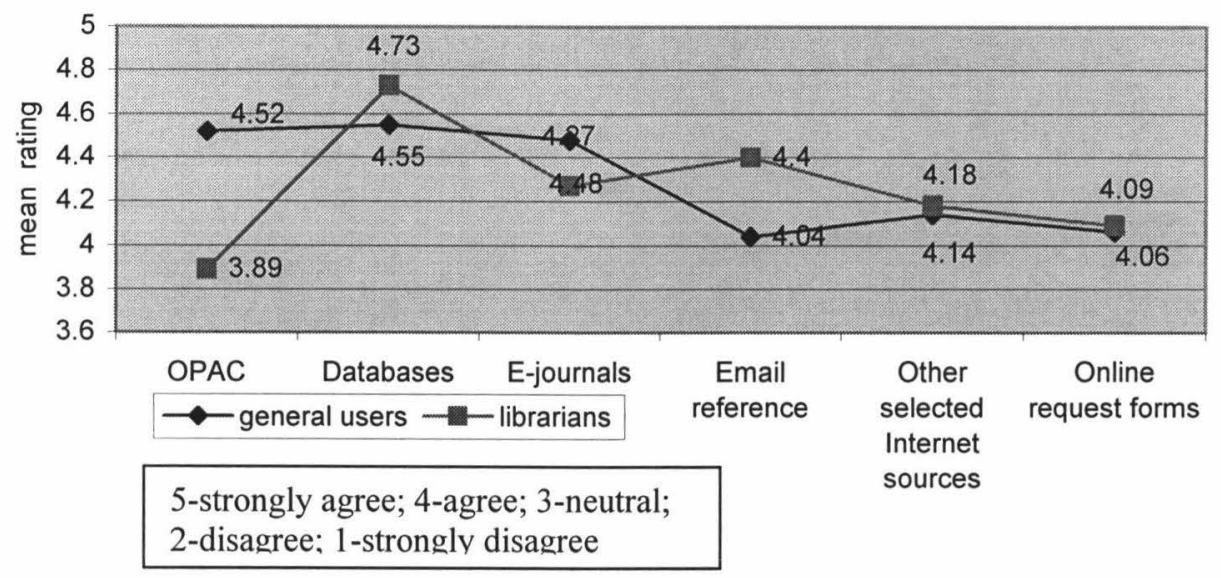

The users' rating of "availability of information about the service" was lower than that for the librarians, as shown in Figure 28. It was one of the features that users paid the least attention to.

Figure 28. Importance of "availability of information about this service" (librarians VS general users)

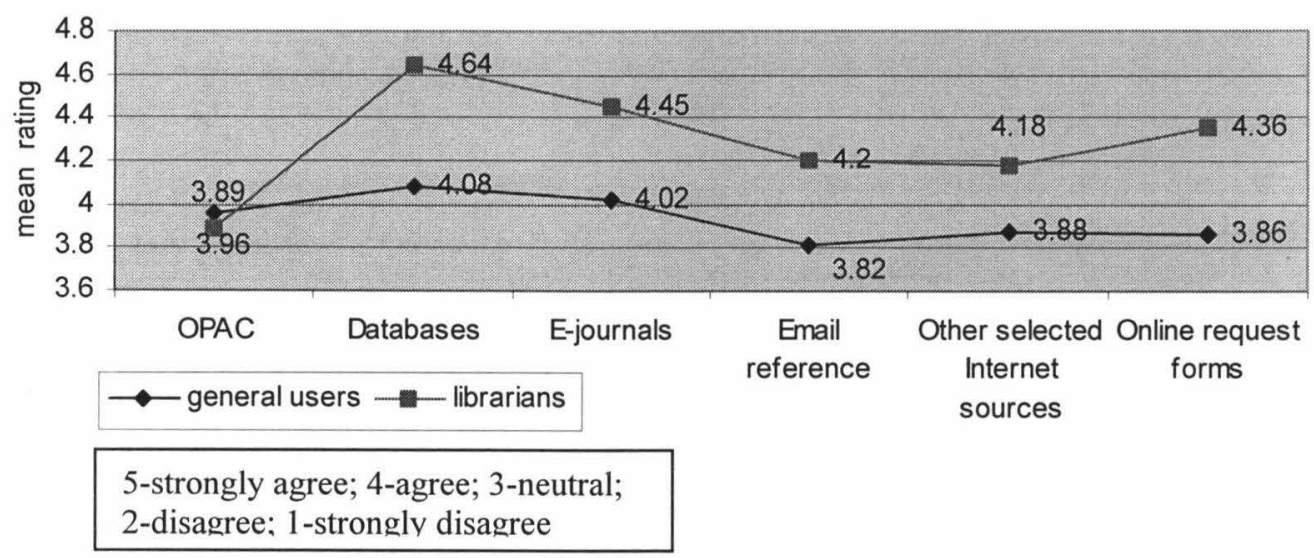

The librarians gave slightly higher ratings to the importance of the features of the services than users. Librarians gave the same high ratings as users to different features of the OPAC. More users than librarians agreed on the importance of "convenient and easy access", "easy to use" and "useful information provided by this service". 
The importance of various database features is shown in Figure 29:

Figure 29. The importance of features of databases (general users VS. librarians)

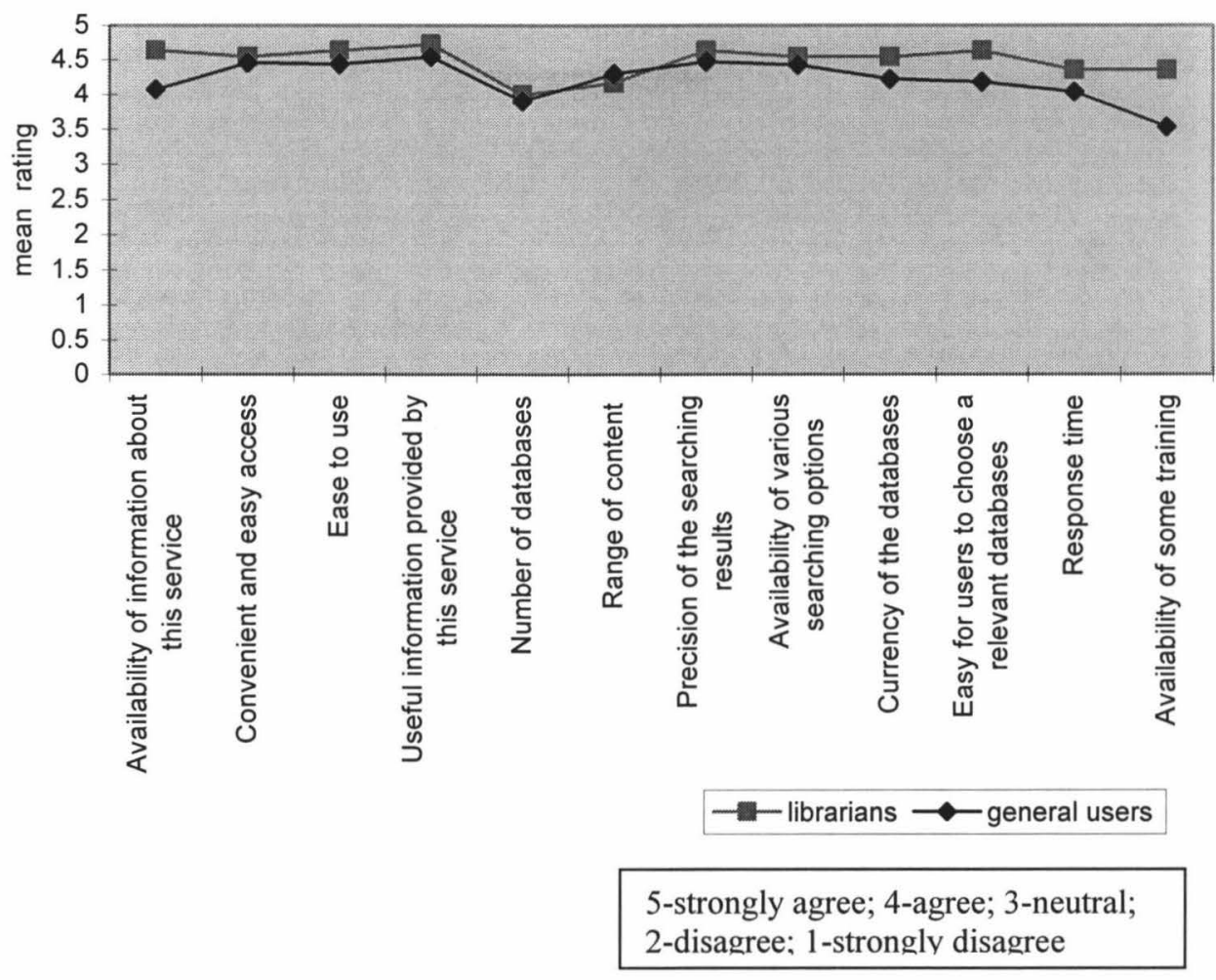

There are clearly differences for several features. "Number of the databases", "range of content", "response time", and "convenient and easy access" were thought more important by users than by librarians. Librarians valued "useful information" and "availability of information about the service" slightly more than users.

"Currency of the content" is the most important feature of "E-journals" in the opinion of librarians, academic staff and postgraduates, but not undergraduates. This is logical since postgraduates and academic staff are the two key beneficiaries of this service. As long as the library focuses on the "currency of the content", "useful information provided by the service" and "range of content" that these two key beneficiaries prefer, the service will be provided successfully.

Table 12 shows the opinions of librarians and users on the delivery of results from "databases" and "E-journals". 
Librarians and users concurred that the preferred delivery format of search results from "databases" and "E-journals" is printing rather than downloading or emailing. Though downloading and emailing are widely used, some users are more comfortable with the traditional method. One possible explanation is that users prefer to read information that has been printed on paper.

Table 12. The preference of delivery format of the results from databases/Ejournals

\begin{tabular}{|l|l|l|l|l|l|l|l|l|l|}
\hline & \multicolumn{3}{|c|}{ Emailing } & \multicolumn{3}{c|}{ Printing } & \multicolumn{3}{c|}{ Downloading } \\
\cline { 2 - 10 } & $\begin{array}{l}\text { Least } \\
\text { favourite } \\
(\%)\end{array}$ & $\begin{array}{l}\text { Next } \\
\text { favourite } \\
(\%)\end{array}$ & $\begin{array}{l}\text { Most } \\
\text { favourite } \\
(\%)\end{array}$ & $\begin{array}{l}\text { Least } \\
\text { favourite } \\
(\%)\end{array}$ & $\begin{array}{l}\text { Next } \\
\text { favourite } \\
(\%)\end{array}$ & $\begin{array}{l}\text { Most } \\
\text { favourite } \\
(\%)\end{array}$ & $\begin{array}{l}\text { Least } \\
\text { favourite } \\
(\%)\end{array}$ & $\begin{array}{l}\text { Next } \\
\text { favourite } \\
(\%)\end{array}$ & $\begin{array}{l}\text { Most } \\
\text { favourite } \\
(\%)\end{array}$ \\
\hline Librarians & 50 & 37.5 & 12.5 & 25 & 0 & 75 & 25 & 62.5 & 12.5 \\
\hline Users & 50.8 & 22.2 & 27.0 & 21.0 & 31.2 & 47.8 & 28.5 & 46.8 & 24.7 \\
\hline
\end{tabular}

"Email reference", "other selected Internet sources" and "online request forms" are the most infrequently used services with their features given low ratings of importance. "Usefulness of the services" and "response time" of "email reference" were thought more important by librarians than users.

There are significant differences in responses regarding the "OPAC", "databases", and "online request forms" between users and librarians at the .001 level. Other differences are significant at the .05 level. No significant differences exist between librarians and users regarding "E-journals" and “other selected Internet source".

\subsubsection{Expectations of the Future Digital Services and Improvements to}

\section{Current Services}

For the three possible future services provided in the survey, librarians had almost the same preferences as users, as shown by the ratings of "importance", "usefulness" and "future use" of the services in Figures 30-32. 
Figure 30. Importance of three future services (general users VS. librarians)

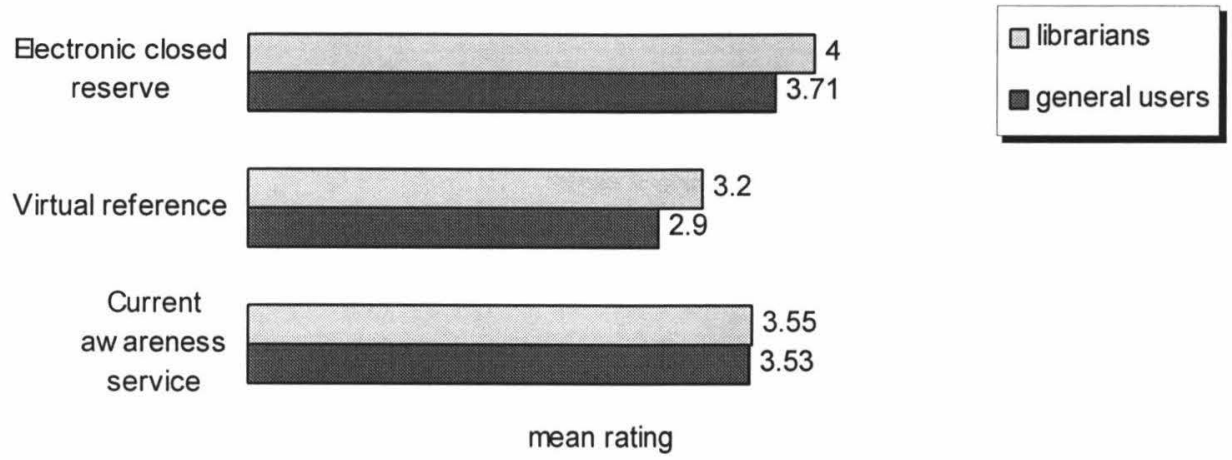

Figure 31. Usefulness of three future services (general users VS. librarians)

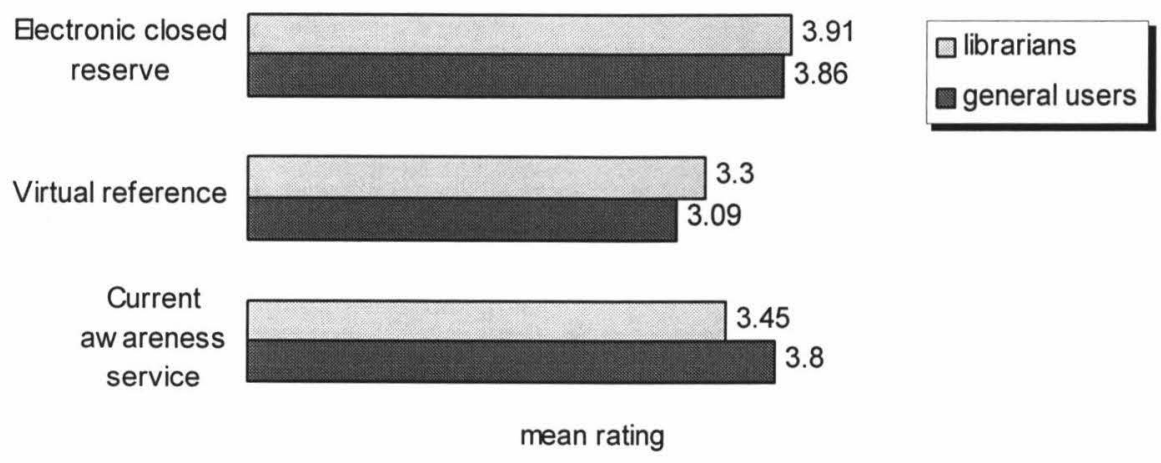

Figure 32. Future use of three future services (general users VS. librarians)

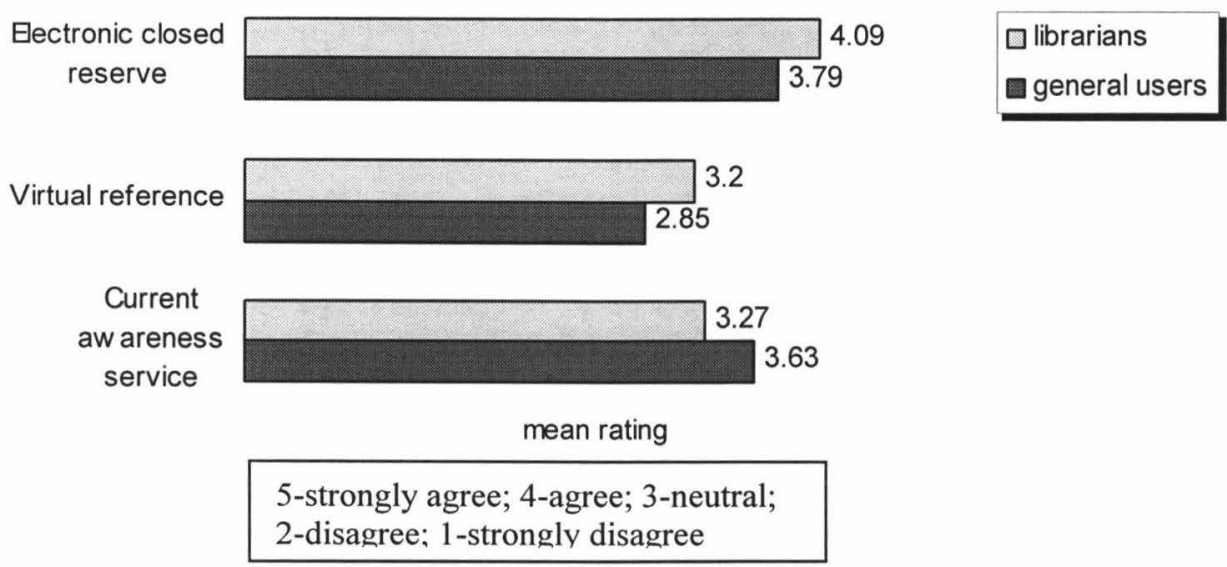

Evidently, users are not interested in these future services, giving relatively low ratings to every statement. However, "electronic closed reserve" has similar ratings of importance, usefulness and future use between users and librarians. It is noticeable that users gave a lower rating than librarians to the importance of "current awareness service" (CAS) but higher ratings than the librarians of usefulness and future use of CAS. Presumably "virtual reference", 
which received the lowest ratings, is not necessary for users as they can use email and phone reference services as well. If the library provides this service, users have one more way to obtain useful information and they would like to try it. The differences in CAS in terms of the importance and usefulness are significant at the .01 level and significant at the .1 level in the future use of this service.

As shown in Table 13, the five services selected for improvement by users and librarians are mainly the "online catalogue", "databases", "E-journals", "digital closed reserve", and "electronic reference".

Table 13. The selection of five choices for improvements

\begin{tabular}{|l|c|c|c|c|c|}
\hline & First choice & $\begin{array}{c}\text { Second } \\
\text { choice }\end{array}$ & Third choice & Fourth choice & Fifth choice \\
\hline Undergraduates & $\begin{array}{c}\text { online } \\
\text { catalogue }\end{array}$ & databases & $\begin{array}{c}\text { electronic } \\
\text { references }\end{array}$ & $\begin{array}{c}\text { digital closed } \\
\text { reserve }\end{array}$ & E-journals \\
\hline Postgraduates & $\begin{array}{c}\text { online } \\
\text { catalogue }\end{array}$ & databases & E-journals & electronic delivery & $\begin{array}{c}\text { digital closed } \\
\text { reserve }\end{array}$ \\
\hline Academic staff & $\begin{array}{c}\text { online } \\
\text { catalogue }\end{array}$ & databases & E-journals & $\begin{array}{c}\text { electronic } \\
\text { references }\end{array}$ & electronic delivery \\
\hline Librarians & $\begin{array}{c}\text { online } \\
\text { catalogue }\end{array}$ & E-journals & $\begin{array}{c}\text { digital closed } \\
\text { reserve }\end{array}$ & databases & $\begin{array}{c}\text { electronic } \\
\text { references }\end{array}$ \\
\hline
\end{tabular}

The "OPAC" was the highest priority for improvement. One difference is that "E-journals" came second place from the perspective of librarians, while users thought databases were more in need of improvement. "Digital closed reserve" was third on the librarians' list but at the bottom of the users' list. Even for academic staff, "digital closed reserve" was ignored in favor of "electronic document delivery". "Electronic reference" was considered more important by users than by librarians.

\subsection{Summary}

In this chapter, data from the user and librarian surveys were interpreted as a basis for further comparative analysis and will be used in the next chapter for the testing of hypotheses. In the first part of this chapter (date analysis overview), Research Questions RQ2 - RQ6 were answered. In the second part of this chapter (i.e., 5.2 Comparative results), RQ7 - RQ10 were answered. 
Then the responses from three communities of undergraduates, postgraduates, and academic staff were compared. These user communities have different information needs as indicated by their different reasons for visiting the University Library website. There are clear differences between them in their frequency of using other services, perceptions of current digital services, and expectations of future services.

Users and librarians were also compared. In some cases, the key beneficiaries of a service are compared with the librarians. There are similarities between users and librarians in the importance of the services and most of their features. The librarians did not agree with users on some features, for example "availability of information about this service". There were obvious differences in satisfaction, future use and the order of priority of services that need improving. Generally, the librarians gave higher ratings to the statements in the questionnaires than users, particularly for some possible future services. 


\section{Chapter 6. Discussion of the Findings and Testing of the Hypotheses}

With the advent of digital services (e.g., OPACs, databases, E-journals, and electronic document delivery) and networked access to information, users do not have to be physically present in the library building in order to access the library's resources. Instead, more and more users now access online library digital services remotely. Moreover, the three categories of academic library users (undergraduates, postgraduates and academic staff) have different information needs and they make different use of information. Thus, it is imperative that academic libraries have the right kinds of content and delivery of digital services for their various user communities. By focusing on delivering the required information services, librarians can be proactive in developing a variety of access options that meet cost and efficacy criteria.

The purpose of the surveys was to assess users' and librarians' perceptions of some current digital services and future services to reveal users' information needs, preferences, and expectations and to identify any gaps between users' perceptions and those of the librarians. The analysis of the data and comparative results were presented in Chapter 5. In this chapter, some of the findings and issues that arose from the comparisons are analyzed; and four categories of hypotheses that were put forward from the research questions are tested; and then discussed.

\subsection{Different User Communities Have Different Opinions on Digital Services}

\subsubsection{Different user communities have different information needs}

The data analysis in Chapter 5 demonstrated that undergraduates, postgraduates and academic staff had different purposes for using information services based on their information needs (refer to Section 5.2). This finding 
confirms the hypothesis that different user communities have different needs for information, demonstrating that when organizing some services, libraries need to consider all kinds of information needs, especially the key beneficiaries' information needs. For services that are mainly used by one community, librarians need to focus on the special information needs and behaviors of this community to avoid wasting money and other resources.

As a case in point, the issue of considering special users groups' information needs was reviewed with a branch librarian. When asked, "Do you think it is necessary to provide some special services such as digitizing some collections for your branch?", the librarian thought that students doing some of the majors in her faculty were more in need of print versions of photos and pictures. Generally, the quality of copies from "databases" or "E-journals" is not ideal, so these users prefer print-based materials, although digitized materials could be used as thumbnail versions for information searching. According to the librarian, the information needs of students outside the main campus need to be considered. More computers with access to "E-journals" are needed for her branch library to provide its users with the same level of access to digital resources as the users in the main branch of Victoria University of Wellington (VUW) Library.

\subsubsection{Different user communities have different perceptions on the current digital services}

There were differences in the perceptions held by different user communities of current digital services in terms of frequency, importance, usefulness, future use and some other features among the three communities (refer to Section 5.2). This finding confirms that different user communities have different perceptions of the digital information services provided by the VUW Library. Generally, more academic staff were aware of the digital services compared to undergraduates and postgraduates, which is reflected in their frequent use of digital services. Similarly, academic staff considered the services more important than other user communities. Some services, such as "email reference", "online request forms", etc., have never been used by more than 
$70 \%$ of the undergraduates. It is important to note that few students know and use these digital services.

The ratings for the importance of the features regarding digital services varied across different communities. Overall, "convenient and easy access", "easy to use" and "useful information" were the most important features identified by academic staff and postgraduates. Different user communities have different opinions on the importance of the features of digital services. Postgraduates and academic staff were relatively more aware of the existence and use of digital services. They preferred advanced features of digital services, for example "the range of resources", "currency of information", etc., and they intended to make full use of the services. Undergraduates, however, emphasized access issues. "Accuracy of the information" was another important feature for undergraduates.

For delivery of search results from "databases" and "E-journals", all user communities preferred printing, followed by downloading. Compared to the other two user communities, undergraduates gave the highest ratings to printing. They were used to textbook-based studying and depended on paperbased materials. It is worth noting that more academic staff gave higher ratings to downloading or emailing compared with the students. The research materials used by academic staff include many kinds of resources and they are used to searching for information on the web. Postgraduates chose either downloading or emailing according to their needs at the time. For materials on their research topic, we can assume that postgraduates preferred to get results in electronic format in order to organize the large amount of information effectively. For assignments, students probably chose to print out the information.

The five selections for possible improvements to digital services highlight the demand for information services from different communities. The "OPAC" was the highest priority for improvement from the perspectives of all the user groups. "Email reference" was given a high priority by undergraduates, while 
postgraduates and the academic staff selected "E-journals" and "document electronic delivery".

Some comments were given with regard to improving the services to meet individual users' information needs. Some undergraduates commented on their lack of awareness and difficulties in using the services by suggesting that the Library should print booklets to explain how to use those services. Suggestions from postgraduates focused on access to some online services, the range of information provided, and the delivery of the retrieved data. Academic staff also commented on the specific delivery format of the data. They have considerable experience of making full use of library digital services. They hoped more convenient services would be developed to support their research and teaching. The more familiar that the users are with the services, the more specific and advanced comments or suggestions they put forward.

\subsubsection{Different user communities are not satisfied with the digital services to the same extent}

In general, users were satisfied with the range of digital services overall and found them helpful. It is not the same for individual services. From the data analysis, the hypothesis that different user communities are not satisfied with the digital services to the same extent is confirmed. Those services with fewer users got the lowest satisfaction. For example, "email reference" was used by $25 \%$ of the undergraduates, $20 \%$ of the postgraduates, and $10 \%$ of the academic staff. Correspondingly, $25 \%$ of the undergraduates, $23 \%$ of the postgraduates, and $11 \%$ of the academic staff were satisfied with this service. For academic staff and undergraduates, the most satisfactory services were the "OPAC" and "databases". Postgraduates, as key beneficiaries and frequent users of "E-journals", were more satisfied with "E-journals". 


\subsubsection{Different user communities have different expectations for future digital services}

The expectations of users are reflected in the ratings given to the three future services and some of their comments on the digital services, which confirm the hypothesis that different user communities have different expectations of future digital services. There are obvious differences among the ratings to three possible future services, as shown in Figures 17-19 in Chapter 5. "Current awareness", which can provide broad access to information, was given high ratings by academic staff in terms of "importance", "usefulness" and "future use". "Closed Reserve", which can help students obtain course materials quickly, was given higher ratings by undergraduates and postgraduates than by academic staff.

\subsection{There Are Relationships between Future Use of a} Service and Users' Satisfaction with the Service, and Between Future Use of a Service and the Rating of Importance of This Service

\subsubsection{The more important the service is, the more likely it is that users will use this service in the future}

In general, as the results from correlation tests demonstrated (refer to 5.2.1.7), there is a strong correlation between the perceived importance of the services and their future use. Variations, however, exist across different services and different user communities. The strongest relationship occurs in "online request forms" and "email reference" services, and the weakest is for the "OPAC" and "databases". For postgraduates and academic staff, there are no significant correlations for "E-journals". The motivation for using digital services stems from users' information needs. As long as users can retrieve useful information through this service, they intend to use it again and consider it important. For undergraduates, this relationship is slightly weaker 
than that for postgraduates and academic staff. Postgraduates and academic staff prefer the usefulness of information for their work to other factors, and this influences their decisions to use the services again in the future. Nonetheless, some other factors, such as satisfaction (to be discussed next), influence undergraduates when determining whether to use this service again. Libraries can still take some remedial actions to improve the usefulness of these services and influence the users' perceptions of the services' importance for information retrieval. By doing this, the libraries will increase the likelihood that the users will use the service again in the future.

\subsubsection{The more satisfied with the services the users are, the more likely they will use the service in the future}

The data analysis shows that there is also a strong relationship between satisfaction and the future use of services except for the "OPAC", where no obvious relationship has been confirmed. The most surprising finding is that no relationship is shown between users' satisfaction and the future use of the "OPAC": although users are not satisfied with this service they will still use it. In this case, their information needs and the importance of this service determine the users' future use of the "OPAC". The "OPAC", as a basic and indispensable service, cannot be rejected by users just because it is unsatisfactory. The "OPAC" is the only means of access to the library collection, making it indispensable.

The survey showed that undergraduates used digital services less frequently than postgraduates and academic staff, as their information needs are narrower. The relationship between satisfaction and future use of digital services tested among undergraduates is more obvious than for postgraduates and academic staff. It seems that the willingness of undergraduates to use the service in the future depends more on their satisfaction with the services and their current experiences of using these services. If some services are not satisfactory, it appears that undergraduates prefer not to try harder to use them, and they tend to explore alternatives. Satisfaction with the services depends on quality, which is reflected in the ratings of some important features. In order to 
improve users' satisfaction, some detailed improvements can be made regarding the features considered important by users. For example, the "OPAC" could link retrieved information to the electronic documents, databases or journals. Searching options could be strengthened for databases. The range of content and currency of the content in "databases" and "Ejournal" services were also addressed by users. The response time was the main feature to be improved for "email reference" and "online request forms".

\subsection{There Are Different Perceptions and Expectations Regarding Some Specific Digital Services between the Users and the Librarians}

\subsubsection{The level of users' awareness of some specific digital services will be lower than librarians thought}

The hypothesis is confirmed that users are not aware of the existence of digital services to the same extent as the librarians assumed. The users' awareness of services impacts on the frequency of use of these services. In other words, frequency of use results from the awareness of users. The "OPAC" and "databases" were used more frequently compared to other services. Postgraduates and academic staff use services such as "E-journals" and “online request forms" more. Seventy-eight percent, $74.9 \%$ and $63.6 \%$ of the users chose the option of "infrequently/not at all" when rating their frequency of use for "email reference", "online request forms", and "other selected Internet sources" respectively. Moreover, $83.9 \%, 75.2 \%$ and $67.2 \%$ of the undergraduates did not use "online request forms", "email reference" and "Ejournals" at all. Some reasons can be found in the answers to the open-ended questions. One third of the respondents said they did not know some services exist nor how to use these services. Therefore, it is important to rectify this lack of awareness. In fact, the librarians were not aware that users felt there was a lack of information about the digital services. Users' and librarians' answers show that there is a need for some promotion of the digital services to improve awareness of the services and how to use them. 
When answering the questions, "Do you think the library has done enough promotions for its services?" and "How can the library make users fully aware of the existence of the services and their use?", the librarians thought that this was an area that needs addressing. In the opinion of Interviewee 5, part of the drive for promotion work is to ensure the availability of the library resources and the usability of the library. According to Interviewee 5, the library has spent $\$ 4.25$ million on the new resources and \$1 million on marketing, yet many users still don't know about the services and how to use them. Promotion is obviously a challenge for university libraries. The VUW Library does have some promotion strategies, for example advertisements, brochures, tutorials, etc. Liaison librarians have one-on-one sessions with users in order to introduce new services and information to them with the aid of subject pages and teaching programs. However, as Interviewee 2 said, a library can always do more promotion work to publicize the resources. The library needs more helpful training programs for users and to encourage users to use the resources more. Interviewee 2 also suggested that libraries could distribute an information package about the library and its services, develop the work of the help desk, and provide online requests for reference services.

\subsubsection{Users have different perceptions from those of librarians on the current delivery of the digital services}

The digital services considered important by users differ slightly from those favored by librarians. Some services, for example "databases", "online request forms", "E-journals" and "email reference", are not thought as important by the users as they were by the librarians. Users used the services infrequently or never, and therefore have not experienced the benefits of these services. This inconsistency may suggest that, although the librarians thought that provision of digital services is responding to the real needs of the users, this might not be the case.

There are three main factors affecting a library's allocation of resources to digital services. The first one, which was mentioned by every interviewee, is 
finance. "How much money does the library get?" is a big question. Interviewee 2 thought that the money allocated to the library was never enough for print materials and even less sufficient for digital services. The VUW Library Digital Service Group budget for buying electronic materials is operational and therefore cannot be depreciated. Interviewee 4 pointed out that if the Library stopped subscribing to electronic resources for whatever reason, access to the past issues that it had paid for would be lost. Thus, with the digital resources the Library has nothing to be depreciated. The Collection Services budget for hard copies, for example monographs and journals is classed as capital because physical materials can be depreciated. Thus, as Interviewee 2 observed, the level of funding for digital services, which is less than for print collections, is insufficient. Funds cannot be transferred from capital to operational expenses. Interviewee 1 said that if the Library got an online version of an item, it could not cancel the printed one to pay for it. This is one big hurdle that needs to be overcome if print and electronic resources are to work well together in the "hybrid" library environment. It is also very important for the Library to determine where the budget allocation is needed and which is the best way to spend it. These decisions depend on which kinds of materials are available to be provided online and what the practical needs are of the various disciplines. Interviewee 5 stated that one of the branch libraries in VUW spent about half a million dollars a year on new content. That is because the nature of the subject requires high use of the Library. Staffing is another issue that should be taken into consideration. The more digital services the Library implements, the more library staff are involved in managing and maintaining the subscriptions, troubleshooting service breakdowns, and managing the licenses of the electronic resources.

One more external factor, according to Interviewee 5, is the way in which the publishing market works. Some electronic resources are tied-subscription, that is, the only way the library can get them is to buy the hard copies as well. Some other electronic resources come from aggregate buying, in which different items are joined together. This means that if you need only one, you must order the whole group, and the library cannot choose what it wants. It is not practical for every digital service thought important by users to be 
implemented. Some users still want print-based materials. Interviewee 3 gave the example that some students preferred interlibrary loans instead of Ejournal articles so that they could hold them and photocopy them.

The ratings of the importance of the features of digital services vary across different communities. However, "easy to use" and "convenient and easy access" are the most necessary features according to both librarians and users. An obvious difference between users and librarians exists for "availability of information about this service" and "availability of some training". Users did not think these features were as important as the librarians thought they would.

According to the librarians, the "OPAC" failed to meet the users' needs. The OPAC system used in the VUW Library did not have a web interface at the time of this research and users felt confused when searching for "E-journals" and "online databases". Since the "OPAC" cannot provide direct access to some of the library's online resources, users may give up looking for those items. An IPAC ${ }^{15}$, on the other hand, can link directly to online documents from "databases" or "E-journals". In the librarians' opinions, searching options and terms are the main difficulties for users in the process of searching "databases" or "E-journals". They feel that a lack of searching knowledge and skills, improper searching terms, and dispersed database lists on the library website are the reason for users' difficulties.

Access issues were repeatedly mentioned by the users. One of the key issues in the provision of access to online services within the Library is the number of PC workstations. There are often problems with the hardware, software and the network. Another issue is that the Library needs enough staff available with a sufficient level of knowledge and skills to solve problems for users.

Access was also mentioned by librarians when talking about "databases" and "E-journals". The survey and interview data suggest that there is a confusing means of access to "E-journals", which is an issue for users. This confusion

\footnotetext{
${ }^{15}$ Internet Public Access Catalogue
} 
results from the lack of a tidy and comprehensive catalogue or access page for the "E-journals". Users also gave high ratings to the importance of the range and currency of "databases" and "E-journals". One senior librarian commented in the questionnaire that the coverage and off-campus access to "databases" and "E-journals" needed to be expanded. In the interviews, the librarians mentioned that the range of "E-journals" to which the Library subscribed was not broad enough, and that the number of "E-journals" was quite small. One reason they gave was that the Library couldn't afford all the "E-journals". Some full-text E-journals are on databases; some are a part of a print subscription, that is, free-with-print or tied subscriptions; and others have no equivalent print version. The Library has not purchased individual "Ejournals" since publishers often sell a whole package of "E-journals" together. Another reason given by the librarians was that some print journals do not have electronic versions so that sometimes users are wondering which journals are available online.

With regard to databases, the librarians recognized that the users' levels of skills influence their searching in terms of how to choose an appropriate database and how to choose specific searching terms. Interviewee 4 pointed out that databases had a variety of structures, which could confuse the users. She also observed that some databases permitted users to limit their searching beforehand and some after getting the results. Help or instructions from the Library on how to use these digital services were considered important by both users and librarians. Interviewee 3 emphasized that the Library must cater to many users who may be technically ignorant. However, some difficulties that users encounter cannot be overcome by the efforts of the Library alone. Many aspects of databases are controlled by the database providers rather than libraries.

Another issue is the preferences for various delivery forms of search results. Users preferred printing them out while librarians had some reservations about this, though they recognized that it was convenient for both users and librarians. Compared with a paper-based environment, librarians spend less time sending out information. Users can download or access electronic 
documents by themselves. One librarian, however, commented that electronic delivery needed to backup results from searching and be supported by advanced computers. Emailing search results from databases or E-journals also involves the issue of copyright. The librarians cannot guarantee that users only use the photocopied or scanned materials in the way permitted by copyright. Moreover, as Interviewee 1 pointed out, the Library needs more staff to photocopy or scan the materials according to users' requests.

The users' selections of services for improvement highlight the various needs for information services from different communities (see Table 14 in Chapter 5). When selecting and rating the five services that should be the focus of the Library's attention for improvement, both users and librarians agreed that the "OPAC" was the first priority. There are significant differences in the other selections. "Databases" received a higher priority than "E-journals" from the perspective of all user groups, probably because "E-journals" are not frequently used, and users have correspondingly fewer insights into them. This finding may suggest that databases are troublesome services for users, and that these difficulties are not addressed by the librarians. A possible reason for the differences among the last few services is that users are not familiar with some services so they did not give them much consideration. Librarians, on the other hand, consider them important based on their professional knowledge.

\subsubsection{The percentage of users who are satisfied with the performance of the digital services is different from that of librarians}

An interesting finding was the fact that both users and librarians gave high ratings to overall satisfaction at the macro level. Seventy percent of the users and half of the librarians are satisfied with the digital services.

As for satisfaction at the micro level, there are noticeable variations, which confirms the hypothesis that the percentage of users who are satisfied with the performance of the digital services is different from that of librarians. Users were not satisfied with some services such as "databases" and "online request forms", while librarians thought these services had a satisfactory performance. 
The satisfaction ratings from users and librarians are the same for "other selected Internet sources" and "E-journals". It is reasonable to assume that, when implementing and providing these two services, librarians have considered the important features of the digital services in order to satisfy users. The satisfaction has not only resulted from the quality of the services themselves but from facilities used to deliver the services as well. Interviewees 2, 3 and 4 all said that facilities in the library needed to be improved. They suggested that more PC workstations needed to be installed in the library. The librarians pointed out that, although users can access the resources remotely, most of them still come to libraries in person. If many people do lengthy catalogue or database searching, users need to queue for their turn. As Interviewee 2 pointed out, it is ironic that users can have less access within the library than outside the library. The Information Technology Services department manages and maintains the machines and facilities for the Library. Sometimes, negotiations and communication between the library and ITS can influence the speed at which technical problems are fixed. Thus this problem also affects the users' satisfaction with the digital services.

\subsubsection{Users' expectations on the importance and usefulness of future digital services differ from the expectations of librarians}

Users and librarians had significantly different opinions regarding "current awareness services" (CAS). Users, especially academic staff, gave high ratings to its importance and usefulness, and they support the implementation of this service. Librarians gave relatively low ratings for the following reasons. Firstly, this service may mislead users into thinking that the librarians can do research for them. Almost every interviewee mentioned that the focus of an academic library was to give the content and description of information and not to deliver the information research results. Interviewee 5 conducted that the mission of academic libraries was not only to support the learning of the students while they were at universities, but also to equip the students for life long independent learning. Reference librarians concentrate on giving people tools to find the information instead of finding the information for them. Interviewee 4 thought that although CAS was helpful, it was not worthwhile 
for an academic library to invest time in this and it was better to direct energy into user education and patron empowerment. Both Interviewees 2 and 4 believed that the second reason for the relatively low ratings was because this service has high costs in terms of time, energy and staff. According to Interviewee 1, an academic library does not have enough staff to provide this service, as well as training the librarians to find research interests for academic staff and select information for them. As observed by Interviewee 5, the situation is different in corporate libraries, where users are always busy with their work and librarians proactively send the information to them by providing CAS.

"Virtual reference service" is a new concept for users. This service, which was mentioned earlier, uses videoconference or chat room for online reference between users and librarians. Around $30 \%$ of the users agreed on its importance and usefulness. Users' interest in this advanced service will inspire them to see how this service works when it is provided. Some postgraduates were concerned about the staffing of the service. One commented that "virtual reference" would need more librarians and limit the number of librarians available to the public at the helpdesk. All the librarians agreed that this was a good service, especially for external students and for those universities with several campuses and few reference librarians. This service is useful for users who have knowledge of new technology or are used to changes in technology. They can ask questions from home and receive answers in due course. However some overnight shiftwork is involved in providing nonstop reference services. It is a demanding service because it requires powerful machines and huge bandwidth. According to Interviewee 1, even under ideal conditions, this service would not be implemented quickly because considerable time would be spent on technical issues. Interviewee 1 also commented that it was also difficult to ensure congruence between the users' expression of their questions and their actual problems, and librarians' understanding. Sometimes the writer's thoughts are not the same as the words typed. Moreover, some commercial virtual reference services available via the Internet and video camera only give the answers instead of how to find the answers, which is not helpful for users' education in the long term. A key function of an academic 
library is to teach users how to find the resources and improve their searching skills.

Users in each group (undergraduates, postgraduate and academic staff) consistently agreed on the "importance", "usefulness" and "willingness to use an electronic closed reserve service". One problem with closed reserve identified by Interviewee 1 is that sometimes students cannot find the items if libraries are not told by academic staff which materials related to their course should be put into closed reserve. Interviewee 3 thought that it was also a good chance to teach users how to look for information from other resources when thousands of users competed for the limited materials. He suggested that users should be encouraged to learn to study and think by themselves. He added that users could also find the same standard answers to questions as those from closed reserve materials. Interviewee 1 introduced that there was already an online closed reserve service in the current OPAC system. If a book is at the closed reserve desk, users can check its status (availability time) and then book it for themselves online. However, this service does not work well without enough customers. Many users do not know this service exists and still complain about the inconvenience of closed reserve. The librarians hoped the new web-based catalogue would give easy and simple access to online closed reserve.

\subsection{Some Other Findings}

The discussion in this section highlights any significant findings not directly related to the testing of the hypotheses but that will help to understand users' needs, preferences, perceptions and expectations. From the two open-ended questions in the last part of the questionnaire, the researcher realized that users' experiences would influence their assessments and evaluations of the services.

Some users gave examples of their experiences to show which areas they were not satisfied with and which were worth improving. Fifty users made recommendations as compared to the 231 users who had "no opinions" or did 
not make any recommendations. Users' comments cover the "OPAC", "databases", and "E-journals", and deal with features such as access, help or training, range of content and the currency of the content. The respondents gave many commendations related to the online request form service and the work of the librarians. They thought the tutorials and help from the library staff were useful and that interlibrary loan service using emailed request forms is well run, giving fast responses and providing useful information.

The high number of students who had "no opinion" was noticeable. This can be attributed to the fact that because the students were not familiar with the library provisions they have used, they were unable to make the informed responses. Another possible explanation is that users found the survey questionnaire repetitive and the topic was of no interest or significance to them. A large percent of users, especially undergraduates, did not attempt to respond to the two open-ended questions which were an opportunity for them to express what could be done. Several reasons are provided here as possible explanations. It is possible that the students were too satisfied with specific digital services to make any recommendations; they may have been satisfied with the existing provisions the Library made for suggestions; or they may have thought their suggestions for improvements would fall on deaf ears so that it did not matter whether they wrote down some recommendations or not.

\subsection{Summary}

In this chapter, on the basis of statistical results and comparisons in Chapter 5, some findings from the survey were discussed. The hypotheses involving some different opinions on digital services between different user communities, and between users and librarians were confirmed. The hypothesis of relationships between future use of a digital service and users' satisfaction with this service, and rating of importance of this service was also tested and confirmed. The possible reasons and explanations for some issues resulted from the hypotheses were given from the follow-up interviews with the librarians. Finally, some other findings from the questionnaires not relevant to the hypotheses were summarized. Further conclusions and 
suggestions for the improvement of digital services in an academic library will be discussed in the following chapter, which is the last one. 


\section{Chapter 7. Conclusions and Recommendations}

This chapter draws the report of this research project to a close. Chapters 1 through 3 introduced the research problem, the relevant literature and the methodology. Chapter 4 provided a description of the digital services offered by the Victoria University of Wellington (VUW) Library that were the focus of this research. The findings from Chapter 5 indicated that some differences exist with regard to the preferences, perceptions and expectations between different user communities and librarians. Chapter 6 further reinforced the differences by testing the hypotheses and by explaining the reasons for the differences. This chapter gives the conclusions of this research and provides recommendations, drawn both from the interviewees and from observations related to the research findings, for improving the digital information services offered by academic libraries. This chapter also highlights the theoretical implications of this study, addresses the limitations, and includes recommendations for future research.

\subsection{Summary of Key Findings}

The VUW Library, like a typical academic library, is now in transition from a traditional physical library to a hybrid one with online information resources and services.

This study of different preferences for digital services among users and librarians highlights the importance for academic libraries to address the specific information needs and preferences of their different user communities. In general, the respondents in this study were satisfied with the digital services at the VUW Library and found them useful and important. However, when the responses from undergraduates, postgraduates and academic staff were compared, there were some noticeable differences. For example, these three user groups had different reasons for visiting the library website: undergraduates visited it primarily for information related to their assignments; postgraduates visited it to search for library resources related to their research; 
academic staff used it to look for literature related to their interests or latest developments in their fields. Academic staff and postgraduates used digital services more frequently than undergraduates. "E-journals" and "online request forms" were thought more important and useful by academic staff and postgraduates than by undergraduates. Undergraduates and postgraduates preferred document delivery by printing, while academic staff preferred downloading. As to future digital services, postgraduates and academic staff gave higher ratings than undergraduates to the importance and usefulness of "current awareness service". "Electronic closed reserve" was the preferred future service for undergraduates and postgraduates.

This study also found that differences exist between the users' and the librarians' perceptions and expectations related to the digital services. For the users, the "OPAC" and "databases" were the most important services and were likely to be used heavily in the future. The users, in comparison to the librarians, felt more satisfied with "databases", the "OPAC" and "other Internet sources". Librarians thought more highly of the importance of "Ejournals" and "databases". The importance of the features of the digital services was not the same for users and librarians. Users gave a higher rating of importance to "convenient and easy access". "Availability of information about the digital services" was thought important by more librarians than users. Of the possible future services, librarians preferred "virtual reference", while users preferred "electronic closed reserve".

This study also found that strong correlations exist both between users saying that they would use a service in the future and the importance they attributed to that service, and between users saying that they would use a service in the future and their satisfaction with that service. However, the OPAC stands out as a specific case in terms of these two correlations. Users' dissatisfaction with the OPAC did not affect their intention to use the service again. This anomaly likely stems from the users' dependence on the OPAC as a key resource for their learning, teaching and research needs. In fact, users have no choice but to use the OPAC, so even when they are dissatisfied with it, they will intend to use it in the future. 
In general, although the VUW Library is making a strong effort to satisfy users' needs, its range of current digital services overall is not fully responsive to the needs of the users. Since the objective of academic libraries is to serve all user communities, university libraries should consider how to deliver satisfactory services for the range of users they serve. From the users' and librarians' assessments and evaluations of digital services, the reasons for the barriers in implementing digital services were identified and analyzed in the previous chapter. Some recommendations are made in this chapter for improving the services to meet the identified information needs and the preferences of different user communities.

\subsection{Issues and Recommendations}

The main objective of this research is to make recommendations for the improvement of digital library services. A number of approaches can be taken to help bridge the gaps of preferences, perceptions and expectations between users and librarians. First of all, before setting up any digital services, libraries must identify the needs and preferences of the user communities. There has been some discussion of the necessity to better understand and define the needs and expectations of library users to provide appropriate kinds and levels of service. The basic principle should be that the delivery of digital library services must satisfy users' needs. Below, some problems related to the provision of digital services are identified and recommendations for resolving the problems are made.

\subsubsection{Awareness of the Services}

It is important to improve the users' awareness of the services because this is an area that will determine whether users make full use of digital services. As found in this study, unfamiliarity with the digital services results in low frequency of use and dissatisfaction. The amount of use of academic libraries is influenced heavily by users' perceived importance of the services, their satisfaction with the services, and their familiarity with the library and its 
resources. Those who think more highly of the digital services and are more familiar with the library are more likely to use digital services frequently. If usage is to be increased, it is important that libraries find ways to familiarize users with the digital services. Promotion of those services needs to be addressed.

The librarians who were interviewed made a range of recommendations to increase user' awareness of the digital services. A recommendation made by Interviewee 1 was to create brochures for users, such as "How to use the catalogue" and "How to use the library resources". Porter (1998), similarly, said that the library needed to be more proactive in publicizing its services to the user communities to improve users' awareness. Another recommendation made by all the interviewees was for university libraries to consider setting up tutorials for all user communities, especially new students. Heaps (1998), in the case study of the University of York, recommended that the way to improve the users' awareness was by demonstrating library skills. A third recommendation, made by Interviewee 3, was to encourage people to use the resources more and to stimulate their interest in learning how to use the services by distributing information packages and introducing library online information services. Interviewee 2 said that liaison librarians have provided one-on-one contact services for users and have maintained a frequent users list in order to introduce new services and information to those users. Another recommendation was for librarians to go to lecture sessions, tutorials or meetings to teach students and academic staff how to use online resources.

However, a range of issues needs to be resolved before these recommendations will produce benefits. For example, Interviewees 3, 4, and 5 pointed out that the users need to be realistic about what a library can and cannot do for them and then they can come to the library for appropriate assistance. The interviewees also pointed out difficulties with promoting library services. Interviewee 2, for example, commented that it was hard to promote new services to those students who had not yet needed the library's resources for their studies. He also mentioned that some postgraduates and academic staff were busy and could not make time for training. Interviewee 1 
mentioned that users in different disciplines also had different information needs. For example, students in history or psychology are heavy users of library services, so they also tend to use online services. However, this is not the case for science students. Interviewee 1 also pointed out that, although librarians should go to lectures and tutorials to teach students how to use online resources, there were not enough staff available. Moreover, he added that some lecturers were reluctant to put aside a teaching session for library instruction, and that the librarians were not used to teaching students. Interviewee 2 recommended, therefore, that lecturers or tutors needed to talk about how to use online services when they gave the assignments to their students.

Recommendations: The VUW Library can improve users' awareness of digital services and resources by undertaking the following actions:

- Creating brochures to introduce how to use library services and resources;

- Setting up tutorials for all the users communities, especially new students;

- Librarians, lecturers or tutors teaching students in lectures or tutorials how to use online services through lessons directly related to their assignments;

- Encouraging users' interests in learning the use of online services by information packages and the promotion work of liaison librarians.

\subsubsection{Access}

Access to resources can be considered a vital criterion when evaluating satisfaction with a library's services. As the findings from the user survey in this research demonstrated, the VUW Library users accessed the digital resources from a range of locations. Consequently, it is important for academic librarians to address the needs of their user communities by networking the library's services and resources so users can easily access them anywhere and anytime. 
Easy access applies not only to the networked resource environment but also to the interface to the resources and the reliability of the related hardware in the library (i.e., computers and servers). From the survey data in this research, "easy access' is one of the important factors influencing the use of digital services from the users' perspective. Ferguson and Bunge (1997) suggested that libraries needed to provide direct access to their electronic resources. Thus, the VUW Library needs to ensure that its resources and services can be reached quickly via minimal links from the first page of the library website and they should appear under obvious headings or categories.

Recommendations: It is important for the VUW Library to require a minimal number of links to online services on its websites. The Library also needs to network its online services so that users can access them as easily as possible from anywhere and at any time.

\subsubsection{Currency of Information}

Libraries have a responsibility to keep their own information and the information related to their information resources up-to-date. Outdated information on the website makes a negative impression on users. Responses from the questionnaire survey show that some users thought the VUW Library did not keep the information on its website up-to-date. The process of

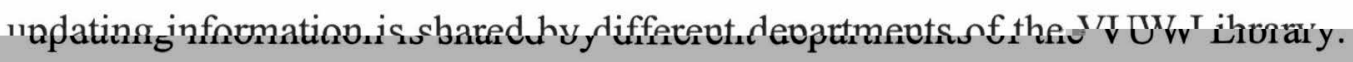
Interviewee 4 stated that the Digital Services Group and the Library Web Manager post information on the website, and the content is provided by different departments of the library. According to Interviewee 4, the Digital Service Group makes sure the information is consistent with the house style and puts the new information on the web. She pointed out that the responsibility of the various departments in the Library is only to change their information regarding their staff or policies. In addition, various liaison librarians keep the information on the subject pages up-to-date by working through them every day, and Collection Services plays a role in updating the textual catalogue information and access points. For example, they check the text of catalogue records to make sure there are no spelling mistakes. 
Interviewee 4 also commented when there were broken links to resources on the Library website, the Library reported them to the service providers and had to wait for them to be addressed. Interviewee 1 suggested that students who find errors or broken links could contact librarians by email and that their actions would help solve the problems.

Recommendations: The VUW Library needs to make a concerted effort to keep its digital information up-to-date. It should also collect users' feedback on online services and report the problems (e.g., broken links) to service providers. Meanwhile, students should be encouraged to assist the Library by reporting to the librarians any errors and broken links in the digital resources as soon as they find them.

\subsubsection{OPAC}

The online catalogue (OPAC) received negative responses related to its lack of functionality. From the comments of interviewed librarians and surveyed users, users cannot get direct access through the catalogue to E-journals even though they are available online. Several librarians in the questionnaires indicated that a new online catalogue called the IPAC would be introduced in 2002 to resolve the problems of the $\mathrm{OPAC}^{16}$.

Interviewee 2 and Interviewee 4 provided details about the new IPAC. Firstly, the IPAC is more user-friendly than the OPAC. The IPAC's web interface is more appealing than the command interface of the old OPAC. Additionally, if users log in from outside the library or university, they do not need to use the passwords and pin numbers currently needed by the OPAC via telnet. The second improvement is that the IPAC is far more functional than the OPAC. According to Wakeling (1999), when OPACs are moved to a web base, libraries can add selected Internet resources to the catalogue to extend the reach of OPACs. The VUW IPAC, according to the interviewees, can provide direct links to a range of online resources. When the resources are held or 
subscribed to by the library, users can go directly to the web site instead of copying and pasting the URL into a browser. If the resources are not held by the library, users can utilize the interlibrary loan service by clicking the relevant links. Another improvement discussed by the interviewees is global searching for words instead of traditional title keywords or subject keywords searching. The search looks for materials in all parts of the catalogue records. It is also easy for users to fill in the boxes on the web-based interface. However, Interviewee 4 suggested that users might still need to go to a user education session for clarification about selecting search terms. Finally, Interviewee 4 stated that it would be possible with the IPAC to export search results directly into programs such as Endnote. This feature allows users to easily save bibliographic information into software that will allow further manipulation.

Recommendations: When implementing highly functional web-based IPACs, the VUW Library should provide instructional resources to inform users about the range of functions available and how to use them. The Library should also provide direct links via the IPAC from records in its catalogue to digital resources that it holds or subscribes to.

\subsubsection{Issues with Databases}

From the comments given by the users and the librarians, the users' first difficulty in searching databases is how to choose the right database. The VUW Library website has three database pages with different database lists. One is the general database page on the Library website. One is on the students' portal for remote access and the other is the database page used in the database searching areas in the Library. The solution to the diffusion of database information, given by Interviewee 2 , is to combine the database pages and incorporate database information into the catalogue system with links to the databases. A different solution is to establish lists of databases subdivided according to their subjects. Interviewee 4 took a different tack,

${ }^{16}$ When the author was completing this thesis (July 2002), the VUW Library implemented an
advanced IPAC, which, from the author's personal observation, was winning positive 
acknowledging that the liaison librarians have done a wonderful job in helping users choose relevant databases on the subject pages of the library website by dealing with specific areas and telling users which databases are best for them.

The survey data also show that users have difficulties in defining the terms they wish to search for or in finding useful search terms. Without appropriate search terms, either too few or too many results will be found. Databases have a range of structures with different ways to do complicated searching. Interviewee 2 said tutorials or similar teaching sessions could be a good way to teach information searching skills. However, he also pointed out, although such tutorials were held regularly, they were not well attended. He pointed out that it only occurred to users to get help from librarians when they encountered difficulties with their assignments. Interviewee 1 suggested that it was a good idea for lecturers to explain to users how to use databases that were related to their subject areas and relevant to their assignments. Interviewee 4 suggested setting up online help on the website covering frequently asked questions and some common topics for databases as it was convenient for users to refer to such aids while searching for information.

According to Interviewee 4, other problems that should be addressed include a lack of cross-references in the databases' search results, excessive jargon used in database searching, and search rules that are difficult to understand. Also, search results are sometimes slow to appear because of network or Internet traffic loads, and users are not sure whether it is easier to print out the results or to email them. Although libraries cannot themselves resolve all these database problems, they can collect users' feedback on searching and pass it on to the database providers.

Recommendations: The VUW Library needs to combine different database list pages and incorporate database information into its catalogue system by providing some links between catalogue pages and database lists pages in order to make it easier for users to select an appropriate database. Lecturers at 
VUW should be encouraged to explain to their students in lectures or tutorials how to use databases related to their assignments. In addition, online help for databases, including how to select search terms, should be provided from the VUW Library website.

\subsubsection{Issues of E-journals}

The issues of E-journals are generalized into several points from the comments of surveyed users and interviewed librarians. The first important issue, which reflects the concerns of users, is the somewhat limited range of Ejournals. Users in various disciplines commented that the range of E-journals needed to be increased to satisfy their needs. One reason for the limited range is that the Library cannot afford all the E-journals. The high cost of E-journals was an issue for all the interviewees. Another reason for the limited range of E-journals given by Interviewee 2 is that the Library cannot select individual E-journals because most of them come within databases, or with tied subscriptions $^{17}$, or as a part of a package. On the other hand, Interviewee 3 said that the range of E-journals found by a user depended on how the user searched for them. The E-journals are not all listed in the Library catalogue and many users do not know that E-journals can be found elsewhere. If the users go to the liaison pages, they can find the specific E-journals related to their disciplines.

Cost and demand are the main considerations for libraries in deciding to which E-journals they should subscribe. Interviewee 3 pointed out that group discussions on current resources of libraries and user needs led to the provision of more E-journals. Interviewee 2 observed that consortium arrangements play a significant role in electronic resources, especially databases and E-journals. The VUW Library's consortia activities occur as a result of membership in CONZUL (Council of New Zealand University Librarians) and CAUL (Council of Australia University Librarians).

\footnotetext{
${ }^{17}$ Some E-journals are parts of print subscription (free-with-print or tied-subscriptions). A library subscribes to a print journal and as a part of the package it gets the online version free. If the library cancels the subscription to the print journals, it will lose access to the E-journals even though it has paid for the past issues
} 
The second issue mentioned by users is making sure it is easy to find which Ejournals are available both on site and off site. The VUW Library has a master E-journal list that is now obsolete because it is too large to maintain. So the library breaks the full master list down into subject lists on the subject pages. Interviewee 2 suggested that the E-journals information should be incorporated into the web-based catalogue to provide clear and direct access. Conversely, Interviewee 4 thought it was reasonable that some E-journals selected by liaison librarians only appeared on the subject pages instead of in the main catalogue. She said the OPAC only focused on the collection the library had paid for or acquired through managed collection development.

The third issue identified by the interviewees is the users' skills in searching for E-journals. Based on comments made by some of the librarians interviewed, it is important to bear in mind that users' searching skills influence their search results. Several interviewees recognized that it was important to make the users familiar with E-journals, and that library information sheets can tell users how to make full and efficient use of this resource.

Interviewee 3 identified another issue observing that in the information about E-journals it was necessary to show whether those journals had full text or just abstracts and whether it was possible to download graphics from the Ejournals.

Recommendations: The VUW Library should attempt to increase the range of required E-journals as much as possible. When choosing which E-journals to provide, it needs to adjust the balance between cost and demands. The Library also should try to make full use of consortia to select and subscribe to valuable E-journals. Information sheets to introduce searching skills also need to be published by the Library for its users. For the VUW Library, the master E-journal list needs to be updated to include more detailed information (e.g., whether an E-journal has full text or just abstracts, and whether it is possible to download graphics). The E-journal information needs to be incorporated 
into the web-based catalogue, and from that information the users should be provided with direct access to the E-journals. Even if the E-journals to which the Library subscribes cannot be shown fully inn the catalogue, some crossreferences (e.g., see, see also) need to be created in the catalogue to encourage users to look for specific E-journals by referring to subject pages.

\subsubsection{Future Services}

\subsubsection{Virtual Reference}

Both users and librarians gave the lowest ratings to "virtual reference". Most interviewees commented that there were difficulties in implementing this service in academic libraries. Interviewee 2 pointed out that "virtual reference" based on videoconference technology requires high costs, powerful machines and librarians who are constantly available, so it may not be an efficient use of resources. He also suggested that it is much easier to telephone or email users to answer their questions. Currently, the University Library provides an "Ask a Reference Librarian" service by using a web form for email. Users often get the answers on the same day or the next day. Hanson (1998) suggested this type of service and considered that libraries needed to clarify the definition of this service for users in terms of the type of enquiries, the response time, and the libraries' responsibility for this service.

Recommendations: It is not advisable for the VUW Library to implement a virtual reference service. The current “Ask a Reference Librarian" service meets the needs of users.

\subsubsection{Closed Reserve}

Most of the librarians who were interviewed thought electronic closed reserve worked well, although it has staffing and copyright issues. There is often greater demand than supply for some reserve materials. Fountain (2000) stated that paper-based reserve materials is a nightmare both for the circulation staff trying to regulate use, and for the frustrated student who is unable to check out needed materials. He recommended electronic reserve software by which users 
could locate materials, read a full-text copy, save the items to their disk, or print out a hard copy. Booking closed reserve materials online is already available on the Library's current OPAC. Students can see the timetable online to find out when the materials will be available, and can reserve a time. However, Interviewee 1 stated that few students know about the existence of and how to use this service. She suggested that it should be given a prominent place in the new web catalogue. In addition, more information about when the closed reserve materials are available and how many people have booked the materials needs to be shown. The users will then know when the materials will be available and they can choose whether to add their names to the waiting list.

Interviewees suggested that photocopying and emailing are useful alternative methods for delivering closed reserve materials if libraries can get copyright permission for reproducing the reserved materials. However, for individual libraries, the cost involved in obtaining copyright agreements can be very high. Consortium involvement may be helpful in order to reduce spending on intellectual property.

Recommendations: The VUW Library should give the online reservation service for closed reserve materials a prominent place in the IPAC with detailed booking information. The Library should seek consortium involvement for the acquisition of electronic reserve software and the resolution of copyright issues to provide full-text reserve materials online.

\subsubsection{Current Awareness Service (CAS)}

CAS is probably useful but all the interviewees thought that it was not worthwhile for an academic library to invest time in it because this service requires too much money, time and energy. Interviewee 1 thought academic libraries did not have enough staff to carry out this service for all users, so its value was limited. On the other hand, the business of an academic library, according to Interviewee 4, is to tell people how to find materials rather than always giving it to them. In this sense, CAS is not consistent with the purpose of information services offered by academic libraries. 
Interviewee 2, who made the following observations, suggested that an academic library could provide access to similar services from other providers. These providers will email users their search results automatically every week according to the profiles on the system set up by the users. He also put forward that there had been little demand for this service in the VUW Library. Many people seem to develop their own ways to keep up with the literature. Another service a library can provide is to notify liaison librarians when new materials arrive and they, in turn, pass the information to their patrons working in those areas. Hanson (1998) thought this proactive service was helpful to encourage users to use libraries' resources.

Recommendations: It is not advisable for the VUW Library to implement CAS. Liaison librarians should provide some alerting services to notify the patrons about new resources and services.

\subsubsection{General Issues Related to Digital Services}

\subsubsection{Positive Factors Influencing Academic Libraries to Adopt Digital Services}

Fountain (2000) realized that many libraries would like to adopt digital services and acquire electronic resources as a result of the development of the Internet and networked technology. One of the reasons for adopting digital services given by Interviewee 1 is that digital services are more convenient for users than hardcopy materials. She observed that more and more people were used to advanced technology and were now comfortable with digital services. Thus, a big incentive for adopting digital services and increasing their funding is that users are now expecting to be provided with digital services.

The second reason for adopting digital services is that it is also more economic to provide online resources rather than to buy hardcopy materials, though this view is controversial. Lin (1997), in her thesis concerning the impact of information technology on library organizations, explained that internal and 
external environmental pressures forced academic libraries to adopt digital services and the economic factor is one of the most important internal environmental pressures. Improvements in technology should mean that large online services could be provided at a relatively low price. However, Interviewee 2 pointed out that the hardware and software involved in digital services were not as cheap as had been expected. Therefore, the main advantage of digital services is accessibility for all students and staff, especially distance students.

Another important factor is that university libraries in New Zealand can cooperate with each other or with universities overseas in the purchase of online resources. One incentive for this cooperation is that resources such as electronic databases are so expensive that they only become affordable by sharing costs. A second incentive is that sometimes the number of users in one university is too small to justify the subscription. Libraries can get the best resources for the least cost by joining consortia. According to Interviewee 4, university libraries in New Zealand have been cooperating for the last 15 years in the purchase of expensive services.

According to Interviewee 1, a final factor encouraging the VUW Library to adopt digital services is that libraries need to keep up with technological developments. According to Interviewee 3, libraries do not want to see themselves lag behind others, and instead, they want help their institutions to attract more students and researchers by providing advanced library services. Interviewee 1 observed that currently users of academic libraries felt comfortable with the technology and were used to online information and services. However, she commented that, if users cannot obtain information conveniently with the aid of modern technology in the library, they would turn to other information sources to meet their information needs.

Recommendations: The VUW Library and other New Zealand academic libraries need to consider the financial and technical advantages listed above for adopting digital services. By taking a user-centered perspective and cooperating with each other in a consortium, academic libraries can improve 
current online services and introduce new ones targeted to the specific needs of their user communities.

\subsubsection{Negative Factors Influencing Academic Libraries to Adopt Digital Services}

The factors that prevent libraries from adopting digital services are also worth considering. Funding is a major problem that constrains libraries from improving current services and adopting new services, a view that was repeated by all the interviewees. Interviewee 2 thought the implementation of digital services involved relatively high costs for software and hardware.

Some other obstacles in implementing digital services were also considered by the interviewees. Whether some resources are suitable to be online was the first issue to be considered. Interviewee 1, working in a branch library of VUW, thought it was worth thinking about whether some materials needed to be available online in specific disciplines. For example, the students in some disciplines need good quality illustrations, citation indexes and full-text articles. However, graphics do not always reproduce very well in electronic formats, therefore, it may be better to continue to acquire the paper versions of the journals for those students.

Another issue is that libraries do not have enough qualified staff to serve users. Hanson (1998) especially talked about the level of library staff skills and strongly suggested that librarians, particularly subject librarians, need to clarify to library staff their key contribution and responsibility and then improve their core skills. Interviewee 2 said that some library assistants in the reference area did not have enough knowledge about database searching to answer students' problems clearly and accurately. He pointed out that nonprofessional staff can serve users very well for about $70 \%$ of queries, but there is a problem that some non-professional staff are not aware of the gaps in their knowledge and will give inaccurate information to the students, which wastes their time. 
Consortia offer one way to address many of the negative aspects of adopting digital services. Up until now, CONZUL has been primarily concerned with buying datasets and online materials along with other partners such as CAUL to obtain discounted prices. Interviewee 3 noted that CONZUL is now looking at joint library management systems and joint technical systems among other things. He contended that it was necessary to have national cooperation because an individual university library was limited financially and technically, so cooperating would help libraries to overcome their staffing and capital problems. Some online materials (i.e., databases and E-journals) can be subscribed to by academic consortia and shared by various university libraries. The intellectual property issues for digital resources (i.e., copyright) could also be more easily resolved in this manner.

Recommendations: It is necessary for the VUW Library to investigate its users' information needs and to decide what online resources and services need to be provided. It is also necessary for the Library to keep a relative balance between paper based resources and online resources considering its users' information needs. Library staff need to improve their qualifications in order to raise the level of professional services to their users. The VUW Library should also make full use of national or international consortia to acquire online resources and copyright permissions.

\subsubsection{Summary}

To sum up, one of the important issues affecting the ability of academic libraries to implement digital services is cost. Interviewee 5 stated that digital services are expensive to run because of the high cost of storing and upgrading information. Interviewee 4 and Interviewee 5 suggested that libraries needed to find a balance between digital and print-based resources and decide how much to spend on the digital services. Also, according to Interviewee 4, 90\% of the people using digital services were postgraduates and academic staff. Most undergraduates were probably not using these expensive resources. This user group needs to be catered for and educated. All the interviewees pointed out that library staff was another issue for digital services: all librarians need 
to be taught how to use the services, and they need to be qualified. According to the interviewees, libraries need to bear users' information needs in minds when seeking to improve their digital services. They need to: evaluate whether current services meet users' needs; collect users' feedback to adjust priorities of the digital services to match users' needs; and judge what the library should hypothetically provide and what it can feasibly provide relevant to users' expectations. Considering there are only seven universities in New Zealand, Interviewee 2 and Interviewee 4 suggested it is necessary for them to cooperate with each other or with overseas universities in order to better their digital services by introducing more advanced digital services including technology and management systems.

\subsection{Assessing the Relevant Theories in Relation to}

\section{Comparing Perceptions and Expectations of Digital Library Services from Different Communities}

An important element in the design of this study has been its use of theory. In particular, the research design has incorporated Taylor's user-centered and value-added theory (1986) by focusing on the users' needs, perceptions and expectations. This research has also incorporated preference evaluation from both users' and librarians' perspectives, and user satisfaction evaluation. The evaluation model used in this research was an integrated theoretical model developed from Taylor (1986), Parasuraman's Gap Model (1988), and SERVQUAL and LibQual+ (Fred, 1999).

By surveying users and librarians and then comparing the results between user communities, and between users and librarians, it is clear that there is a discrepancy of perceptions and expectations with relation to digital services. The findings of this study show that when academic libraries develop digital information services, those services are worth analyzing from the different perspectives of users and librarians. If libraries ignore users' perceptions and expectations, the services might not meet users' needs and therefore might not be successful. Thus, user-centered and value-added analysis of information 
services, rooted in Taylor's theory (1986), is an essential foundation for such studies.

Parasuraman's Gap Model (1988) was also used in the design of this research. By comparing perceptions and expectations between different user communities, and between users and librarians, some gaps were found in the following areas:

1. Customers' expectations and management's perceptions of these expectations;

2. Customers' expected services and perceived services delivered;

3. Different preferences, perceptions and expectations of digital services between different user communities.

The first and second gaps are part of Parasuraman's Gap model. The third gap extends the comparison area of the Gap Model and it also results in some valuable recommendations for a library to improve its service by addressing these differences. This research confirms that the Gap Model provides an important perspective on service quality and offers a framework to identify the issues of library services.

The evaluation indicators used in the survey were also taken from some existing models, for example Service Quality and User Satisfaction, Crawford's model for evaluating library services in terms of performance, satisfaction and effectiveness (1996) etc., and revised according to the characteristics of digital services by adding or deleting some evaluation indicators. These theoretical models proved valuable in answering the research questions, confirming the hypotheses and making recommendations for improving the digital services.

\subsection{Limitations of the Study}

This research is based on a case study of the VUW Library which entailed surveying users and interviewing librarians. The findings cannot be generalized to all academic libraries. However, because the VUW Library is a relatively typical New Zealand academic library, a number of valuable lessons 
can be learned from this study. The recommendations made in this study may be of value to other academic libraries, bearing in mind their own contexts and the specific circumstances that are unique to VUW.

Another limitation for this research is that in the data analysis, the results are not compared across different faculties although it is possible that there is a relationship between faculties and users' perceptions and expectations. The stratified random sample of undergraduates, postgraduates and academic staff was based on the individual population numbers of these three communities. Investigating different faculties would require a stratified random sample of users by faculties, (i.e., dividing the users into different faculties) and sampling a certain percentage of users from every faculty. Limited by time, the researcher only chose one way to categorize the users into their three broadly based communities.

Out of a total of 495 questionnaires for users and 38 questionnaires for librarians, $72 \%$ of undergraduates, $30 \%$ of postgraduates, $50 \%$ of academic staff and $34.2 \%$ of the librarians responded. The fact that the response rate varied across the different groups suggests that the data's reliability also varies and this must be borne in mind when reading the research findings and conclusions. For example, if the majority of respondents within a surveyed group (e.g., academics) were those who were greatly interested in digital services, the results of some of the statistical relationships examined in the study may have been too strong or too weak. In addition, the case study nature of this research has meant that it is not possible to generalize the findings of this study. Nonetheless, it seems safe to say that some differences in perceptions and expectations will exist in different settings between librarians and different user communities, and between user communities with different information needs and preferences. 


\subsection{Recommendations for Future Research and Final}

\section{Conclusion}

More detailed statements or measures need to be used in the questionnaires to determine personal preferences and trends in academic libraries. This increased specificity would enable more specific recommendations for improving the services to be given. A broader survey could be conducted including distant-learning students because they are heavy users of digital services. Considering distance-learning students are currently only a small group in VUW, this research did not focus on them. However, their studying and learning rely on the online services from the library website and when the number of distance students increases, their opinions would have considerable weight in evaluating digital services. Various faculties could be compared to assess the diversity of information needs, preferences and expectations. A study could be designed to judge the benefits from digital services compared to paper-based traditional services.

Looking ahead, I am not suggesting that digital services will replace print. The hybrid library will be the model for academic libraries for a long time. Brophy (2000) described the generic model for the hybrid library by identifying the library as an intermediary between users and the information universe. Digital services will affect the library's work processes and the librarians' jobs. Library staff will not only teach users how to use the resources bought by the library but also Internet resources. The library has a duty to accommodate all users' needs and it should take on the responsibility to provide the necessary help to support users' information needs. The library must ensure that users are given opportunities to acquire information retrieval skills and to practice them throughout their years of study. Meanwhile, students need to take the necessary initiative to improve their competence in using libraries.

The field of digital services experiences constant and rapid changes. Interviewee 2 recalled that a few years ago, when he arrived at the VUW 
Library, it had hardly any networked databases at all, only stand-alone CDs. He commented that now the Library has a wide range of online databases and E-journals, and whereas previously it had no liaison service, this service is now working quite well. The VUW Library has come a long way and its digital services have improved considerably. This study has provided a range of recommendations that will help the VUW Library in continuing to improve its digital services well into the future. 
Appendices 


\section{Appendix A: Flow Chart of the Research Method}

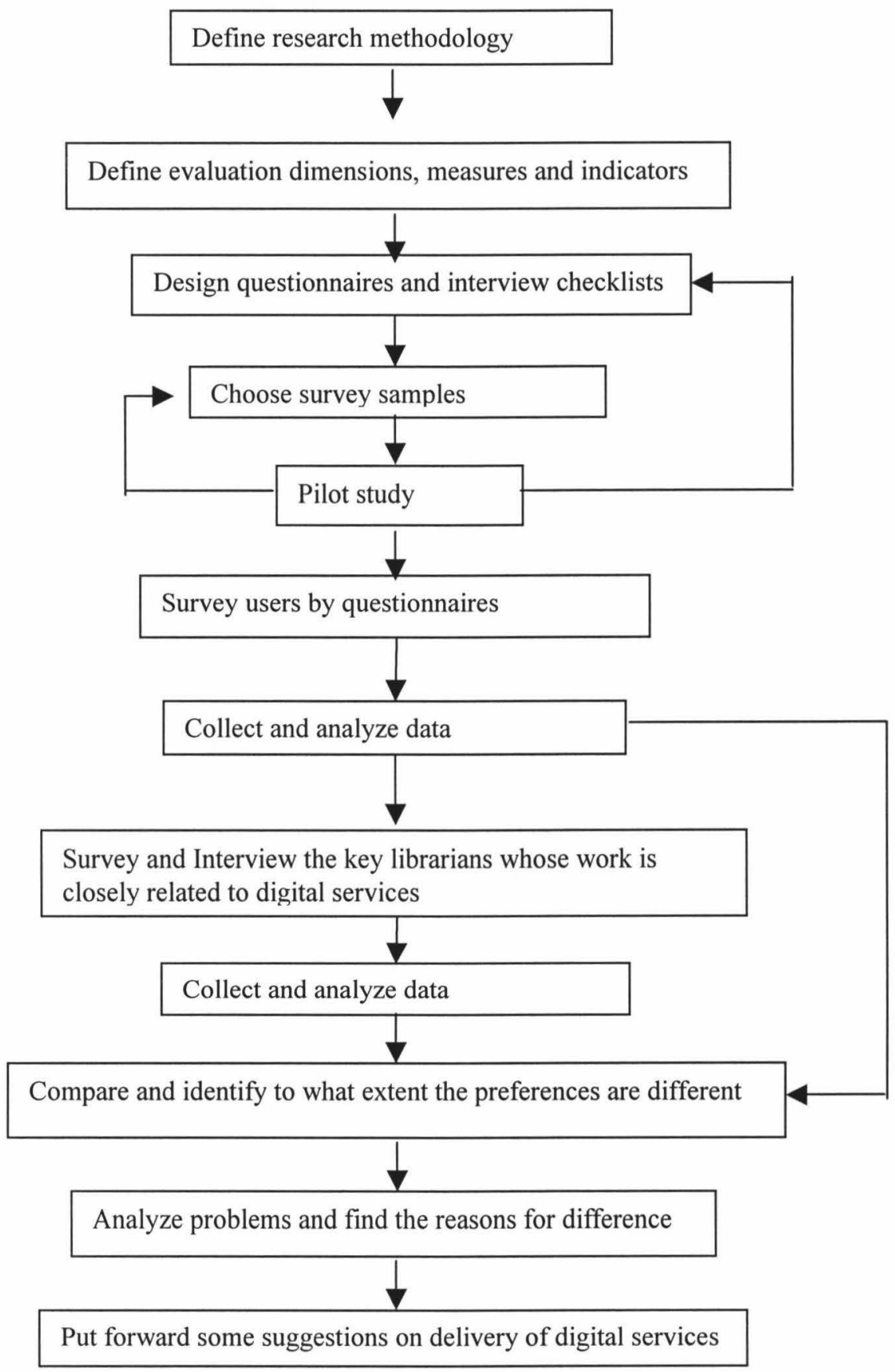




\section{Appendix B: Questionnaire Samples and Interview}

\section{Checklist}

Questionnaire for undergraduates, postgraduates and academic staff

Part One: General Demographic Information

1.1 What is your primary faculty?

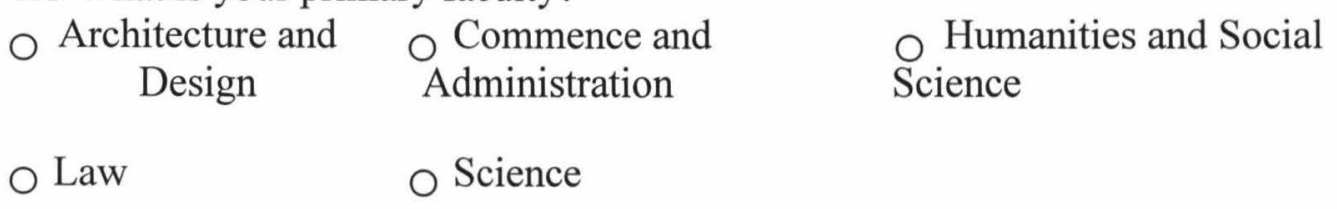

1.2 What is your status?

O Undergraduate $\bigcirc$ Postgraduate $\bigcirc$ Staff

2. Why do you visit the University Library website or use the Library's information or services?

(Please tick all that apply)

O Browse casually

$\bigcirc$ Check and review my personal records

O Search for library resources

O Look for literature related to my interests or latest development in my field

$O$ For reasons relating to assignments

O For reasons relating to the research in my field

O Review newly arrived items (books, journals, or videos)

O Look for information about the library

O Others (please specify)

O N/A

Part Two: Opinions on digital services

From Question 4 to Question 9 screenshots representing digital services are shown at the start of questions relevant to those. If you have never used one of the services mentioned below, please skip the assessment questions relating the corresponding service (i.e. Q4.3and Q5.3) and continue responding to the questions on the important features of that service (i.e. Q4.4)

3. Please rate the importance of the following features of an academic library website

\begin{tabular}{|llllll|}
\hline & Important & Neutral & & Unimportant \\
\hline "User friendly" interface & 5 & 4 & 3 & 2 & 1 \\
\hline Reliability of information & 5 & 4 & 3 & 2 & 1 \\
\hline $\begin{array}{l}\text { Ease of navigation to find my } \\
\text { needed information }\end{array}$ & 5 & 4 & 3 & 2 & 1 \\
\hline
\end{tabular}


4. Online Catalogue

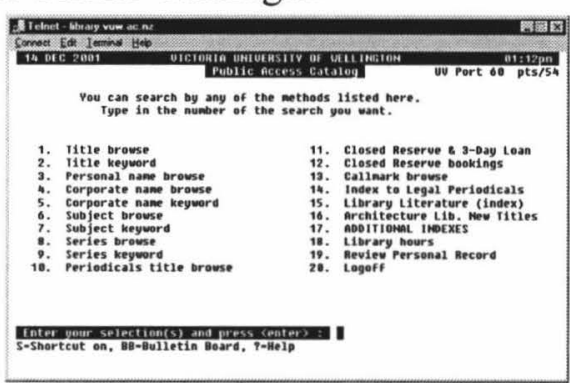

\begin{tabular}{|c|c|c|c|c|}
\hline \begin{tabular}{l}
\multicolumn{1}{c}{4.2 On } \\
average, I use \\
the online \\
catalogue \\
(select one)
\end{tabular} & Daily Weekly & Monthly & Quarterly & $\begin{array}{l}\text { Very } \\
\text { infrequently/Not } \\
\text { at all }\end{array}$ \\
\hline
\end{tabular}

4.3 Please give your assessment based on your last use of the VUW Library Catalogue

I used (please tick one):

\begin{tabular}{|llllll|}
\hline & Agree & Neutral & Disagree \\
\hline $\begin{array}{l}\text { This service played an important role in } \\
\text { my information retrieval strategy }\end{array}$ & 5 & 4 & 3 & 2 & 1 \\
\hline I was satisfied with this service & 5 & 4 & 3 & 2 & 1 \\
\hline $\begin{array}{l}\text { I will want to use this service again in the } \\
\text { future }\end{array}$ & 5 & 4 & 3 & 2 & 1 \\
\hline
\end{tabular}

4.4 Please rate the importance of the following features of online catalogue services in an academic library:

\begin{tabular}{|llllll|}
\hline & Important & Neutral & & Unimportant \\
\hline $\begin{array}{l}\text { Availability of information about } \\
\text { this service }\end{array}$ & 5 & 4 & 3 & 2 & 1 \\
\hline Convenient and easy access & 5 & 4 & 3 & 2 & 1 \\
\hline Easy to use & 5 & 4 & 3 & 2 & 1 \\
\hline $\begin{array}{l}\text { Useful information provided by } \\
\text { this service }\end{array}$ & 5 & 4 & 3 & 2 & 1 \\
\hline $\begin{array}{l}\text { Helpful online tutorials for } \\
\text { catalogue services }\end{array}$ & 5 & 4 & 3 & 2 & 1 \\
\hline $\begin{array}{l}\text { Accurate source of information } \\
\text { about the materials held by library }\end{array}$ & 5 & 4 & 3 & 2 & 1 \\
\hline
\end{tabular}


5. Databases (online indexes of journal articles---some with abstracts and some with abstract and full text)

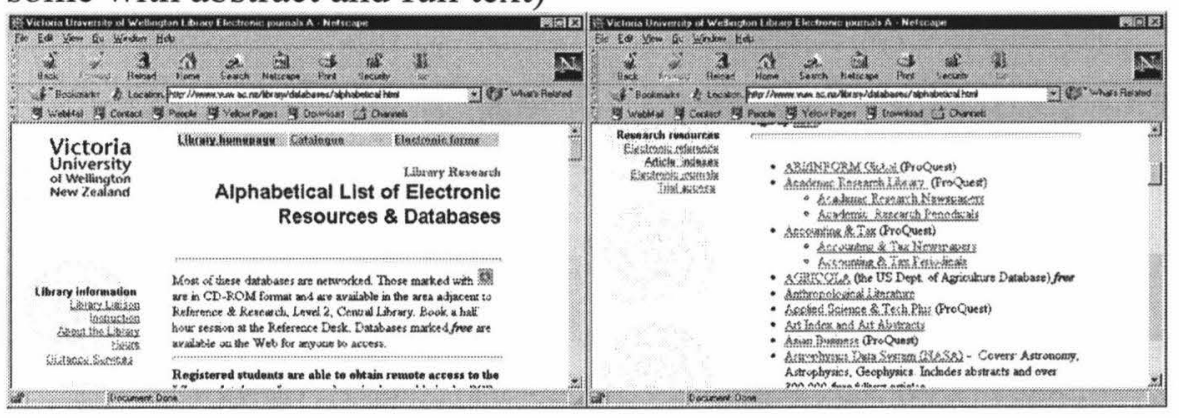

5.1 I mostly use the Electronic Databases (select one)

\begin{tabular}{|c|c|c|c|}
\hline ithin & $\begin{array}{c}\text { OOn } \\
\text { campus }\end{array}$ & $\begin{array}{l}\text { From some Internet service } \\
\text { providers authorized by the } \\
\text { Univeristy Library, VUW, Such as } \\
\text { Paradise }\end{array}$ & $\begin{array}{l}\text { O Outside via } \\
\text { other Internet } \\
\text { service } \\
\text { provider }\end{array}$ \\
\hline
\end{tabular}

\begin{tabular}{|c|c|c|c|c|c|}
\hline $\begin{array}{l}5.2 \text { On average, } \\
\text { I use the } \\
\text { databases (select }\end{array}$ & Daily & Weekly & Monthly & Quarterly & $\begin{array}{l}\text { Very } \\
\text { infrequently/Not } \\
\text { at all }\end{array}$ \\
\hline
\end{tabular}

5.3 Please give your assessment based on your last use of the Databases

\begin{tabular}{|llllll|}
\hline & Agree & Neutral & Disagree \\
\hline $\begin{array}{l}\text { This service played an important role in } \\
\text { my information retrieval strategy }\end{array}$ & 5 & 4 & 3 & 2 & 1 \\
\hline I was satisfied with this service & 5 & 4 & 3 & 2 & 1 \\
\hline $\begin{array}{l}\text { I will want to use this service again in the } \\
\text { future }\end{array}$ & 5 & 4 & 3 & 2 & 1 \\
\hline
\end{tabular}

5.4 Please rate the importance of the following features of electronic database services in an academic library:

\begin{tabular}{|llllll|}
\hline & Important & & Neutral & & Unimportant \\
\hline $\begin{array}{l}\text { Availability of information about } \\
\text { this service }\end{array}$ & 5 & 4 & 3 & 2 & 1 \\
\hline Convenient and easy access & 5 & 4 & 3 & 2 & 1 \\
\hline Easy to use & 5 & 4 & 3 & 2 & 1 \\
\hline $\begin{array}{l}\text { Useful information provided by } \\
\text { databases }\end{array}$ & 5 & 4 & 3 & 2 & 1 \\
\hline Number of databases & 5 & 4 & 3 & 2 & 1 \\
\hline Range of content & 5 & 4 & 3 & 2 & 1 \\
\hline Precision of the searching results & 5 & 4 & 3 & 2 & 1 \\
\hline $\begin{array}{l}\text { Availability of various searching } \\
\text { options (such as author, title...) }\end{array}$ & 5 & 4 & 3 & 2 & 1 \\
\hline Currency of the databases & 5 & 4 & 3 & 2 & 1 \\
\hline $\begin{array}{l}\text { Easy for users to choose a relevant } \\
\text { database }\end{array}$ & 5 & 4 & 3 & 2 & 1 \\
\hline Response time & 5 & 4 & 3 & 2 & 1 \\
\hline Availability of some training & 5 & 4 & 3 & 2 & 1 \\
\hline
\end{tabular}


6. E-journals: online access to electronic copies of the full text of specific journal titles

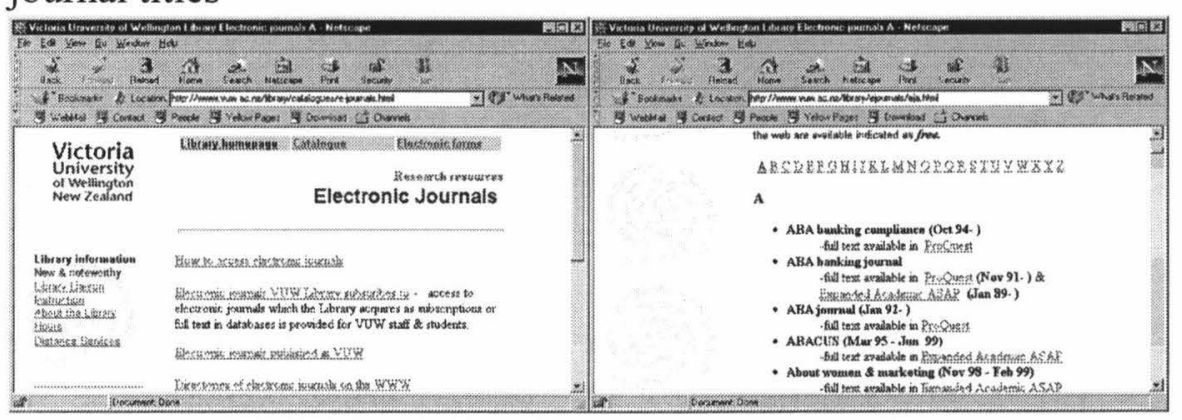

\begin{tabular}{|c|c|c|c|c|}
\hline $\begin{array}{l}6.1 \text { On average, } \\
\text { I use the e- } \\
\text { journals (select } \\
\text { one) }\end{array}$ & Daily & Weekly Monthly & Quarterly & $\begin{array}{l}\text { Very } \\
\text { infrequently/Not } \\
\text { at all }\end{array}$ \\
\hline
\end{tabular}

6.2 Please give your assessment of the last time you used the Electronic Journals.

\begin{tabular}{|llllll|}
\hline & Agree & Neutral & Disagree \\
\hline $\begin{array}{l}\text { This service played an important role in } \\
\text { my information retrieval strategy }\end{array}$ & 5 & 4 & 3 & 2 & 1 \\
\hline I was satisfied with this service & 5 & 4 & 3 & 2 & 1 \\
\hline $\begin{array}{l}\text { I will want to use this service again in the } \\
\text { future }\end{array}$ & 5 & 4 & 3 & 2 & 1 \\
\hline
\end{tabular}

6.3 Please rate the importance of the features of electronic journal service in an academic library:

\begin{tabular}{|llllll|}
\hline & Important & Neutral & & Unimportant \\
\hline $\begin{array}{l}\text { Availability of information about } \\
\text { of this service }\end{array}$ & 5 & 4 & 3 & 2 & 1 \\
\hline Convenient and easy access & 5 & 4 & 3 & 2 & 1 \\
\hline Easy to use & 5 & 4 & 3 & 2 & 1 \\
\hline $\begin{array}{l}\text { Useful information provided by } \\
\text { this service }\end{array}$ & 5 & 4 & 3 & 2 & 1 \\
\hline Range of content & 5 & 4 & 3 & 2 & 1 \\
\hline Currency of the content & 5 & 4 & 3 & 2 & 1 \\
\hline
\end{tabular}

6.3 What kind of results from e-journals and databases do you prefer? (Please rank your preferences, giving 1 to your most favorite option, 2 to your next favorite and 3 to your least favorite)
- Download from
- Print out
- $\quad$ Have full-text articles web emailed to you 


\section{Email Reference Service}

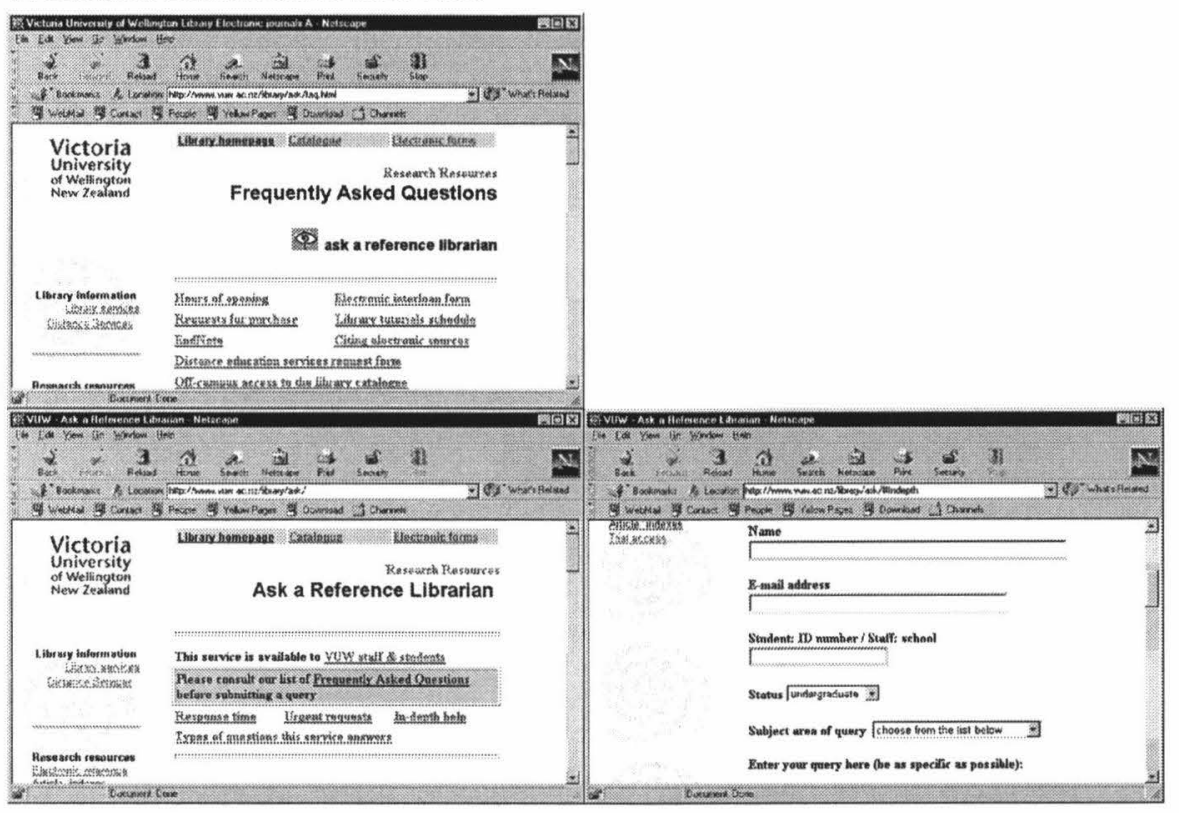

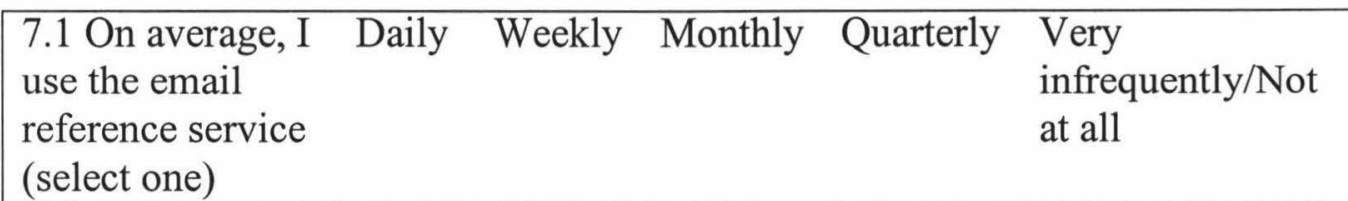

7.2 Please give your assessment of Email Reference Service (emailing the library the questions)

\begin{tabular}{|llllll|}
\hline & Agree & Neutral & Disagree \\
\hline $\begin{array}{l}\text { This service played an important role in } \\
\text { my information retrieval strategy }\end{array}$ & 5 & 4 & 3 & 2 & 1 \\
\hline I was satisfied with this service & 5 & 4 & 3 & 2 & 1 \\
\hline $\begin{array}{l}\text { I will want to use this service again in the } \\
\text { future }\end{array}$ & 5 & 4 & 3 & 2 & 1 \\
\hline
\end{tabular}

7.3 Please rate the importance of the following features of email reference service in an academic library:

\begin{tabular}{|llllll|}
\hline & Important & Neutral & & Unimportant \\
\hline $\begin{array}{l}\text { Availability of information about } \\
\text { this service }\end{array}$ & 5 & 4 & 3 & 2 & 1 \\
\hline Convenient and easy access & 5 & 4 & 3 & 2 & 1 \\
\hline Easy to use & 5 & 4 & 3 & 2 & 1 \\
\hline $\begin{array}{l}\text { Useful information provided by } \\
\text { this service }\end{array}$ & 5 & 4 & 3 & 2 & 1 \\
\hline Friendliness of the response & 5 & 4 & 3 & 2 & 1 \\
\hline Quick response time & 5 & 4 & 3 & 2 & 1 \\
\hline
\end{tabular}


8. Other Selected Internet Resources

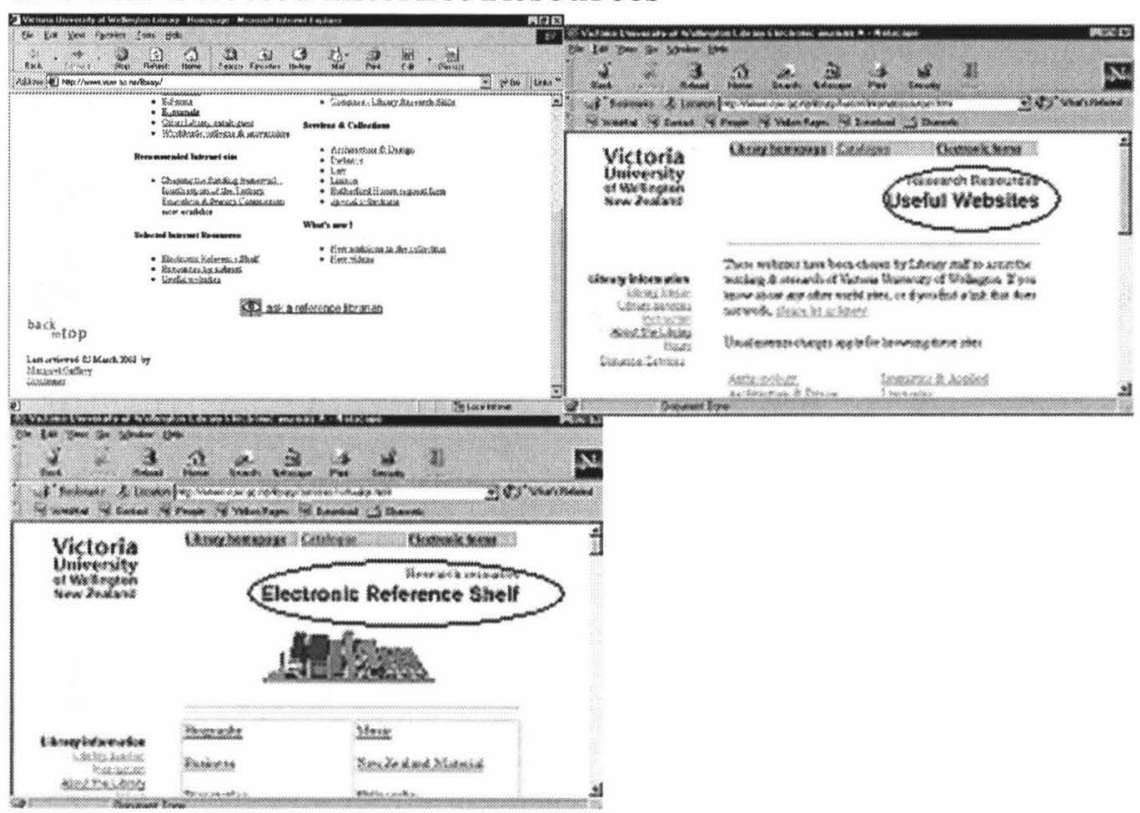

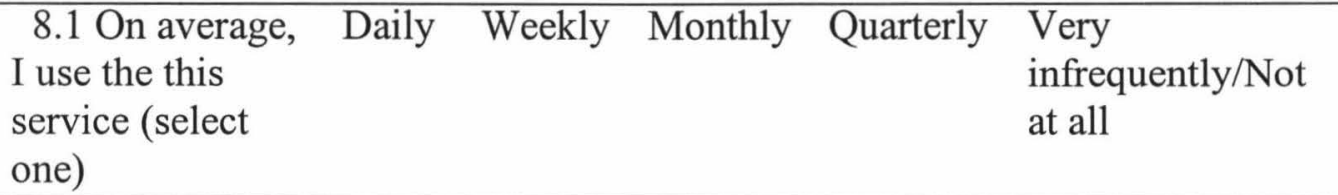

\subsection{Please give your assessment of Other Selected Internet Resources}

\begin{tabular}{|llllll|}
\hline & Agree & Neutral & Disagree \\
\hline $\begin{array}{l}\text { This service played an important role in } \\
\text { my information retrieval strategy }\end{array}$ & 5 & 4 & 3 & 2 & 1 \\
\hline I was satisfied with this service & 5 & 4 & 3 & 2 & 1 \\
\hline $\begin{array}{l}\text { I will want to use this service again in the } \\
\text { future }\end{array}$ & 5 & 4 & 3 & 2 & 1 \\
\hline
\end{tabular}

8.3 Please rate the importance of the following features of Other Selected Internet Resources

\begin{tabular}{|llllll|}
\hline & Important & & Neutral & & Unimportant \\
\hline $\begin{array}{l}\text { Availability of information about } \\
\text { this service }\end{array}$ & 5 & 4 & 3 & 2 & 1 \\
\hline Convenient and easy access & 5 & 4 & 3 & 2 & 1 \\
\hline Easy to use & 5 & 4 & 3 & 2 & 1 \\
\hline $\begin{array}{l}\text { Useful information provided by } \\
\text { this service }\end{array}$ & 5 & 4 & 3 & 2 & 1 \\
\hline Range of content & 5 & 4 & 3 & 2 & 1 \\
\hline
\end{tabular}


9. Online request forms: You can submit the online request forms for Interlibrary Loan or Distance Education

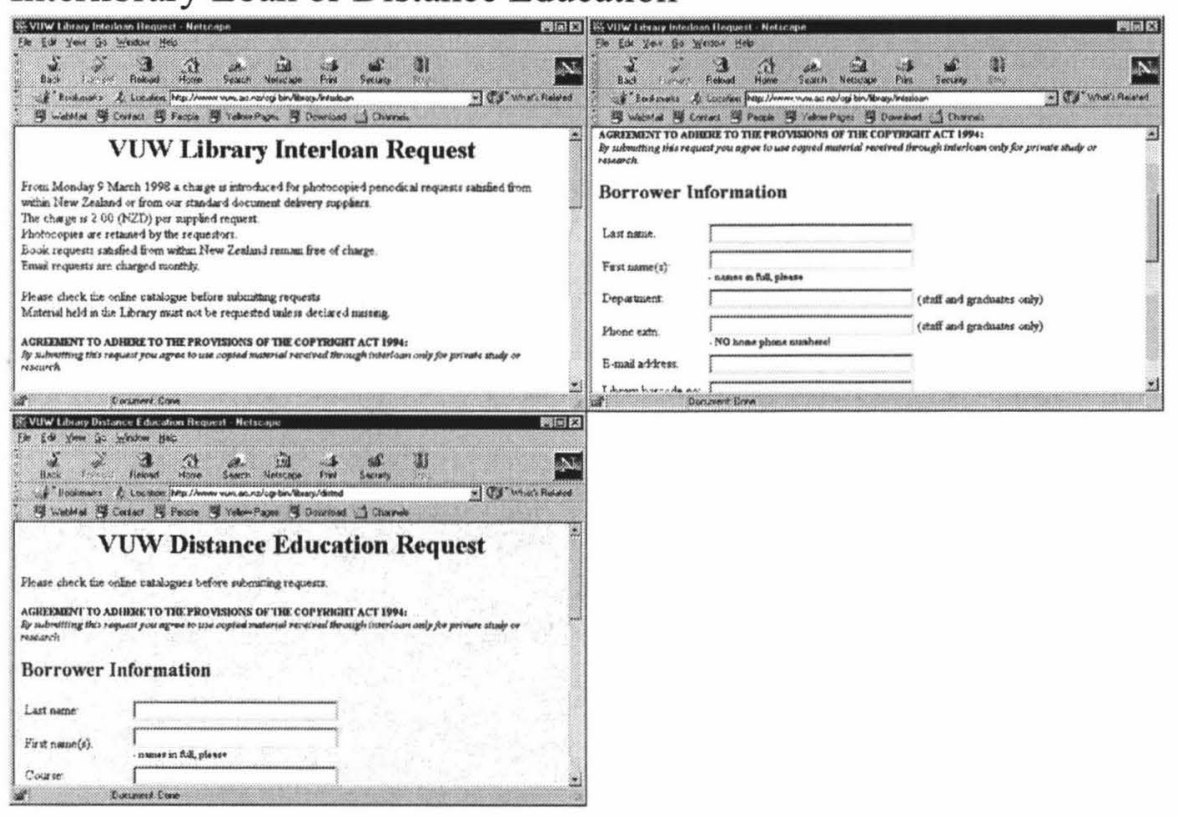

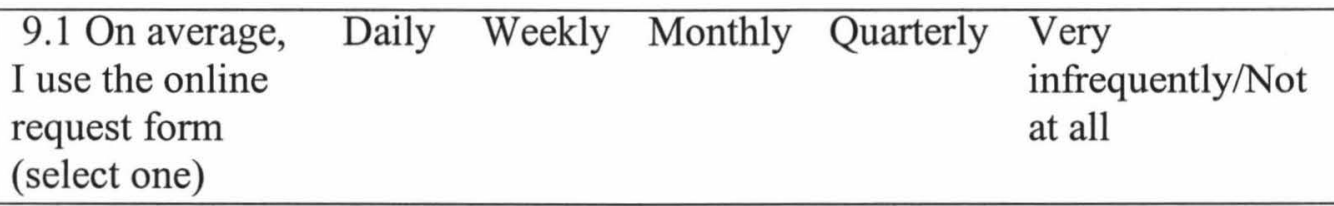

9.2 Please give your assessment of Online Request Forms

\begin{tabular}{|llllll|}
\hline & Agree & Neutral & Disagree \\
\hline $\begin{array}{l}\text { This service played an important role in } \\
\text { my information retrieval strategy }\end{array}$ & 5 & 4 & 3 & 2 & 1 \\
\hline I was satisfied with this service & 5 & 4 & 3 & 2 & 1 \\
\hline $\begin{array}{l}\text { I will want to use this service again in the } \\
\text { future }\end{array}$ & 5 & 4 & 3 & 2 & 1 \\
\hline
\end{tabular}

9.3 Please rate the importance of the following features of online request forms service in an academic library:

\begin{tabular}{|llllll|}
\hline & Important & Neutral & Unimportant \\
\hline $\begin{array}{l}\text { Availability of information about } \\
\text { this service }\end{array}$ & 5 & 4 & 3 & 2 & 1 \\
\hline Convenient and easy access & 5 & 4 & 3 & 2 & 1 \\
\hline Easy to use & 5 & 4 & 3 & 2 & 1 \\
\hline Usefulness & 5 & 4 & 3 & 2 & 1 \\
\hline Quick response time & 5 & 4 & 3 & 2 & 1 \\
\hline
\end{tabular}

10. Possible future services to be offered by the VUW Library The following services have the possibility to be provided by the University Library. Please give your opinions about these services. 
10.1 Current Awareness Service: You ask the VUW library to retrieve information for you based on a profile of your personal information needs and to send the results to you on a regular basis.

\begin{tabular}{|llllll|}
\hline & Agree & Neutral & Disagree \\
\hline $\begin{array}{l}\text { This service is important in my } \\
\text { information retrieval strategy }\end{array}$ & 5 & 4 & 3 & 2 & 1 \\
\hline $\begin{array}{l}\text { This service would be useful for me to } \\
\text { find the information }\end{array}$ & 5 & 4 & 3 & 2 & 1 \\
\hline I would use this service in the future & 5 & 4 & 3 & 2 & 1 \\
\hline
\end{tabular}

10.2 In which form would you prefer the result? (Please choose one answer) $\bigcirc$ Print documents and post to me $\bigcirc$ Email me

10.3 Virtual Reference: Use of videoconferencing or chat rooms for online interactions so that users can ask librarians questions and get the answers immediately via the web.

\begin{tabular}{|llllll|}
\hline & Agree & Neutral & Disagree \\
\hline $\begin{array}{l}\text { This service is important in my } \\
\text { information retrieval strategy }\end{array}$ & 5 & 4 & 3 & 2 & 1 \\
\hline $\begin{array}{l}\text { This service would be useful for me to } \\
\text { find the information }\end{array}$ & 5 & 4 & 3 & 2 & 1 \\
\hline I would use this service in the future & 5 & 4 & 3 & 2 & 1 \\
\hline
\end{tabular}

10.4 Closed Reserve Services in Digital Environment such as booking closed reserve materials online and emailing users some materials instead of providing paper-based materials

\begin{tabular}{|llllll|}
\hline & Agree & Neutral & Disagree \\
\hline $\begin{array}{l}\text { This service is important in my } \\
\text { information retrieval strategy }\end{array}$ & 5 & 4 & 3 & 2 & 1 \\
\hline $\begin{array}{l}\text { This service would be useful for me to } \\
\text { find the information }\end{array}$ & 5 & 4 & 3 & 2 & 1 \\
\hline I would use this service in the future & 5 & 4 & 3 & 2 & 1 \\
\hline
\end{tabular}

Part Three Overall Assessment

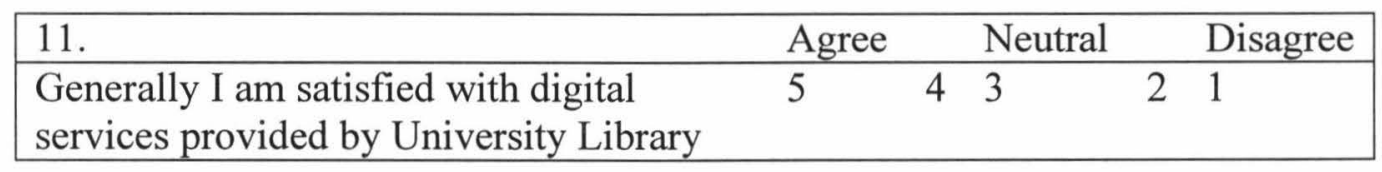


12. Please select and rank in priority order the $\mathbf{5}$ services that you feel should be the focus of library attention in order to improve services to users? (Note that the scale runs from $1=$ the highest priority, to $5=$ the lowest priority)

\begin{tabular}{|l|l|l|l|}
\hline $\begin{array}{l}\text { Online } \\
\text { catalogue( ) }\end{array}$ & Database( ) & $\begin{array}{l}\text { Digital closed } \\
\text { reserve( ) }\end{array}$ & $\begin{array}{l}\text { SDI and Current } \\
\text { Awareness Services( ) }\end{array}$ \\
\hline $\begin{array}{l}\text { Electronic } \\
\text { reference } \\
\text { service( ) }\end{array}$ & $\begin{array}{l}\text { E- } \\
\text { journals( ) }\end{array}$ & $\begin{array}{l}\text { Online } \\
\text { instruction( ) }\end{array}$ & $\begin{array}{l}\text { Delivering documents } \\
\text { electronically( ) }\end{array}$ \\
\hline & & $\begin{array}{l}\text { Online request } \\
\text { forms( ) }\end{array}$ & $\begin{array}{l}\text { Other selected Internet } \\
\text { sources( ) }\end{array}$ \\
\hline
\end{tabular}

13. Please describe any instance of particularly good or particularly bad service that have impacted on your views of the digital services offered by the VUW Library.

14. Please provide any additional comments that you feel are relevant to your perceptions of the importance or usefulness of the current or future digital services described in the above survey. 


\section{Questionnaire for librarians}

Part One: General Information

1. Please indicate your group and job title at the University Library

Group

Job Title

Part Two: Opinions on digital services

2. Please rate the importance of the features of the Website of the University

Library

\begin{tabular}{|llllll|}
\hline & Important & Neutral & & Unimportant \\
\hline "User friendly" interface & 5 & 4 & 3 & 2 & 1 \\
\hline Reliability of information & 5 & 4 & 3 & 2 & 1 \\
\hline $\begin{array}{l}\text { Ease of navigation to find my } \\
\text { needed information }\end{array}$ & 5 & 4 & 3 & 2 & 1 \\
\hline
\end{tabular}

3.1 Please give your assessment of Online Public Access Catalogue (OPAC)

\begin{tabular}{|llllll|}
\hline & Agree & Neutral & Disagree \\
\hline $\begin{array}{l}\text { This service played an important role in } \\
\text { users information retrieval strategy }\end{array}$ & 5 & 4 & 3 & 2 & 1 \\
\hline Users are satisfied with this service & 5 & 4 & 3 & 2 & 1 \\
\hline $\begin{array}{l}\text { Most users will want to use this service } \\
\text { again in the future }\end{array}$ & 5 & 4 & 3 & 2 & 1 \\
\hline
\end{tabular}

3.2 Please rate the importance of the following features of the Catalogue

Service in an academic library

\begin{tabular}{|llllll|}
\hline & Important & & Neutral & & Unimportant \\
\hline $\begin{array}{l}\text { Availability of information about } \\
\text { this service }\end{array}$ & 5 & 4 & 3 & 2 & 1 \\
\hline Convenient and easy access & 5 & 4 & 3 & 2 & 1 \\
\hline Ease to use & 5 & 4 & 3 & 2 & 1 \\
\hline $\begin{array}{l}\text { Usefulness of the information } \\
\text { provided by this service }\end{array}$ & 5 & 4 & 3 & 2 & 1 \\
\hline $\begin{array}{l}\text { Helpful online tutorials for } \\
\text { catalogue services }\end{array}$ & 5 & 4 & 3 & 2 & 1 \\
\hline $\begin{array}{l}\text { Accurate source of information } \\
\text { about the materials held by library }\end{array}$ & 5 & 4 & 3 & 2 & 1 \\
\hline
\end{tabular}

\subsection{Please give your assessment of the Databases}

\begin{tabular}{|llllll|}
\hline & Agree & Neutral & Disagree \\
\hline $\begin{array}{l}\text { This service played an important role in } \\
\text { users information retrieval strategy }\end{array}$ & 5 & 4 & 3 & 2 & 1 \\
\hline Users are satisfied with this service & 5 & 4 & 3 & 2 & 1 \\
\hline $\begin{array}{l}\text { Most users will want to use this service } \\
\text { again in the future }\end{array}$ & 5 & 4 & 3 & 2 & 1 \\
\hline
\end{tabular}


4.2 Please rate the importance of the following features of the Electronic

Databases Service in an academic library

\begin{tabular}{|llllll|}
\hline & Important & Neutral & & Unimportant \\
\hline $\begin{array}{l}\text { Availability of information about } \\
\text { this service }\end{array}$ & 5 & 4 & 3 & 2 & 1 \\
\hline Convenient and easy access & 5 & 4 & 3 & 2 & 1 \\
\hline Ease to use & 5 & 4 & 3 & 2 & 1 \\
\hline $\begin{array}{l}\text { Usefulness of the information } \\
\text { provided by databases }\end{array}$ & 5 & 4 & 3 & 2 & 1 \\
\hline Number of the databases & 5 & 4 & 3 & 2 & 1 \\
\hline Range of content & 5 & 4 & 3 & 2 & 1 \\
\hline Precision of the searching results & 5 & 4 & 3 & 2 & 1 \\
\hline $\begin{array}{l}\text { Availability of various searching } \\
\text { options (such as author, title...) }\end{array}$ & 5 & 4 & 3 & 2 & 1 \\
\hline Currency of the databases & 5 & 4 & 3 & 2 & 1 \\
\hline $\begin{array}{l}\text { Easy for users to choose a relevant } \\
\text { database }\end{array}$ & 5 & 4 & 3 & 2 & 1 \\
\hline Response time & 5 & 4 & 3 & 2 & 1 \\
\hline Availability of some training & 5 & 4 & 3 & 2 & 1 \\
\hline
\end{tabular}

5.1 Please give your assessment of the Electronic Journals.

\begin{tabular}{|llllll|}
\hline & Agree & Neutral & Disagree \\
\hline $\begin{array}{l}\text { This service played an important role in } \\
\text { users information retrieval strategy }\end{array}$ & 5 & 4 & 3 & 2 & 1 \\
\hline Users are satisfied with this service & 5 & 4 & 3 & 2 & 1 \\
\hline $\begin{array}{l}\text { Most users will want to use this service } \\
\text { again in the future }\end{array}$ & 5 & 4 & 3 & 2 & 1 \\
\hline
\end{tabular}

5.2 Please rate the importance of the following features of the Electronic Journal Service in an academic library

\begin{tabular}{|llllll|}
\hline & Important & Neutral & & Unimportant \\
\hline $\begin{array}{l}\text { Availability of information about } \\
\text { this service }\end{array}$ & 5 & 4 & 3 & 2 & 1 \\
\hline Convenient and easy access & 5 & 4 & 3 & 2 & 1 \\
\hline Ease to use & 5 & 4 & 3 & 2 & 1 \\
\hline $\begin{array}{l}\text { Usefulness of the information } \\
\text { provided by this service }\end{array}$ & 5 & 4 & 3 & 2 & 1 \\
\hline Range of content & 5 & 4 & 3 & 2 & 1 \\
\hline Currency of the content & 5 & 4 & 3 & 2 & 1 \\
\hline
\end{tabular}

5.3 What kind of results do users prefer? (Please rank the preferences, giving 1 to users' most favorite option, 2 to the next favorite and 3 to their least favorite)
- Download
- Print out
Have full-text articles
from
emailed to users
web 
6.1 Please give your assessment of Email Reference Service

\begin{tabular}{|llllll|}
\hline & Agree & Neutral & Disagree \\
\hline $\begin{array}{l}\text { This service played an important role in } \\
\text { users information retrieval strategy }\end{array}$ & 5 & 4 & 3 & 2 & 1 \\
\hline Users are satisfied with this service & 5 & 4 & 3 & 2 & 1 \\
\hline $\begin{array}{l}\text { Most users will want to use this service } \\
\text { again in the future }\end{array}$ & 5 & 4 & 3 & 2 & 1 \\
\hline
\end{tabular}

6.2 Please rate the importance of the following features of Email Reference Service in an academic library

\begin{tabular}{|llllll|}
\hline & Important & Neutral & & Unimportant \\
\hline $\begin{array}{l}\text { Availability of information about } \\
\text { this service }\end{array}$ & 5 & 4 & 3 & 2 & 1 \\
\hline Convenient and easy access & 5 & 4 & 3 & 2 & 1 \\
\hline Ease to use & 5 & 4 & 3 & 2 & 1 \\
\hline $\begin{array}{l}\text { Usefulness of the information } \\
\text { provided by this service }\end{array}$ & 5 & 4 & 3 & 2 & 1 \\
\hline Friendliness of the response & 5 & 4 & 3 & 2 & 1 \\
\hline Quick response time & 5 & 4 & 3 & 2 & 1 \\
\hline
\end{tabular}

\subsection{Please give your assessment of Other Selected Internet Resources}

\begin{tabular}{|llllll|}
\hline & Agree & Neutral & Disagree \\
\hline $\begin{array}{l}\text { This service played an important role in } \\
\text { users information retrieval strategy }\end{array}$ & 5 & 4 & 3 & 2 & 1 \\
\hline Users are satisfied with this service & 5 & 4 & 3 & 2 & 1 \\
\hline $\begin{array}{l}\text { Most users will want to use this service } \\
\text { again in the future }\end{array}$ & 5 & 4 & 3 & 2 & 1 \\
\hline
\end{tabular}

7.2 Please rate the importance of the following features of Other Internet

Resources in an academic library

\begin{tabular}{|llllll|}
\hline & Important & Neutral & & Unimportant \\
\hline $\begin{array}{l}\text { Availability of information about } \\
\text { this service }\end{array}$ & 5 & 4 & 3 & 2 & 1 \\
\hline Convenient and easy access & 5 & 4 & 3 & 2 & 1 \\
\hline Ease to use & 5 & 4 & 3 & 2 & 1 \\
\hline $\begin{array}{l}\text { Usefulness of the information } \\
\text { provided by this service }\end{array}$ & 5 & 4 & 3 & 2 & 1 \\
\hline Range of content & 5 & 4 & 3 & 2 & 1 \\
\hline
\end{tabular}

8.1 Please rate the importance of the following features of Online Request Forms in an academic library

\begin{tabular}{|llllll|}
\hline & Important & Neutral & & Unimportant \\
\hline $\begin{array}{l}\text { Availability of information about } \\
\text { this service }\end{array}$ & 5 & 4 & 3 & 2 & 1 \\
\hline Convenient and easy and access & 5 & 4 & 3 & 2 & 1 \\
\hline Ease to use & 5 & 4 & 3 & 2 & 1 \\
\hline Usefulness & 5 & 4 & 3 & 2 & 1 \\
\hline Quick response time & 5 & 4 & 3 & 2 & 1 \\
\hline
\end{tabular}


8.2 Please give your assessment of Online Request Forms

\begin{tabular}{|llllll|}
\hline & Agree & Neutral & & Disagree \\
\hline $\begin{array}{l}\text { This service played an important role in } \\
\text { users' information retrieval }\end{array}$ & 5 & 4 & 3 & 2 & 1 \\
\hline Users are satisfied with this service & 5 & 4 & 3 & 2 & 1 \\
\hline $\begin{array}{l}\text { Most users will want to use this service in } \\
\text { the future }\end{array}$ & 5 & 4 & 3 & 2 & 1 \\
\hline
\end{tabular}

9. Some future services in the University Library of VUW

The following services have the possibility to be provided by the University

Library. Please give your opinions about these services.

9.1 Current Awareness Service: Users ask the VUW Library to retrieve information for them based on a profiles of their personal information needs and send the results to them on a regular basis.

\begin{tabular}{|llllll|}
\hline & Agree & Neutral & Disagree \\
\hline $\begin{array}{l}\text { This service is important for users' } \\
\text { information retrieval strategy }\end{array}$ & 5 & 4 & 3 & 2 & 1 \\
\hline $\begin{array}{l}\text { It would be practical for the library to } \\
\text { provide this service }\end{array}$ & 5 & 4 & 3 & 2 & 1 \\
\hline $\begin{array}{l}\text { This service would be useful for users to } \\
\text { find the information }\end{array}$ & 5 & 4 & 3 & 2 & 1 \\
\hline Users would use this service in the future & 5 & 4 & 3 & 2 & 1 \\
\hline
\end{tabular}

9.2 In which form would users prefer the result? (Please choose one answer)

$\bigcirc$ Print documents and post to them $\bigcirc$ Email them

9.3 Virtual Reference: Use videoconferencing or chat rooms in effort to create online close interactions so that users can ask librarians questions and get the answers immediately via the web

\begin{tabular}{|llllll|}
\hline & Agree & Neutral & Disagree \\
\hline $\begin{array}{l}\text { This service is important for users' } \\
\text { information retrieval strategy }\end{array}$ & 5 & 4 & 3 & 2 & 1 \\
\hline $\begin{array}{l}\text { It would be practical for the library to } \\
\text { provide this service }\end{array}$ & 5 & 4 & 3 & 2 & 1 \\
\hline $\begin{array}{l}\text { This service would be useful for users to } \\
\text { find the information }\end{array}$ & 5 & 4 & 3 & 2 & 1 \\
\hline Users would use this service in the future & 5 & 4 & 3 & 2 & 1 \\
\hline
\end{tabular}


9.4 Closed Reserve Services in Digital Environment such as booking closed reserve materials online and emailing users some materials instead of providing paper-based materials

\begin{tabular}{|llllll|}
\hline & Agree & Neutral & Disagree \\
\hline $\begin{array}{l}\text { This service is important for users' } \\
\text { information retrieval strategy }\end{array}$ & 5 & 4 & 3 & 2 & 1 \\
\hline $\begin{array}{l}\text { It would be practical for the library to } \\
\text { provide this service }\end{array}$ & 5 & 4 & 3 & 2 & 1 \\
\hline $\begin{array}{l}\text { This service would be useful for users to } \\
\text { find the information }\end{array}$ & 5 & 4 & 3 & 2 & 1 \\
\hline Users would use this service in the future & 5 & 4 & 3 & 2 & 1 \\
\hline
\end{tabular}

Part Three Overall Assessment

11.

Generally users are satisfied with digital services provided by University Library
Agree
5
43
Disagree
21

12. Please select and rank in priority order the $\mathbf{5}$ services that you feel should be the focus of library attention in order to improve services to users. (Note that the scale runs from $1=$ the highest priority, to $5=$ the lowest priority)

\begin{tabular}{|l|l|l|l|}
\hline $\begin{array}{l}\text { Online } \\
\text { catalogue( ) }\end{array}$ & Database( ) & E-journals( ) & $\begin{array}{l}\text { SDI and Current } \\
\text { Awareness Services( ) }\end{array}$ \\
\hline $\begin{array}{l}\text { Reference } \\
\text { service( ) }\end{array}$ & $\begin{array}{l}\text { Closed } \\
\text { eserve( ) }\end{array}$ & $\begin{array}{l}\text { Online } \\
\text { guide( ) }\end{array}$ & $\begin{array}{l}\text { Delivering documents } \\
\text { electronically( ) }\end{array}$ \\
\hline & & $\begin{array}{l}\text { Online request } \\
\text { form( ) }\end{array}$ & $\begin{array}{l}\text { Other selected Internet } \\
\text { sources( ) }\end{array}$ \\
\hline
\end{tabular}

13. Please provide any additional comments that you feel are relevant to your perceptions of the importance or usefulness of the current or future digital services described in the above survey. 


\section{Interview Checklist}

1. What is your role in terms of provision of digital/electronic services?

2. Some comments given by librarians on the questionnaires show that a new online catalogue called IPAC will be provided soon. In your view, how does the new IPAC improve on the OPAC in meeting users' needs? --What are the main functions of this new catalogue service? --- Does this new catalogue system provide direct access to some E-documents?

3. In your mind, what kind of difficulties do users have when searching databases? (How about the choices of searching options?)---What kind of actions can be taken for database provider or the library to help users to overcome these difficulties?

4. What are important issues in terms of E-journals that you think affect the use? (How about the range of E-journals?)---How does the library decide which E-journals to provide?

5. How does the library ensure that the information about services on the website is kept up-to-date? Do you feel this process works well?

6. Do you think it is helpful to provide SDI/CAS for users? ---Why doesn't the library provide this kind of service?

7. Does the library intend to provide virtual reference services? (Yes--Reasons? or No---Reasons?)

8. Does the closed reserve work well for user groups?

For closed reserve materials, there is often great demand than supply for some materials at times such as one week before the due day some assignments. Students have to queue for the returned materials.

---What are your views if users would be allowed to book closed reserve from online timetable for some closed reserve collection? ---How about 
photocopying or emailing some materials to users according to their online request? ---Any other ways you could see library to improve this service?

9. You may recall in my survey, you were asked to choose and rank 5 services that you felt should be the focus of library's attention for improvement. What are the criteria you used for choosing and ranking 5 services that are most important to be improved?

10. Do you think library have done enough promotion for their services? How can it make users fully aware of the existence of the services and how to use services?

11. What factors are affecting library's allocation of the resources to different digital services?

12. What are the key issues with respect to the provision of access to online services for users from within the library itself rather than from remote site?

13. In your view, what positive factors are influencing library to adopt digital services (e.g. academic consortium, support from the top considering the value of services)? ---Which ones are holding library back from adopting more digital services?

14. In conclusion, any issues I forget to talk about that you think important with respect to the provision of digital/electronic services? ---Do you personally have any idea about the future services? 


\section{Appendix C: Information Sheets}

Letter to the undergraduates in the research sample (going along with the questionnaire)

Dear fellow student:

You may have had experience of using services or getting information online from the University Library. As a part of my MA thesis, I am surveying the opinions of users about the delivery of digital services provided by Victoria University of Wellington Library. Your responses may help to improve the current services and future digital library services.

I hope that you will help by taking time (approximately 7 minutes) to complete and return the enclosed questionnaire. Please note that this research has been designed to comply with the guidelines established by the Human Ethics Committee of Victoria University's Faculty of Commerce and Administration. Part 1 of the questionnaire asks for some details about yourself to provide background information. Part 2 asks for your preferences for features related to the delivery of specific digital services. Part 3 asks for your general impression and satisfaction with these services. Your name will not be connected to the questionnaire and will not be passed to third parties for any reason. Your responses will be anonymous and used only for statistical analysis, and will be destroyed on completion of the project.

If you cannot finish the questionnaire in your tutorial for some reasons, alternatively you can send it through the university internal mail system to me (Wei Xia, c/o School of Information Management), or deliver it to Room 201, KP42-44 (Reception of School of Information Management) from 9:00am to $17: 00 \mathrm{pm}$ every day. If you could return it by $26^{\text {th }}$ April, you will be rewarded with a chocolate bar as a token of my appreciation.

A copy of the research project will be kept in the VUW Library and the results may be published in a journal or presented at a conference. The summarized results of this survey will be available to you on your request after the completion of this research (around the end of this July). Please ring me at 463-8081 or email me at xiawei@scs.vuw.ac.nz to request the summarized results or to raise any queries. You also can contact my supervisor Dan Dorner (dan.dorner@vuw.ac.nz) for information about this research.

I greatly appreciate your time and cooperation, and look forward to receiving your completed questionnaire. Your participation will add to the value of the overall results.

Sincerely

Wei Xia 
Dear fellow student:

As a part of my MA thesis, I am surveying the opinions of users about the delivery of digital services such as online catalogue, databases and online request forms provided by Victoria University of Wellington Library. The aim of my research is to investigate perceptions and expectations of users and librarians with respect to specific aspects of digital services offered by university libraries with a view to improving those services over the longer term.

I hope that you will help by taking time (approximately 8 minutes) to complete and return the enclosed questionnaire. Please note that this research has been designed to comply with the guidelines established by the Human Ethics Committee of Victoria University's Faculty of Commerce and Administration. Part 1 of the questionnaire asks for some demographic details about yourself to provide background information. Part 2 asks for your opinions about aspects of the delivery of specific digital services. Part 3 asks for your general impression and satisfaction with these services. Your name will not be connected to the questionnaire and will not be passed to a third party for any reason. Your responses will be anonymous and used only for statistical analysis, and will be destroyed on completion of the project.

You can return the finished questionnaire to me (Wei Xia, c/o School of Information Management) through the university internal mail system or you can deliver it in-person to Room 201, KP42-44 (Reception for the School of Information Management) from 9:00am to 17:00pm every day. If you return it in-person by $26^{\text {th }}$ April, you will be rewarded with a chocolate bar as a token of my appreciation.

A copy of the research project will be kept in the VUW Library and the results may be published in a journal or presented at a conference. The summarized results of this survey will be available on your request after the completion of this research (around the end of this July). Please ring me at 463-8081 or email me at xiawei@scs.vuw.ac.nz to request the summarized results and to raise any queries or concerns. You also can contact my supervisor Dan Dorner (dan.dorner@vuw.ac.nz) for information about this research.

I greatly appreciate your time and cooperation, and look forward to receiving your completed questionnaire. Your participation will add to the value of the overall results.

Sincerely

Wei Xia 


\section{Letter to the academic staff in the research sample (going along with the questionnaire)}

\section{Dear Sir or Madam:}

I am doing research in library and information studies. My research proposes to compare preferences of users and librarians regarding aspects of specific digital services provided by academic libraries. As a part of my MA thesis, I am surveying the opinions of academic staff about the delivery of digital services provided by Victoria University of Wellington Library.

I hope that you will help by taking time (approximately 8 minutes) to complete and return the enclosed questionnaire. Please note that this research has been designed to comply with the guidelines established by the Human Ethics Committee of Victoria University's Faculty of Commerce and Administration. Part 1 of the questionnaire asks for some demographic details about yourself to provide background information, and the second part asks for your opinions about the delivery of specific digital services. Part 3 asks for your general impression and satisfaction of these services. Your name will not be connected to your questionnaire. Further, your name will not be passed to a third party for any reason. Your responses will be anonvmous and used onlv, for statistical analysis, and will be destroyed on completion of the project.

You can return the finished questionnaire to me (Wei Xia, c/o School of Information Management) through the university internal mail system or you can submit it in-person to Room 201, KP42-44 (Reception for the School of Information Management) from 9:00am to 17:00pm every day. If you return it in-person by $29^{\text {th }}$ April, you will be rewarded with a chocolate bar as a token of my appreciation.

A copy of the research project will be kept in the VUW Library and the results may be published in a journal or presented at a conference. The summarized results of this survey will be available on your request after the completion of this research (around the end of this July). Please ring me at 463-8081 or email me at xiawei@scs.vuw.ac.nz to request the summarized results or raise any queries or concerns. You also can contact my supervisor Dan Dorner (dan.dorner@vuw.ac.nz) for information about this research.

I greatly appreciate your time and cooperation, and look forward to receiving your completed questionnaire. Your participation will add to the value of the overall results.

Thank you for your support

Sincerely

Wei Xia 
Dear Sir or Madam:

I am a MA (thesis) student in Library and Information Studies. I am now doing research on delivery of digital library services provided by academic libraries. My research investigates views of users and librarians regarding specific digital services provided by academic libraries. I would like you, as one of VUW's librarians, to complete this questionnaire. In several weeks time, I plan to conduct follow-up interviews with a small sample of the participating VUW librarians to obtain professional opinions about the delivery of digital services by the University Library. Your participation will add to the value of my research.

I understand that your time is valuable. However, I hope that you will help by taking time (approximately 8 minutes) to complete the accompanying questionnaire. Please note that this research has been designed to comply with the guidelines established by the Human Ethics Committee of Victoria University's Faculty of Commerce and Administration. Your responses to the questionnaire will be kept confidential and will be used only for statistical analysis, and will be destroyed on completion of the project. I will be grateful if you can return the completed questionnaire using the VUW internal mail by $28^{\text {th }}$ April to the following address:

\section{Wei Xia}

Research Room101, KP42-44

School of Information Management

A copy of the research project will be kept in the VUW Library and the results may be published or presented at a conference. The summarized results of this survey will be available on your request after the completion of this research (around the end of this July). Please ring me at 463-8081 or email me at xiawei@scs.vuw.ac.nz to request the summarized results or if you have any queries about the research. You also can contact my supervisor Dan Dorner (dan.dorner@,vuw.ac.nz) for information about this research.

Thank you very much for considering this request!

I am looking forward to receiving your completed questionnaire.

Respectfully,

Wei Xia 


\section{Dear Sir or Madam:}

I am a MA (thesis) student in Library and Information Studies. I am now doing research on the delivery of digital library services provided by academic libraries. My research investigates views of users and librarians regarding aspects of digital services provided by academic libraries. In the past few weeks, you have filled out a questionnaire for me. I would like to have a follow-up interview with you to obtain your professional opinion about the delivery of digital services provided by the University Library. Your participation will add to the value of my research and will be greatly appreciated.

I understand that your time is valuable. However, I hope you will help by giving me a chance to interview you (not more than one hour). Please note that this research has been designed to comply with the guidelines established by the Human Ethics Committee of Victoria University's Faculty of Commerce and Administration. Your responses will be confidential and used only for my research. In order to facilitate the analysis, the whole interview will be recorded. I will send the transcript to you to look over. The tape recording of the interview will be destroyed after completion of the thesis. The transcript will be kept confidential and destroyed at the conclusion of the research.

A copy of the research project will be kept in the VUW Library and the results may be published in a journal or presented at a conference. The summarized results of this research will be available on your request after the completion of this research (around the end of this July).

I will phone you in late April to confirm your agreement to participate and to arrange a time for the interview. In the meantime can you please read and sign the enclosed Consent Form and return it to me via the internal mail system (Wei Xia, c/o School of Information Management). Please ring me at 4638081 or email me at xiawei@scs.vuw.ac.nz if you have any queries about the research. You also can contact my supervisor Dan Dorner (dan.dorner@vuw.ac.nz) for information about this research.

Thank you very much for considering this request!

I am looking forward to talking with you.

Respectfully,

Wei Xia 


\section{VICTORIA UNIVERSITY OF WELLINGTON CONSENT TO PARTICIPATE IN RESEARCH}

Title of project: A Comparison of Library Users' and Librarians' Preferences for Digital Services in an Academic Library

I have been given and have understood an explanation of this research project. I have had an opportunity to ask questions and have them answered to my satisfaction. I understand that I may withdraw myself (or any information I have provided) from this project (before data collection and analysis is complete) without having to give reasons or without penalty of any sort.

I understand that any information I provide will be kept confidential to the researcher, her supervisor and the person who transcribes the tape recordings of our interview, the published results will not use my name, and that no opinions will be attributed to me in any way that will identify me. I understand that the interview will be recorded by the researcher and the tape-recording of interviews will be electronically wiped at the end of the project unless I indicate that I would like that item returned to me.

Signed:

Name of participant:

(please print clearly)

Date: 


\section{References}

Information access \& delivery services: A strategic direction for research libraries. (1994). Paper presented at the Research Library the Day after Tomorrow: ARL Proceedings of the 124th Annual Meeting, Austin,Texas.

The University of California digital library: A framework for planning and strategic initiatives (1996). Library Council \& Committee on Intercampus Networking and Information Technology for Academic Purposes. Retrieved Aug6th, 2001, from the World Wide Web: http://sunsite.berkeley.edu/UCDL/summary.html

The national electronic library: A guide to the future for library managers(review). (1997). Library Software Review, 16(1), 47-48.

Digital library research programme: A list of current projects (1998). ISG of UKLON. Retrieved Sep1st, 2001, from the World Wide Web: http://www.ukoln.ac.uk/services/bl/digital-library-research-projects/

Digital libraries initiative-phase2 (1998). Retrieved Sep1st, 2001, from the World Wide Web: http://www.nsf.gov/pubs/1998/nsf9863.html

Digital projects of the UC Berkeley library (1999). Retrieved Sep1st, 2001, from the World Wide Web: http://sunsite.berkeley.edu/R+D/ucblibrary.html

Distance learning development project 1999-2000 plan (1999). University of Minnesota Library Twin Cities Campus. Retrieved Oct5th, 2001, from the World Wide Web: http://www.lib.umn.edu/dist/99-00plan.phtml

Digital library research programme: A list of current projects (2000). Retrieved Sep1st, 2001, from the World Wide Web: http://www.ukoln.ac.uk/services/bl/digital-lib-research-projects/ 
General information (2002, 28 Jan, 2002). University Library, Victoria University of Wellington, New Zealand. Retrieved November 18, 2001, from the World Wide Web: www.vuw.ac.nz/library/about/general.html

Abell, M., \& Brand, M. (1994). Introduction project steering committee. ARL. Retrieved Sep1st, 2001, from the World Wide Web: http://sunsite.berkeley.edu/ARL/Proceedings/124/ps5steer.html

Alexander, M., \& Prescott, A. (1998). The initiatives for access programme: An overview, Towards the Digital Library (pp. 15-27). St Pancras: The British Library Board.

Alreck, P. L., \& Settle, R. B. (1985). Sampling design, The survey research handbook (pp. 63-94). Homewood: Irwin.

Armstrong, C., \& Fenton, R., et al. (2001). A study of the use of electronic information systems by higher education students in the UK. Program: Electronic Library and Information System, 35(3), 241-262.

Arthur, J. (1998). Case study: University of Hertfordshire learning and information services. In T. Hanson \& J. Day (Eds.), Managing the electronic library (pp. 369-389). NJ: East Grinstad House.

Atkinson, R. (1996). Library functions, scholarly communication and the foundation of the digital library: Laying claim to the control zone. The Library Quarterly, 66(3), 239-265.

Attkisson, C., Hargreaves, W. A., Horowitz, M., \& Sorenson, J. (1978). Evaluation of human service programs. New York: Academic Press.

Baker, S. L., \& Lancaster, F. W. (1991). The measurement and evaluation of library service (2 ed.). Arlington: Information Resources Press. 
Bates, A. W. (1995). Technology, open learning and distance education. London: Routledge.

Bawden, D., \& Rowlands, I. (1999). Understanding digital libraries: Towards a conceptual framework (British Library Research and Innovation Report 170). West Yorkshire: British Library Document Supply Centre.

Bertot, J. C., McClure, C. R., \& Ryan, J. (2000). Developing national library network statistics and performance measures for U.S. public libraries: Issues, findings, and recommendations. Performance Measurement and Metrics: The International Journal for Library and Information Services, 1(1), 15-42.

Bertot, J. C. (2001). Measuring services quality in the networked environment: Approaches and considerations. Library Trends, 49(4), 758-774.

Besser, H. (1998). The shape of the twenty-first-century library. In M. T. Wolf \& P. Ensor \& M. A. Thomas (Eds.), Information Imagineering: Meeting at the Internet (pp. 133-146). Chicago: American Library Association.

Bindsall, W. (1994). The myth of the electronic library: Librarianship and social change in America. Westport, CT: Green Wood Press.

Blagden, J. (1998). Overview: Managing the just-in-time library. In T. Hanson \& J. Day (Eds.), Managing the electronic library (pp. 271-291). NJ: East Grinstad House.

Blixrud, J. (1999). The continuing quest for new measures ARL Newsletter: $A$ Bimonthly Report on Research Library Issues and Actions from ARL, CNI, and SPARC 207 (December), 11

Braid, J. A. (1993). Electronic document delivery: A reality at last? Aslib Proceedings, 45(6), 161-166. 
Brophy, P. (1998). Overview: Management information for the electronic library. In T. Hanson \& J. Day (Eds.), Managing the electronic library (pp. 247-268). NJ: East Grinstad House.

Brophy, P., \& Fisher, S. (1998). The hybrid library. The New Review of Information and Library Research, 4, 3-16.

Brophy, P., \& Craven, J. (1999). The integrated accessible library: A model of service development for the 21st century (British Library Research \& Innovative Report 168). London: Centre for Research in Library \& Information Management, The Manchester Metropolitan University.

Brophy, P. (2000). Towards a generic model of information and library services in the information age. Journal of Documentation, 56(2), 161184.

Brophy, P. (2000). The academic library. London: Library Association Publishing.

Broughton, K. (2001). Our experiment in online, real-time reference. Computer in Libraries, 21(4), 26.

Buttenfield, B. (1999). Usability evaluation of digital libraries. Science and Technology Libraries, 17(3/4), 39-59.

Calvert, P. J. (2001). International variations in measuring customer expectations. Library Trends, 49(4), 732-757.

Cameron.Kim. (1981). Domains of organizational effectiveness in colleges and universities. Academy of Management Journal, 24, 25-27.

Carter, D., \& Janes, J. (2000). Unobtrusive data analysis of digital reference 
questions and service at the Internet public library: an exploratory study. Library Trends, 49(2), 251-265.

Chen, C.-Y. (1994). The influence of modern information technology on library organisation structures. National Cheng-Gong University Library Newsletter, 14(April), 25-35.

Childers, T. (1989). Evaluative research in the library and information field. Library Trends, 38(2), 250-267.

Childers, T., \& Van House, N. A. (1989). Dimensions of public library effectiveness. Library and Information Science Research, 11, 273-301.

Choudhury, S. (2002). A framework for evaluating digital library services. $D$ Lib Magazine, 8.

Cline, H. F., \& Sinnott, L. T. (1983). The electronic library. Tornoto: Lexington Books.

Committee, I. E. R. (1999). Illinois digital academic library: A request for FY 2000 funds. Illinois Digital Library. Retrieved Sep1st, 2001, from the World Wide Web: http://www.lis.uiuc.edu/ b-sloan/idal.html

Cook, C., \& Heath, F. M. (2001). Users' perceptions of library service quality: A LibQual+ qualitative study. Library Trends, 49(4), 548-584.

Cook, C., \& Thompson, B. (2001). Psychometric properties of scores form the web-based LibQual+ study of perceptions of library service quality. Library Trends, 49(4), 585-604.

Cormier, R. (2000). The online medieval \& classical library. Choice: Supplement, 37, 73.

Covi, L., \& Kling, R. (1998). Shift or drift? Decision making in the movement 
from paper to digital collections. In M. T. Wolf \& P. Ensor \& M. A. Thomas (Eds.), Information imagineering: Meeting at the Internet (pp. 109-117). Chicago: American Library Association.

Crawford, J. (1996). Evaluation of library and information services. London: Aslib.

Crawford, J. (2000). Evaluation of library and information services (2 ed.). London: Aslib.

Cronin, B. (1982). Performance measurement and information management. Aslib Proceedings, 34(5), 227-236.

Cullen, R. (2001). Perspectives on user satisfaction surveys. Library Trends, 49(4), 662-686.

Dalton, P., Hampson, A., Nankivell, C., \& Pinfield, S. (1998). The hybrid library and university strategy: A consultation exercises with senior university managers. The New Review of Information and Library Research, 4, 43-52.

Davies, A., \& Ian, K. (1995). Face to face with the sovereign consumer: Service quality and the changing role of professional academic librarians. The Sociology Review, 43(4).

Davies, C. (1998). User issues. In A. Ramsden (Ed.), ELINOR: Electronic library project (pp. 71-85). NJ: Bowker-Saur.

Davies, C. (1998). Future user issues for the networked multimedia electronic library. In A. Ramsden (Ed.), ELINOR: Electronic library project (pp. 105-130). NJ: Bowker-Saur.

Day, J., Edwards, C., \& Walton, G. (1998). How to electronic libraries after 
people? Insights from IMPEL project. The New Review of Information and Library Research, 4, 53-66.

Deegan, M. (1998). The electronic library in teaching and research. In T. Hanson \& J. Day (Eds.), Managing the electronic library (pp. 3-24). NJ: East Grinstad House.

Dervin, B., \& Nilan, M. (1986). Information needs and uses. In M. E. Williams (Ed.), Annual review of information science and technology, volume 21 (pp. 1-33). NJ: Knowledge Industry Publications.

Dougherty, R. M., \& Williams, J. (1999). Interlibrary services from both sides of the desk. In D. S. Montanelli \& P. F. Stenstrom (Eds.), People come first: User-centered academic library service. Chicago: Association of College and Research Libraries.

Dowlin, K. F. (1984). The electronic library. New York: Neal-Schuman Publishers Inc.

Drake, M. A. (1994). A special library perspective. ARL. Retrieved Aug18th, 2001, from the World Wide Web: http://sunsite.berkeley.edu/ARL/Proceedings/124/ps3spec.html

Dugger, L. (1999). Service models for the emerging digital library. Serials Review, 25(1), 41-42.

Eaton, N. (1994). Access committee report and discussion. Paper presented at the The Research Library the Day after Tomorrow: ARL proceedings of the 124th annual meeting, Austin, Texas.

Eaton, J. (1998). Project headline: Access control and authentication--- issues for access to networked information resources. The New Review of Academic Librarianship, 4, 11-17. 
Ekers, A. (1998). Automated request processing. In L. Carpenter \& S. Shaw \& A. Prescott (Eds.), Towards the digital library (pp. 218-221). London: The British Library Board.

Erens, B. (1996). Modernizing research libraries: The effect of recent developments in university libraries on the research progress. NJ: Bowker:Saur.

Fayen, E. G. (1983). The electronic library in an academic setting. In M. Koening (Ed.), Managing the electronic library: Papers of the1982 conference of the library management division of Special Libraries Association (pp. 9-13). NY: Special Libraries Association.

Ferguson, C. D., \& Bunge, C. A. (1997). The shape of services to come: Values-based reference service for the largely digital library. College \& Research Libraries, 58(3), 252-263.

Follet, B., Sir. (1993). Joint funding councils' libraries review group. Bristol: High Education Funding Council for England.

Forrest, B., \& Barber, D. (1994). Building the digital library: The University of Michigan's Um library text project. Information Technology and Librarians, 13(1), 20.

Fountain, L. M. (2000). Trends in web-based services in academic library. In P. D. Fletcher \& J. C. Bertot (Eds.), World libraries on the information superhighway: Preparing for the challenges of the new millennium (pp. 80-93). Hershey: Idea Group Publishing.

Garred, P. (1998). User needs and interface design: Issues from the HyLiFe project. The New Review of Information and Library Research, 4, 6773. 
Garvey, W. D., Tomita, K., \& Woolf, P. (1979). The dymanic scientificinformation user. In W. D. Garvey (Ed.), Communication: The essence of scinece (pp. 256-279). Elmsford: Pergamon Press.

Gay, L. R. (1996). Educational research: Competencies for analysis and application (5 ed.). NJ: Merrill/Prentice Hall.

Golland, R., \& Hathaway, P. (1986). Computerised current awareness and information retrieval: Daily intelligence bulletin. In T. Whitehall (Ed.), Practical current awareness services from libraries. Hants: Gower Publishing.

Gorman, M. (1999). Avoiding the seven deadly sins or techbology and the future of library services in academic libraries. In D. S. Montanelli \& P. F. Stenstrom (Eds.), People come first: User-centered academic library service (pp. 1-12). Chicago: Association of College and Research Libraries.

Gray, S. M. (2000). Virtual reference services directions and agendas. Reference \& User Services Quarterly, 39(4), 365.

Greenstein, D. (1998). Scholar's information needs in a digital age: Executive summary. The New Review of Academic Librarianship, 4, 147-150.

Greenstein, D. (2000). Digital library and their challenge. Library Trends, 49(2), 290-303.

Grimes, D. J. (1998). Academic library centrality: User success through sevice, access and tradition. Chicago: Association of Colleges and Research Libraries.

Guenther, K. (2001). Building digital libraries: Know the reomte users. Computer in Libraries, 21(4), 52-54. 
Guernsey, L. (1999). University of California's digital library opens its online doors. The Chronicle of Higher Education, 45(21), A31.

Gulliford, B. (1998). Making choice in the virtual world: The new model at united technologies information network. Library Trends, 47(1), 158171.

Hanson, T., \& Day, J. (1998). Managing the electronic library. NJ: East Grinstad House.

Hanson, T. (1998). Managing current awareness services. In T. Hanson \& J. Day (Eds.), Managing the electronic library (pp. 623-637). NJ: East Grinstad House.

Hanson, T. (1998). Managing reference and information services. In T. Hanson \& J. Day (Eds.), Managing the electronic library (pp. 335356). NJ: East Grinstad House.

Haricombe, L. J. (1998). Introduction. Library Trends, 47(1), 1-6.

Hartzer, S., Paterson, B., Snyman, D., Thompson, L., Heerden, L. V., Vorster, M., \& Watkins, A. (1998). Web information services at the University of South Africa library: A work in progress. Library Trends, 47(1), 91116.

Hayes, R. M. (1993). Strategic management for academic libraries: A handbook. Westport: Greenwood.

Heaps, E. (1998). Case study: The University of York. In T. Hanson \& J. Day (Eds.), Managing the electronic library (pp. 657-672). NJ: East 
Grinstad House.

Heichler, E. (1994). Beowulf prowls the Internet through library project. Computer World, 28(21), 77.

Hernon, P., \& Nitecki, D. A. (2001). Service quality: A concept not fully explored. Library Trends, 49(4), 687-708.

Hey, J. M. N., \& Wissenburg, A. (1998). Modeling the hybrid library: Project MALIBU. The New Review of Information and Library Research, 4, 103.

Hiller, S. (2001). Assessing user needs, satisfaction, and library performance at th University of Washington libraries. Library Trends, 49(4), 605625.

Horney, K. (1983). The electronic library at Northwestern. In M. Koening (Ed.), Managing the electronic library: Papers of the1982 conference of the library management division of Special Libraries Association (pp. 1-9). NY: Special Libraries Association.

ILCSO Electronic Resources Committee. (1999). Illinois digital academic library: A request for FY 2000 funds. Illinois Digital Library. Retrieved Sep1st, 2001, from the World Wide Web: http://www.lis.uiuc.edu/ b-sloan/idal.html

Jefcoate, G. (1998). Portico: The British Library's online information server. In L. Carpenter \& S. Shaw \& A. Prescott (Eds.), Towards the digital library (pp. 201-209). London: The British Library Board.

Jephcott, S. (1998). Why digitise? Principles in planning and managing a successful digitisation project. The New Review of Academic 
Librarianship, 4, 39.

Jones, S., \& Cunningham, S. (1998). An analysis of usage of a digital library. Waikato: Department of Computer Science, University of Waikato.

Jordan, S. (2000). A review of the presentation literature,1993-1998---The coming age. Library Resource \& Technical Services, 44(1), 4-21.

Kessler, J. (1996). Internet digital library:The international dimension. MA: Artech House Inc.

Koening, M. (Ed.). (1983). Managing the electronic library: Papers of the1982 conference of the library management division of Special Libraries Association. NY: Special Libraries Association.

Krejcie, R. V., \& Morgan, D. W. (1970). Determining sample size for research activities. Educational and Psychological Measurement, 30(608).

Kresh, D., Arret, L., \& Columnists, G. (1999). Do birds fly? Some thoughts after the library of congress institute on " reference service in a digital age". Reference \& User Services Quarterly, 38(1), 17-21.

Kyrillidou, M., \& Heath, F. M. (2001). Introduction. Library Trends, 49(4), $541-547$.

Lancaster, F. W. (1982). The future of the library in the age of telecommunications, Changing information concepts and technologies: $A$ reader for the professional librarian. White Plains: Knowledge Industry Publications.

Lancaster, F. W. (1995, Oct 29-31, 1995). Are evaluation criteria applied to traditional libraries equally applicable to digital library. Paper presented at the 37th Allerton Institute, Graduate School of Library and Informatin Science, University of Illinois, Champaign, Urbana. 
Lang, B. (1998). Developing the digital library. In L. Carpenter \& S. Shaw \& A. Prescott (Eds.), Towards the digital library (pp. 227). London: The British Library Board.

Lee, O. (2000). National Library of Korea: South Korea government-run digital library-RISS and KRIC. In P. D. Fletcher \& J. C. Bertot (Eds.), World libraries on the information superhighway: Preparing for the challenges of the new millennium (pp. 63-79). Hershey: Idea Group Publishing.

Lee, H.-L. (2000). What is a collection? Journal of the American Society for Information Science, 51(12), 1106-1113.

Leedy, P. D. (1997). Practical research: Planning and design (6 ed.). New Jersey: Merrill.

Library Policy Group. (2002, March, 2002). Library Statue. University Library, Victoria University of Wellington, New Zealand. Retrieved November 18, 2001, from the World Wide Web: ftp://aida.its.vuw.ac.nz/policy/general statute - library statute.doc

Lin, S. K. (1997). The impact of information technology on library organisations: A thesis submitted to the Victoria University of Wellington in fulfillment the requirements for the degree of Master of Arts in Librarianship. Unpublished M.A. in Librarianship, Victoria University of Wellington, Wellington.

Lindauer, B. G. (1998). Defining and measuring the library's impact on campus wide outcomes. College \& Research Libraries, 59(6), 546-570.

Lynden, F. C. (1994). Remote access issues: Pros and cons. In S. H. Lee (Ed.), Access, ownership and resource sharing (pp. 19-36). New York: Haworth. 
Maccoll, J. (2001). Virtuous learning environment: The library and the ULE. Program: Electronic Library and Information System, 35(3), 227-239.

Marshall, C. C. (1994). Beyond stacks: Navigating the library without walls. ARL. Retrieved Aug18th, 2001, from the World Wide Web: http://sunsite.berkeley.edu/ARL/Proceedings/124/ps2stack.html

Martin, M. S. (1998). Perils at home: Changing constituencies in cyberspace. In M. T. Wolf \& P. Ensor \& M. A. Thomas (Eds.), Information imagineering: Meeting at the Internet (pp. 166-177). Chicago: American Library Association.

McElroy, A. R. (1982). Library-information services evaluation: A casehistory from pharmaceutical R and D. Alisb Proceedings, 34(5), 249265.

Mcgown, K. A. (2000). Knowledge management in the twenty-first century: The role of the academic librarian. Unpublished Ed.D, University of Thomas, St.Paul.

Michell, B. G., \& Harris, R. M. (1986). The social context of reference work: Assessing the effects of gender and communication skill on observers. Library and Information Science Research, 8, 85-101.

Mick, C. K., Lindsey, G. N., \& Callahan, D. (1980). Towards usable user studies. Journal of the American Society of Information Science, 31(5), 347-356.

Moore, M. G. (1995). American distance education: A short literature review. In F. L. Wood (Ed.), Open and distance learning today (pp. 32-38). London: Routledge.

Morgan, E. L. (1996). See you see a librarian final report. Retrieved Oct1st, 
2001, from the World Wide Web:

http://sunsite.berkeley.edu/ emorgan/see-a-librarian/index.html

Murrin, A. (1998). Publishers' views of electronic short-Loan collections and copyright clearance issues. Journal of information Science, 24(4), 215229.

O'Donnell, J. (1994). Where are we going and when did we get there? ARL. Retrieved Sep15th, 2001, from the World Wide Web: http://sunsite.berkeley.edu/ARL/Proceedings/124/ps2going.html

Oder, N. (2001). The shape of e-reference. Library Journal, 126(2), 46.

Oppenheim, C. (1999). What's the hybrid library? Journal of Information Science, 25(2), 97-112.

Orr, R. H., et al. (1968). Development of methodological tools for planning and managing library services. Standardized Inventories of Library Services. Bulletin of the Medical Library Association, 56(4), 380-403.

Payne, P., \& Walller, E. (2000). Academic libraries. Librarianship and Information Work WorldWide, 51-70.

Peters, T. A. (1998). Remote familiar: Using computerized monitoring to study remote use. Library Trends, 47(1), 7-20.

Peters, T. A. (2000). Assessing digital library services - Introduction. Library Trends, 49(2), 221-227.

Phipps, S. (2001). Beyond measuring service quality: Learning from the voices of the customers, the staff, the processes, and the organization. Library Trends, 49(4), 635-661.

Pinfield, S. (1998). Builder: An institutional hybrid library strategy. The New 
Review of Academic Librarianship, 4, 31.

Poll, R. (2001). Performance, processes and costs: Managing services quality with the balanced scorecard. Library Trends, 49(4), 709-717.

Porter, S. (1998). Into the future: Scholarly needs, current provision, and future directions. The New Review of Academic Librarianship, 4, 190214.

Priestley, J. (1998). Integrate, co-operate, innovate keynot address. The New Review of Information and Library Research, 4, 27-33.

Ramsden, A. (1998). Introduction. In A. Ramsden (Ed.), ELINOR: Electronic library project (pp. 1-13). NJ: Bowker-Saur.

Ramsden, A. (1998). ELINOR electronic library system. In A. Ramsden (Ed.), ELINOR: electronic library project (pp. 29-39). NJ: Bowker-Saur.

Raizen, S. A., \& Rossi, P. H. (1981). Program evaluation in education: When? How? To what ends? Washington, DC: National Academy Press.

Reid, G. (2000). The digitisation of heritage material: Arguing for an interpretative approach based on the experience of the Powys digital library project. Program, 34(2), 143-158.

Riggs, D. E. (2000). Library and information work in context. Librarianship and Information Work WorldWide: An Annual Survey, 7.

Rogers, J. (1986). Present-day developments in current awareness services. In T. Whitehall (Ed.), Practical current awareness services from libraries. Hants: Gower Publishing.

Rowley, J. (1998). The electronic library (4 ed.). London: Library Association Publishing. 
Rustein, J. S., DeMiller, A., \& Fuseler, E. A. (1993). Ownership versus access: Shifting perspective for libraries. Advanced in Librarianship, 17, 33-60.

Saracevic, T. (2000). Digital library information: Towards an evolution of concepts. Library Trends, 49(2), 221-227.

Saunders, L. M. (1999). The human element in the virtual library. Library Trends, 47(4), 771.

Schmidt, J., Croud, J., \& Turnbull, D. (2000). The University of Queens land Cybrary: A virtual library in a wired university. In P. D. Fletcher \& J. C. Bertot (Eds.), World libraries on the information superhighway: Preparing for the challenges of the new millennium (pp. 107-124). Hershey: Idea Group Publishing.

Scott, W. R. (1987). Organizations: Rational, natural and open systems. NJ: Prentice Hall, Englewood Cliffs.

Scully, P. (1996). Threat or opportunity: Libraries and an Internet future. LASIE, 27(2), 20-29.

Shoebridge, M. (1998). Case study: Managing converged reference services at the University of Birmingham. In T. Hanson \& J. Day (Eds.), Managing the electronic library (pp. 357-368). NJ: East Grinstad House.

Shoham, S. (1998). Scholarly communication: A study of Israeli academic researchers. Journal of Librarianship and information science, 30(2), 113-121.

Simmonds, P., \& Andaleeb, S. S. (2001). Usage of academic libraries: The role of service quality, resources and user characteristics. Library 
Trends, 49(4), 626-634.

Singh, D. (2000). Impact of the Internet on Malaysian libraries. In P. D. Fletcher \& J. C. Bertot (Eds.), World libraries on the information superhighway: Preparing for the challenges of the new millennium (pp. 95-106). Hershey: Idea Group Publishing.

Sloan, B. (1998). Service perspectives for the digital library remote reference services. Library Trends, 47(1), 117-143.

Smith, A. (2000). Annual report of the librarian for 1999. University Library, Victoria University of Wellington, New Zealand. Retrieved November, 2001, from the World Wide Web: www.vuw.ac.nz/library/about/annual-report1999.html

Smith, L. C. (1981, Apr 26-29, 1981). New information technologies---New opportunities. Paper presented at the 1981 Clinic on Library Applications of Data Processing, Illionois.

St Clair, G. (Ed.). (1994). Power and influence. London: Bowker Saur.

Stalker, J. C. (1999). Reference: Putting users first. In D. S. Montanelli \& P. F. Stenstrom (Eds.), People come first: User-centered academic library service (pp. 79-92). Chicago: Association of College and Research Libraries.

Stamatoplos, A., \& Mackoy, R. (1998). Effects of library instruction on university's students satisfaction with the library: A longitudinal study. College \& Research Libraries, 59(4), 323.

Straw, J. E. (2000). A virtual understanding. Reference \& User Services Quarterly, 39(4), 376. 
Taylor, R. S. (1986). Value-added process in information systems. NJ: Ablex Publishing Corporation.

Tennant, R. (1999). Personalizing the digital library. Library Journal, 124(12), 36-38.

Tenopir, C. (1998). The digital reference of world. Online, 22(4), 22.

Thompson, R. H. (1988). Evaluating academic library service. Technical Services Quarterly, 5(4), 27-39.

Van House, N. A., Weil, B. T., \& McClure, C. R. (1990). Measuring academic library performance: A practical approach. Chicago: American Library Association.

Wakeling, W. (1998). Managing technical service in the electronic library: Modernization before transformation. In T. Hanson \& J. Day (Eds.), Managing the electronic library (pp. 445-465). NJ: East Grinstad House.

Walton, G., \& Edwards, C. (1998). Joint ventures to support innovation lessons from the HyLiFe project. The New Review of Information and Library Research, 4, 35.

Waston, M. (1998). Overview: Managing user education and training. In T. Hanson \& J. Day (Eds.), Managing the electronic library (pp. 393412). NJ: East Grinstad House.

Webb, S. P. (1996). Creating an Information Service (3 ed.). London: Aslib.

Weiser, A. (1998). UC state library in digital archive. Library Journal, 18-20.

West, R. (1994). Task force on scientific and technical information. ARL. Retrieved November, 2002, from the World Wide Web: 
http://sunsite.berkeley.edu/ARL/Proceedings/124/ps5scitc.html

Whitehall, T. (1986). Alternatives for current awareness service (CAS). In T. Whitehall (Ed.), Practical current awareness services from libraries. Hants: Gower Publishing.

Wigington, R. L. (1981, Apr26-29,1981). Technology alone is not enough. Paper presented at the 1981 Clinic on Library Applications of Data Processing, Illionois.

Wilkinson, J. (1998). The hybrid libraries programme: Papers form a workshop at the University of Leeds. The New Review of Academic Librarianship, 4, 1-2.

Wills, G., \& Oldman, C. (1977). The beneficial library : A methodological investigation to identify ways of measuring the benefits provided by libraries. Cranfield: Cranfield School of Management.

Wilson, T. D. (1981). On user studies and information needs. Journal of Documentation, 37(1), 3-15.

Wilson, L. A. (1999). The gateway library: Rethinking undergraduate services. In D. S. Montanelli \& P. F. Stenstrom (Eds.), People come first: Usercentered academic library service (pp. 13-44). Chicago: Association of College and Research Libraries.

Winkworth, I. (2001). Innovative United Kingdom approaches to measuring service quality. Library Trends, 49(4), 718-731.

Wissenburg, A. (1998). Aspects of seamless access provision in the context of hybrid libraries: The MALIBU ( Managing the hybrid Library for the Benefit of the User) project. The New Review of Academic Librarianship, 4, 19-24. 
Withnell, L. A. (1994). Faculty opinions of academic library services policies. Journal of Interlibrary, Loan, Document Delivery \& Information Supply, 4(3/4), 23-79.

Witten, I. H., \& Manning, N. (1995). Building a public digital library based on full-text retrieval. Waikato: Department of Computer Science, University of Waikato.

Witten, I. H., \& Rodger, M. N. (1998). Managing multiple collections, multiple languages and multiple media in a distributed digital libraries. Waikato: Department of Computer Science, University of Waikato.

Woods, L. A. (1981). Application of microcomputers in library. Paper presented at the 1981 Clinic on Library Applications of Data Processing, Illionois.

Wright, C. (1999). Towards the digital library: The British library's initiatives for access programme. Interlending \& Document Supply, 27(2), 99100.

Wynne, P. M., \& Edwards, C. (1998). The elib HyLiFe project implication for the user community. The New Review of Academic Librarianship, 4, 310.

Zammuto, R. F. (1984). A comparison of multiple constituency models of organizational effectiveness. Academy of Management Review, 9, 606616.

Zhang, S. (1998). Academic library leaders confer in Beijing. American Libraries, 29(11), 26.

Zhao, D. (1998). The personal digital library. In A. Ramsden (Ed.), ELINOR: Electronic library project (pp. 97-103). NJ: Bowker-Saur. 